Teachers' professional growth during the development and class

enactment of context-based chemistry student learning material

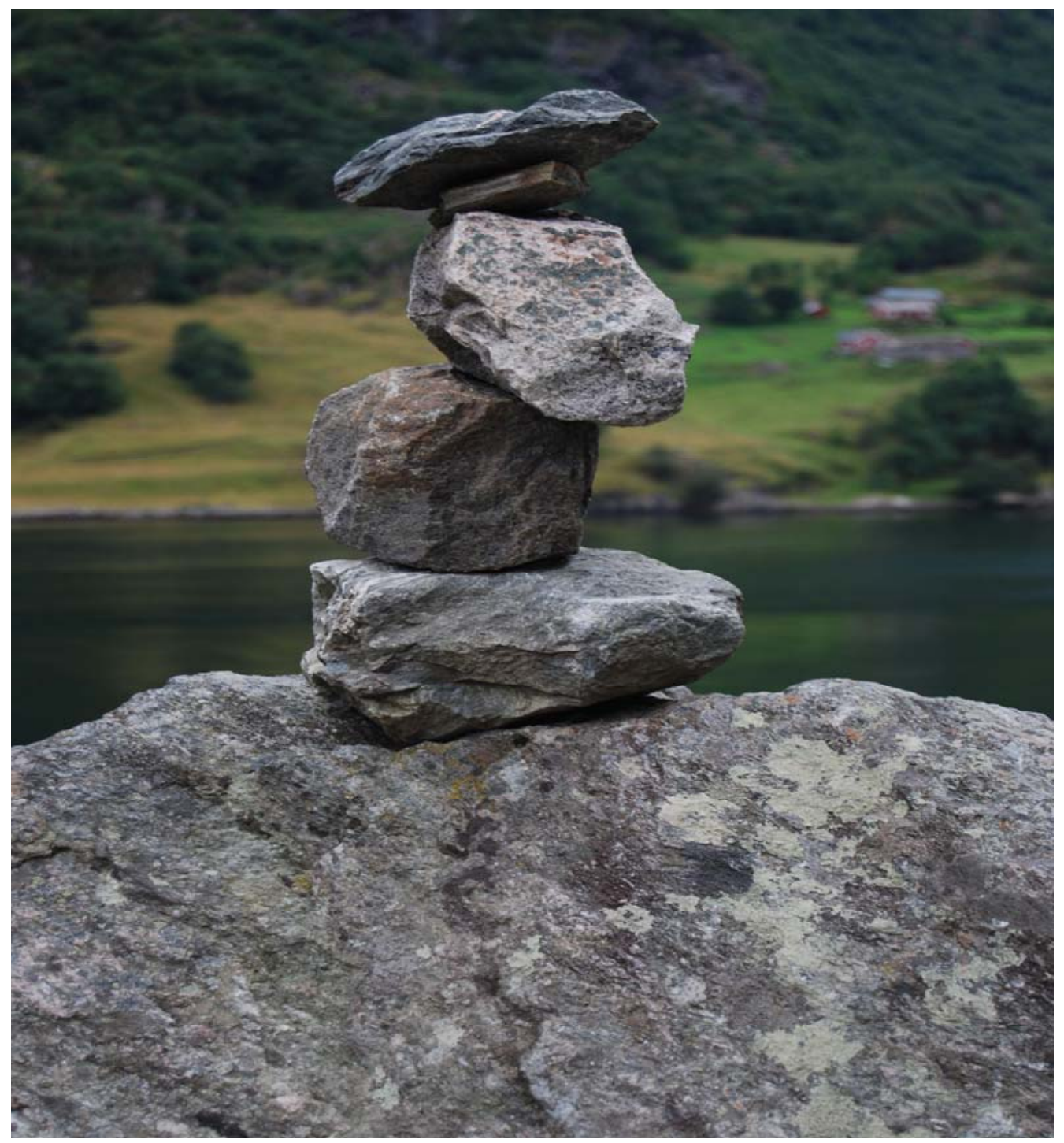

Fer Coenders 


\section{TEACHERS' PROFESSIONAL GROWTH DURING THE DEVELOPMENT AND CLASS ENACTMENT OF CONTEXT-BASED CHEMISTRY STUDENT LEARNING MATERIAL}

Fer Coenders 
Chairman Prof. Dr. H. W. A. M. Coonen - University of Twente

Promoters $\quad$ Prof. Dr. S. Dijkstra - University of Twente

Prof. Dr. J. M. Pieters - University of Twente

Assistant promoter $\quad$ Dr. C. Terlouw - Saxion Highschool

Members Prof. Dr. J. J. H. van den Akker = University of Twente

Prof. Dr. W. Jochems - Technical University of Eindhoven

Prof. Dr. N. Velthorst - Free University of Amsterdam

Prof. Dr. Th. Bergen - Technical University of Eindhoven

Dr. J. M. Voogt - University of Twente

Coenders, F.G.M.

Teachers' professional growth during the development and class enactment of context-based chemistry student learning material

Thesis University of Twente, Enschede.

ISBN 978-90-365-3009-5

DOI http:/ / dx.doi.org/10.3990/1.9789036530095

Layout: Sandra Schele

Press: Ipskamp Drukkers B.V. - Enschede

(C) Copyright, 2010, F.G.M. Coenders

All rights reserved. No part of this book may be produced in any form: by print, photocopy, microfilm, or any other means without written permission from the author. 


\title{
TEACHERS' PROFESSIONAL GROWTH DURING THE DEVELOPMENT AND CLASS ENACTMENT OF CONTEXT-BASED CHEMISTRY STUDENT LEARNING MATERIAL
}

\author{
DISSERTATION \\ to obtain \\ the degree of doctor at the University of Twente \\ on the authority of the rector magnificus \\ prof. dr. H. Brinksma \\ on account of the decision of the graduation committee \\ to be publicly defended \\ on Wednesday the $26^{\text {th }}$ of May 2010 at 13:15
}

by

Fer Coenders

born on the $25^{\text {th }}$ of July 1952

in Lottum 
Promoters

Assistant promoter
Prof. Dr. S. Dijkstra

Prof. Dr. J. M. Pieters

Dr. C. Terlouw

This dissertation has been approved by the promoters and assistant promoter. 


\section{CONTENTS}

LIST OF FIGURES AND TABLES vii

PREFACE ix

ACKNOWLEDGEMENTS $\quad$ xi

1. BACKGROUND, CONTEXT AND AIM OF THIS STUDY 1

$\begin{array}{ll}1.1 & \text { Background of this study }\end{array}$

1.2 Context of the study 4

$\begin{array}{ll}1.3 \text { Aim of this study } & 6\end{array}$

$\begin{array}{lll}1.4 & \text { Research question } & 7\end{array}$

2. A THEORETICAL FRAMEWORK FOCUSED ON TEACHER KNOWLEDGE FOR TEACHING AND TEACHER LEARNING 9

2.1 Teacher knowledge for teaching 9

$\begin{array}{ll}2.1 .1 & \text { Teacher beliefs } \\ & 10\end{array}$

2.1.2 Pedagogical Content Knowledge (PCK) 12

$\begin{array}{ll}2.2 \text { Models for teacher learning } & 14\end{array}$

2.2.1 Concerns Based Adoption Model 15

2.2.2 Joyce and Showers' training components 16

2.2.3 Interconnected Model of Teacher Professional Growth 16

$\begin{array}{lll}2.3 & \text { Research questions } & 18\end{array}$

$\begin{array}{ll}2.4 \text { Method } & 19\end{array}$

3. ASSESSING TEACHERS' BELIEFS TO FACILITATE THE TRANSITION TO A NEW CHEMISTRY CURRICULUM: WHAT DO THE TEACHERS WANT? 21

$\begin{array}{lll}3.1 & \text { Introduction } & 21\end{array}$ 
3.1.1 Context of the study 22

3.1.2 Curriculum reform 23

$\begin{array}{lll}3.1 .3 & \text { Teacher knowledge } & 24\end{array}$

3.1.4 Teacher beliefs $\quad 25$

3.1.5 Teacher learning and reform of practice 26

$\begin{array}{ll}3.2 \text { Method } 28 & 28\end{array}$

3.2.1 Participants 28

$\begin{array}{lll}3.2 .2 & \text { Instruments } & 28\end{array}$

3.2.3 Data and data processing 29

3.2.4 Determination of the reliability 30

$\begin{array}{lll}3.3 & \text { Results } & 30\end{array}$

3.3.1 Teachers' beliefs about the curriculum content: essential elements in assignments to foster knowledge construction 30

3.3.2 Curriculum content: ideal chemistry curriculum 31

3.3.3 Current curriculum: general remarks made by the interviewees 32

3.3.4 Teachers' beliefs about their roles 33

3.3.5 Teachers' beliefs about the development of learning materials 34

3.3.6 Teachers' learning and reform of practice 35

3.4 Discussion 37

3.4.1 Teacher knowledge 37

3.4.2 Teacher beliefs $\quad 37$

3.4.3 Teacher learning and reform of practice 39

3.4.4 Toward a new curriculum 40

3.4.5 Implications for further research 41

4. THE EFFECTS OF THE DESIGN AND DEVELOPMENT OF A CHEMISTRY CURRICULUM REFORM ON TEACHERS'

PROFESSIONAL GROWTH, A CASE STUDY 43

$\begin{array}{lll}4.1 & \text { Introduction } & 43\end{array}$

4.1.1 Teacher learning in preparation of a reform 44

4.1.2 Teacher as developer of learning material 46

4.1.3 The context of the study 47

$\begin{array}{lll}\text { 4.1.4 Aims of the study } & 48\end{array}$ 
$\begin{array}{lll}4.2 & \text { Method } & 48\end{array}$

4.2.1 Participants $\quad 49$

$\begin{array}{lll}4.2 .2 & \text { Instruments } & 49\end{array}$

4.2.3 Procedure $\quad 50$

4.2.4 Analysis $\quad 51$

4.3 Results 52

4.3.1 Perceived goals $\quad 53$

4.3.2 Teacher-developer learning $\quad 56$

4.4 Discussion 63

4.4.1 Teacher learning during the development and enactment of learning material 63

4.4.2 Teacher learning and the five PCK domains 66

$\begin{array}{lll}4.5 & \text { Appendix } & 68\end{array}$

5. PREPARING CHEMISTRY TEACHERS FOR A CURRICULUM RENEWAL THROUGH DEVELOPMENT AND CLASS ENACTMENT OF STUDENT LEARNING MATERIAL: A CASE STUDY OF TEACHERS' Pedagogical Content KNOWLEDGe (PCK) CHANGES

$\begin{array}{lll}5.1 & \text { Introduction } & 71\end{array}$

$\begin{array}{lll}5.1 .1 & \text { Teacher learning for a renewal } & 72\end{array}$

$\begin{array}{lll}5.1 .2 & \text { The context of this study } & 73\end{array}$

5.1.3 Pedagogical Content Knowledge $\quad 74$

$\begin{array}{lll}5.2 \text { Method } & 76\end{array}$

$\begin{array}{lll}\text { 5.2.1 Participants } & 76\end{array}$

5.2.2 Development procedure of learning material 76

$\begin{array}{lll}5.2 .3 & \text { Research instruments } & 78\end{array}$

$\begin{array}{lll}\text { 5.2.4 Design and Analysis } & 78\end{array}$

$\begin{array}{lll}5.3 & \text { Results } & 79\end{array}$

$\begin{array}{lll}5.3 .1 & \text { Pete } & 79\end{array}$

$\begin{array}{lll}5.3 .2 & \text { Lisa } & 83\end{array}$

$\begin{array}{lll}5.3 .3 & \mathrm{Ed} & 87\end{array}$

$\begin{array}{lll}\text { 5.3.4 Summarizing conclusions } & 91\end{array}$

$\begin{array}{lll}5.4 & \text { Discussion } & 93\end{array}$

5.4.1 Changes in teachers' PCK 93

5.4.2 Teacher learning for a new curriculum 95

$\begin{array}{lll}5.4 .3 & \text { Implications } & 96\end{array}$

$\begin{array}{lll}5.5 & \text { Appendix } & 97\end{array}$ 
6. THE EFFECT OF CLASS ENACTMENT OF INNOVATIVE CHEMISTRY LEARNING MATERIALS ON TEACHERS' PeDAGOGICAL CONTENT KNOWLEDGE

6.1 Introduction 99

6.1.1 The context of this study 101

6.1.2 Pedagogical Content Knowledge 101

6.2 Method 103

6.2.1 Participants 103

6.2.2 Learning material 103

$\begin{array}{ll}\text { 6.2.3 Procedure and instruments } & 104\end{array}$

6.2.4 Design and analysis 104

6.3 Results 105

$\begin{array}{lll}\text { 6.3.1 Ann } & 106\end{array}$

$\begin{array}{lll}\text { 6.3.2 Art } & 107\end{array}$

$\begin{array}{lll}6.3 .3 & \text { Iris } & 108\end{array}$

$\begin{array}{lll}6.3 .4 & \text { Hank } & 110\end{array}$

6.3.5 Gene 111

6.3.6 Summary of the results 114

6.4 Conclusion and discussion 115

6.4.1 Changes in teacher PCK 115

6.4.2 Theoretical and policy implications 117

$\begin{array}{lll}6.5 \text { Appendix } & 119\end{array}$

7. TEACHER CHANGE IN TERMS OF A MODEL OF TEACHER LEARNING AND POLICY IMPLICATIONS

7.1 Summary of the main findings of the previous chapters 121

7.2 Modelling teacher-developers' growth 124

7.2.1 Extension of the Interconnected Model of Teacher Professional Growth (IMTPG) 125

7.2.2 "Change sequence" or "growth network" 128

7.2.5 Extended IMTPG in relation to CBAM and effective training components 129

7.3 Modelling teacher enactors' growth 130

7.4 The Extended Interconnected Model of Teacher Professional Growth (EIMTPG) as a predictive tool 130

7.5 Practical and policy implications for professional development programs 133

$\begin{array}{lll}7.6 & \text { Discussion } & 135\end{array}$ 
REFERENCES

SUMMARY

NEDERLANDSE SAMENVATTING

APPENDICES

Cooperative learning: T-card

Cooperative learning: group roles

158

Cooperative learning: logbook for effective cooperation

159

Developed module in a nutshell 


\section{LIST OF FIGURES AND TABLES}

\section{FIGURES}

1.1 The organizational model for the development of student learning material

1.2 The organizational model of a development network 3

1.3 Framework of the development process of a module 4

2.1 Traditional professional development model 14

2.2 Guskey's teacher change model 14

2.3 The Interconnected Model of Teacher Professional Growth 17

4.1 Framework of the development process of a module 47

4.2 Data collecting timing within network development activities 50

5.1 Framework of the network development activities, and timing of data collection 78

7.1 Framework of the development process of a module 122

7.2 Change model for teachers enacting innovative material 123

7.3 Extended Interconnected Model of Teacher Professional Growth 126

\section{TABLES}

2.1 Stages and expressions of concern, and phases about an innovation

3.1 Essential elements in assignments and exercises to facilitate knowledge construction 31

3.2 Perceived characteristics of an ideal chemistry curriculum 32

3.3 Perceived roles as chemistry teacher 34

3.4 Perceived teacher roles with respect to self-regulated learning 34

3.5 Development work carried out and beliefs about the teacher as developer 35

3.6 Perceived areas of support in preparation of a new curriculum 36 
3.7 Perceived ways of support in preparation of a new curriculum

4.1 Data collection instruments in relation to the research questions

4.2 Perceived goals of chemistry education for students in their first year chemistry according to Pete, Lisa and Ed

4.3 Teacher learning during the writing phase

4.4 Teacher learning during the class enactment phase

5.1 Pete's knowledge and beliefs on context-based education, on cooperative learning, and on requirements for learning during the three phases of the development process

5.2 Lisa's knowledge and beliefs on context-based education, on cooperative learning, and on requirements for learning during the three phases of the development process

5.3 Ed's knowledge and beliefs on context-based education, on cooperative learning, and on requirements for learning during the three phases of the development process

5.4 Teacher-developers' responses to the opposing viewpoints questions

6.1 Ann's PCK 106

6.2 Art's PCK 108

$\begin{array}{lll}6.3 & \text { Iris's PCK } & 109\end{array}$

6.4 Hank's PCK 110

6.5 Gene's PCK 112

6.6 Teachers' responses to the opposing viewpoints questions 113

6.7 Overview of cooperative learning strategies used by each teacher 115 


\section{PREFACE}

The picture on the cover of this book can be seen as a metaphor for a teachers' knowledge base. Each piece of rock symbolizes a specific field of knowledge whereas the whole pile stands for all the knowledge and skills a teacher uses in his profession. The landscape in which the pile comes into view represents the societal context. The rock at the bottom represents a solid foundation in the subject matter content, a prerequisite for teaching. This knowledge is, in the Dutch situation, mainly acquired at university. Another stone represents the knowledge about learning: what learning entails, what learning subject matter means for specific groups of students, and how learning can be stimulated and at the end assessed. A third piece of rock embodies knowledge on the orientations towards teaching and on teaching strategies. What strategies are suitable to reach specific goals and objectives for certain student groups, how can these be used and under what circumstances? Teachers also need to understand the processes children from twelve to nineteen go through, how this affects their learning, and what this means for teachers' actions, all embedded in rock four. The school environment requires teachers to cooperate with colleagues in and outside their own school, to communicate with parents and other stakeholders, all small but important pieces of rock. Teachers have acquired all these different kinds of knowledge from diverse sources, such as initial and in-service teacher training and experiences as a teacher, as might be the case with the pieces of rock in the pile. Piling these rocks can be done in different ways, creating for each specific pile different contact areas. New rocks can be added to create an even larger construction. When one rock or a section of a rock is removed, chances are high that the pile collapses. The main weakness of the metaphor is that in the pile all rocks remain discrete entities, whereas in a teachers' knowledge base the different areas overlap and sometimes even partly merge.

My first involvement in a curricular reform was in the SMART (Science and Maths Advice and Regional Training) project in Swaziland in 1992. The aim of this project was to reform the teaching of science and mathematics in Swazi High Schools. 
Teachers were to move away from just 'talk-and-chalk', and engage students in meaningful activities. On paper this seems a simple and straightforward mission, but I experienced it as a very complicated endeavor, especially because this shift in practice also meant updating teachers' knowledge and changing their beliefs and skills. Teachers had to unlearn teaching strategies they were used to, and for which they knew from experience what using this strategy meant for their students' learning, and had to replace these by teaching methods in line with the curricular reform. Teachers not only needed materials with student activities, but they also had to learn how to use these activities meaningfully in class, and this required teachers to reconceptualize learning and teaching.

In terms of the pile of rocks metaphor it can be argued that in times of a curricular reform some pieces of rock will change shape. This will lead to changes in the contact areas, also affecting the shape of the pile. It will take some time for the pile to be stable again and to fit in the landscape.

The discussions about a curricular reform for high school chemistry in the Netherlands started around 2000. The shortcomings with the existing curriculum were presented in 2002. Recommendations for a new curriculum followed in 2003 and these looked promising from the point of view of teacher involvement. Teacher networks would be set up to produce modules for a new curriculum. This would facilitate a bottom up curriculum development process in which teachers would be the main stakeholders.

My first worry was whether or not the proposed curricular reform would be supported by the teachers themselves. I therefore interviewed a number of teachers about their vision on this reform. This is the first part of my research.

A curricular reform requires substantial financial input, and therefore also effective use of these means. The claim by the Steering Committee responsible for the curriculum reform was that teacher participation in the development of the student learning material would serve as learning processes for the teachers involved. What these teachers learn, from what they learn and how this learning process can be seen, is the second aspect of this book.

Involving all Dutch chemistry high school teachers in the development of student learning material is a costly way of professionalization. This notion leads to the third part of this research. Do chemistry teachers not involved in the development of student learning material, go through a learning process when they enact this new learning material in their classes, and if so what is it they learn, what from and how can this learning process be seen. 


\section{ACKNOWLEDGEMENTS}

Many people have been involved in this study and contributed, in some way or another, to this book. First and foremost, I am deeply indebted to the teachers and technical teaching assistants, who were involved in this research. Some were interviewed, others participated in one of the teacher networks and developed a module, and several teachers used this student material in their classes. The data collection was only possible through the participation of these teachers whom all allowed me insights in their knowledge, beliefs and practices in a very open and honest way. I particularly want to thank: Ada Bax, Irene Brinkman, Arjan Dijkman, Wil Gradussen, Mieke Heuker of Hoek, Janny Huiskes, Kitty Jansen, Guido Janze, Jan Legebeke, Harrie Jorna, Aonne Kerkstra, Herman Mooij, Paul van Puijenbroek, Joost Schaareman, Miek Scheffers, Han Steenbergen, Patrick Vedder, Peter Velthuis, Maureen Velzeboer and Hans Vogelzang,

Quite a number of colleagues have provided me with opportunities to discuss issues related to this research and through these processes have contributed with suggestions and ideas. I want to thank especially my ELAN colleagues and former colleagues: Wilma Elferink, Margarita Jeliazkova, Henny Kramers, Nelly Verhoef, Frans Carelsen, Patrick van Haren, Harm Scholte, Han Vermaat, and a group of PhD researchers in chemistry education, to mention Machiel Stolk, Hanna Westbroek, Rutger van de Sande.

I am grateful to Iwan Sanders, who has been a great help in the transcription of the recorded interviews and network meetings. Pauline Teppich and Marion Meenink have taken care of a lot of the paperwork and Sandra Schele has diligently worked on the lay-out.

My promoter and co-promotor of the first hour, Sanne Dijkstra and Cees Terlouw have been invaluable for the shaping of this research. They have assisted me to find my way in the field of educational research allowing me space to follow my 
own path. Jules Pieters, my promoter who later joined in, has contributed in this process. The numerous discussions have sharpened my thoughts. Above all I particularly appreciate their moral support, as doing this kind of research in a very busy working environment at a teacher training institution is challenging.

I am indebted to my parents and my brothers and sisters who have stimulated me to further my studies. Unfortunately some of them have passed away and cannot be part of this occasion. I also want to thank my wife Jeannette and my children Sjors, Guus and Alies, for their support during all these years.

This study has given me greater insights in the complexity of teaching. My appreciation and admiration for chemistry teachers has increased and I therefore want to commemorate this book to them.

To all chemistry teachers 


\title{
CHAPTER 1 \\ Background, context and aim of this study
}

\begin{abstract}
Teachers are crucial when it comes to a curriculum renewal as they are the ones to implement a new curriculum through enactment in their classrooms. Teachers therefore need to understand the new curriculum, to be professionally prepared for an adequate use of new subject matter and embedded pedagogical knowledge, and have to be able to develop and use the new curriculum materials in an adequate manner. This study is about the effect on teacher development when teachers are involved in the development and subsequent class enactment of learning materials meant to be implemented in a new context-based chemistry high school curriculum. A special focus will be on the difference in development outcomes between those teachers who are actively involved in the development and enactment of curriculum materials and those who merely enact the material in their classes.

In section 1.1 the background of the study is outlined, followed by the context in 1.2. The aim of this study is the focal issue of section 1.3. The overall research question forming the basis of this study is dealt with in section 1.4.
\end{abstract}

\subsection{BACKGROUND OF THIS STUDY}

In 1999, the Dutch Ministry of Education introduced a new nationwide curriculum for the upper grades of General Education, students of ages between 16 and 19. The innovation was based on two sets of requirements: a new instructional design and teaching model, and the inclusion of more examination subjects. In the new teaching model the teachers were no longer seen as information providers, but more as facilitators assisting students in their own learning processes. The teachers' role shifted from explaining content to coaching students, both with respect to subject matter as to acquiring learning skills. The inclusion of more subjects resulted in fewer periods per week per subject. As a result, the number of chemistry periods was reduced from nine to six in upper 
secondary classes. This had a direct impact on the chemistry content that could be taught, and the chemistry syllabus had to be adapted. It was mainly pruned, as a lot of topics were removed and only a few new ones were added. This operation acted as a catalyst on the discontent that already existed amongst chemists about the curriculum, resulting in a discussion amongst chemistry education stakeholders about the syllabus, leading to strategic guidelines to come to a major curriculum overhaul (Bulte, et al., 2000). The Dutch Ministry of Education appointed in 2002 a committee (Van Koten, de Kruijff, Driessen, Kerkstra, \& Meinema, 2002) to address this issue. This committee portrayed different problems of the current secondary school syllabus:

1. There is a gap between the picture of chemistry that is presented at school and the state of the art of reality of modern chemistry in science and industry;

2. The exam requirements for chemistry are a constrain straitjacket;

3. Practical assignments and personal research receive too little attention;

4. This program makes it impossible to have extramural activities.

In a follow-up report (Driessen \& Meinema, 2003), recommendations for a new curriculum to be implemented in 2010 were suggested, and the crucial role teachers play in an innovation was acknowledged. The major recommendations for this new curriculum were: (a) school chemistry content should convey a realistic picture to students of the meaning of chemistry for society; (b) present and future challenges in chemistry and questions asked by society are the basis of the new program; and (c) the introduction of the context-based approach in pedagogy. Teachers were to be involved in the curriculum design through participation in so called teacher development Network groups, or through assessment of draft learning material in their classes. Cooperation in network groups enables teachers to professionalize, to change their knowledge and beliefs. Figure 1.1 shows the organizational model for the development of student learning material.

The National Steering Committee, supported by a Resonance Group, determined the framework of the chemistry curriculum, and the process leading to such a curriculum. The Project Group took responsibility for the actual curriculum development process, and as such directed the teacher network groups. 


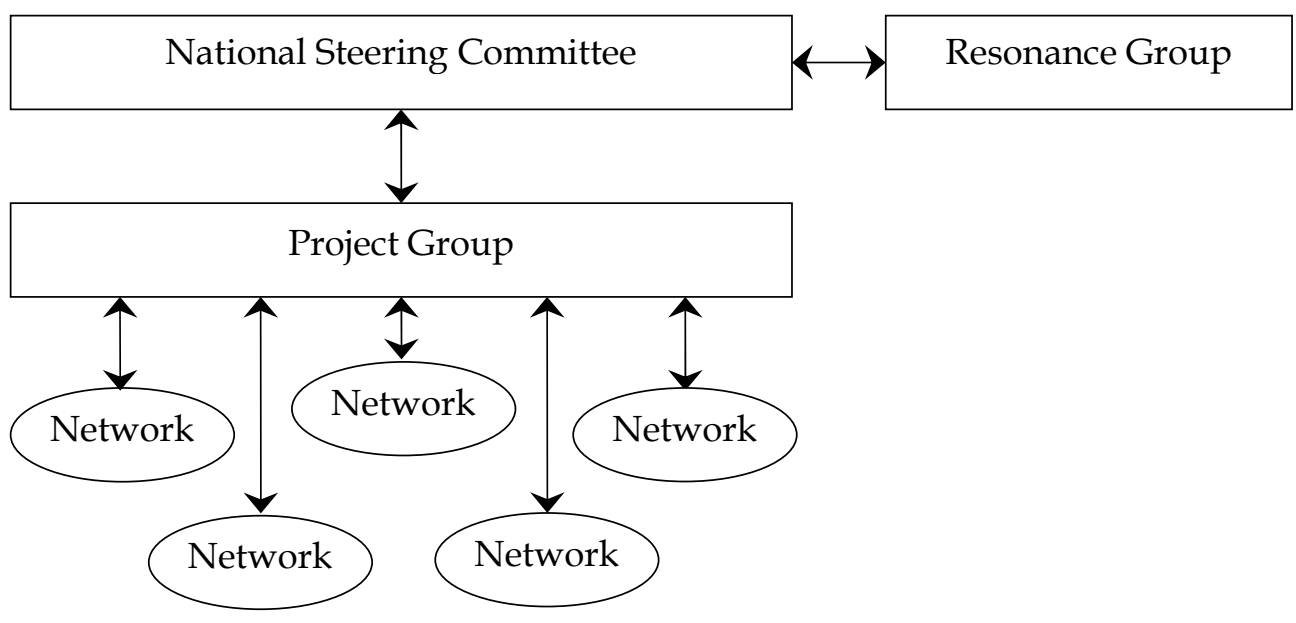

Figure 1.1 The organizational model for the development of student learning material

The model of a teacher network, in charge of developing student learning material, is shown in Figure 1.2. Three teachers from different schools under the supervision of a coach developed student learning material in the form of a module. The project group mainly instructed the network group on the framework characteristics of the material. These will be described in section 1.2 about the context of the study. The school administration facilitated the teacherdevelopers by reducing their workload and agreed to let teachers use the developed material in their classes.

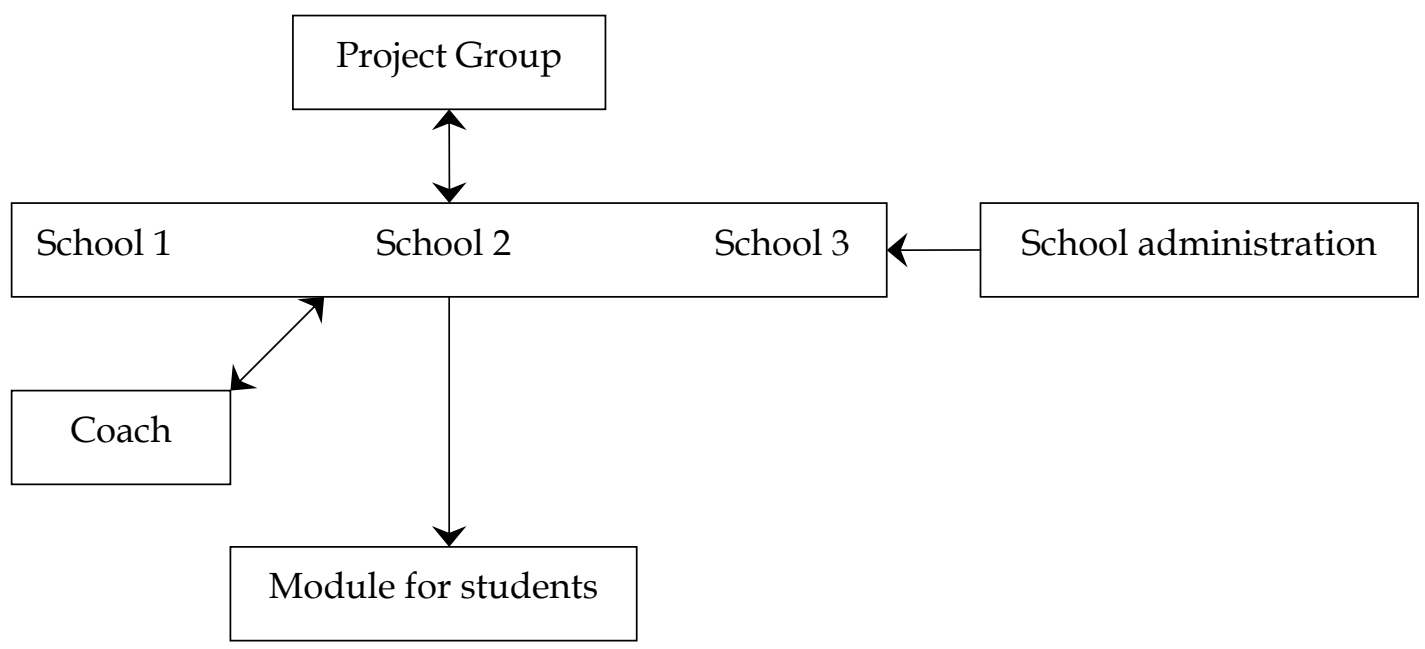

Figure 1.2 The organizational model of a development network 


\subsection{CONTEXT OF THE STUDY}

In 2003, the project group invited chemistry teachers interested in the development of student learning material to register. They also invited chemistry teachers willing to enact this material, after development and improvement, in their classes. For the first group of teacher-developers involvement would mean a major time investment as they were supposed to develop the learning material, enact it in class, and incorporate the results from class enactment in a new version of the learning material. The second group of teachers committed themselves to using this new version in their classes, and to provide feedback of their experiences to the teacher-developers who would prepare a third version for further distribution.

In this study both groups of teachers participated. The changes in knowledge and beliefs of teacher-developers will be described in the chapters 4 and 5. The effect of class enactment of innovative materials on knowledge and beliefs from teachers who merely enacted the material in their classes can be found in chapter 6 .

To avoid confusion, in the rest of this book the term 'teacher-developer' will be used for those teachers who, next to performing normal teaching tasks in their own school, are involved in the development of student learning material in a network.

A teacher network consisted of three to five teacher-developers from different schools (Figure 1.2). A coach, who acted as a chair and served as the liaison between the network and the national coordination, was assigned to the network. The mission of the network was to develop and test student learning material, in the form of a complete module, in line with the national recommendations, in particular the context-based approach. A complete module had to comprise of all texts, exercises and assignments, practical activities, and other student learning activities, ready for direct class use. A framework of the development process of a module is depicted in Figure 1.3.

\begin{tabular}{|c|c|c|c|}
\hline $\begin{array}{l}\text { National level: } \\
\text { - curriculum } \\
\text { change } \\
\text { - development } \\
\text { guidelines }\end{array}$ & $\begin{array}{l}\text { Self regulatory } \\
\text { network developing } \\
\text { student learning } \\
\text { materials (a } \\
\text { module): } \\
\text { writing phase }\end{array}$ & $\begin{array}{l}\text { Class use of } \\
\text { the module } \\
\text { by the } \\
\text { developers: } \\
\text { enactment } \\
\text { phase }\end{array}$ & $\begin{array}{l}\text { Revision: } \\
\text { tested } \\
\text { module } \\
\text { ready for } \\
\text { other } \\
\text { schools }\end{array}$ \\
\hline
\end{tabular}

Figure 1.3 Framework of the development process of a module 
Networks received the following guidelines: (a) The module had to be suitable for Form 3, the first year students (of about 15 years of age) take a chemistry course in secondary school; (b) The interaction between an interesting context for students and a number of chemistry concepts present in this context had to be the central element (context-based approach); (c) The selection of the context and of the concepts students have to learn was the responsibility of the network; (d) Concepts should follow "naturally" from the context (Campbell, et al., 1994), as exemplified in the "Salters" materials like Salters Advanced Chemistry (Burton, Holman, Lazonby, Pilling, \& Waddington, 2000). Rigid following of syllabus objectives or of a subject content structure should be avoided; (e) The four stages used by Chemistry in Context in Germany (Parchmann, et al., 2006) had to be applied in the module: the teacher first introduces the context; students are made curious and plan their investigations; students carry these out and process the results; and finally all knowledge is brought together; (f) The module should be appropriate for approximately 8 to 10 periods of 50 minutes each. Active student engagement through the use of meaningful activities, group work, and cooperative learning was seen as another important characteristic of this new curriculum.

Within these guidelines, a teacher network had substantial freedom with respect to choice of the context, the kind of learning activities and materials, the kind of learning processes and pedagogy, and the way of assessment of the student learning results. Several teacher networks were established throughout the country; as we wanted to do an in-depth case study one of these networks participated in this research. It was chosen because the teachers were based at schools not too far from the university of the researcher. The teacher networks could operate autonomously, and draw on an own approach, including the members' task allocation within the network, the number of face-to-face meetings, and the communication between the meetings.

During the writing phase of the module, all texts, exercises and assignments, practical activities, and other learning activities were developed. After completion, the module was class enacted and the obtained experiences were used to revise the module.

The network that participated in this research developed two modules. In both modules cooperative learning was the pedagogy used, including the use of Tcards to teach students cooperative skills (Ebbens, Ettekoven, \& Rooijen, 1996) (see appendix 1 for an example), student group roles (appendix 2), and a group 
logbook (appendix 3). In one of the modules role-plays were included, having the purpose to illustrate chemical processes.

To prepare the teachers interested in class enactment on the use of the modules, a short workshop was held. The teacher-developers explained the 'why-andhow' $^{\prime}$ of the material, talked about practicalities for class use, and shared their experiences with the modules. Five teachers who used one of the modules in their class participated in this research.

\subsection{AIM OF THIS STUDY}

A curriculum change affecting classroom practices is a complex endeavor that has an effect on the development of the various curriculum components. Moreover, such a change will have consequences for all the stakeholders, teachers, students, school administrators and parents. New curriculum materials, including tests and other evaluation tools, have to be developed and implemented, students need to get acquainted with the newly designed materials, with the content and with alternative ways of learning, the school administration has to attend to new contextual factors, parents need to know how to assist their children, and teachers have to deal with the new materials, the students and their parents and with the school administration.

The National Steering Committee (Driessen \& Meinema, 2003) emphasized the crucial role teachers have in the implementation process and proposed to involve teachers from the beginning in the renewal, both through participation in the development process as teacher-developers as well as through class enactment of materials developed by colleagues. It was supposed that participation would act as a learning process for the teachers involved, in which teachers would acquire new knowledge, beliefs and skills, both in the field of the subject matter they are teaching as well as in the pedagogy.

This study is meant to elucidate how chemistry teachers professionally change with respect to their knowledge and beliefs, when they adapt to a new pedagogical and subject matter orientation in the context of a complex curriculum change. The empirical evidence that has been collected through the analysis of the process of preparing for this change, and of the process of adaptation, will be applied to further elaborate a model of teacher professional growth. This model can be used in future to professionalize other teachers for this context-based curriculum change in chemistry education. 


\subsection{RESEARCH QUESTION}

The overall research question of this study is fourfold: (a) what are chemistry teachers' beliefs about the chemistry curriculum and about their roles, about the teacher as developer, and about professional development; (b) how do chemistry teachers professionally change, in other words what changes in knowledge and beliefs arise, when teachers are involved in the development and subsequent class enactment of innovative student learning material for the context-based approach; (c) how do teachers professionally change when they merely enact this material in their classes; and (d) what teacher professional growth model is suitable to understand and interpret the observed changes in knowledge and beliefs.

In order to answer this question, three different studies were conducted. The first study, meant to assess teachers' beliefs with respect to the proposed curriculum change, is reported in chapter 3 . In the second study teacherdevelopers professional growth when they develop and class enact a module is described in the chapters 4 and 5 . In chapter 6 , the effect of class enactment on knowledge and beliefs of teachers who were not involved in the development of the module, is reported. Finally a model to interpret teacher-developers' change in knowledge and beliefs is accounted for in chapter 7. In each of the chapters 3, 4, 5, and 6 specific research questions have been formulated and answered. First of all a theoretical framework focusing on teacher knowledge and teacher learning will be presented in chapter 2 . 


\section{CHAPTER 2}

\section{A theoretical framework focused on teacher knowledge for teaching and teacher learning}

This chapter provides a theoretical framework that enables the description of processes and results of this study. In each of the following chapters parts of this framework will be defined in more detail.

In all learning situation it is important, that new knowledge and beliefs should connect to what learners already know. For teachers this means connecting to the knowledge they use in their teaching. The kind of professional knowledge and beliefs teachers use in class during their daily work will therefore be described first. In section 2.1 the knowledge base for teaching is explored, which is specified in 2.1.1 for teacher beliefs and in 2.1.2 for Pedagogical Content Knowledge.

We then look into models useful to picture and explain professional growth for in-service teachers when these become involved in a curriculum change. These models for teacher learning and the usefulness of these models for this study are outlined in 2.2 .

Finally all specific research questions addressed in this study are presented in 2.3 .

\subsection{TEACHER KNOWLEDGE FOR TEACHING}

The knowledge base for teaching has been the subject of many studies (Barnett \& Hodson, 2001; Cochran, DeRuiter, \& King, 1993; Loughran, Mulhall, \& Berry, 2004; Van Driel, Verloop, \& De Vos, 1998; Veal, 2004). These studies show that teachers' actions in classrooms are largely determined by their knowledge and beliefs about teaching and learning. Scholars categorize and describe a teachers' knowledge base in different ways, some use the term 'practical knowledge', others 'pedagogical context knowledge' and still others 'pedagogical content knowledge'. However, all studies have in common that teachers need to have a 
good command of: (a) the subject content knowledge, (b) knowledge of learning theories and educational psychology, (c) knowledge about instruction including knowledge of assessment strategies, methods and instruments, and (d) knowledge about the context in which teaching takes place. Teachers have acquired part of this knowledge before graduation during their initial university education and during their teaching apprenticeships, and after graduation when teaching their own classes. Class experiences therefore determine teachers' knowledge and beliefs to a large extent. This latter kind of knowledge, as it is experiential knowledge, is highly situated, and often tacit.

In this study the term pedagogical content knowledge will be used to examine and portray teachers' professional change. Shulman (1987) introduced Pedagogical Content Knowledge (PCK) as a major component of the knowledge base of teaching, which, according to him, consisted of (a) subject matter knowledge, (b) curricular knowledge, (c) pedagogical knowledge, (d) knowledge of students, (e) knowledge of the context, and (f) knowledge of educational goals. The context-based curriculum, to be introduced in the Netherlands, hardly necessitates teachers to acquire new subject matter knowledge. It is most likely that, as this study is situated within a framework of a context-based approach, teachers will professionally develop in terms of changes of pedagogical content knowledge. A context-based curriculum requires teachers to organize their knowledge base differently, i.e. to reassess and reorganize their pedagogical content knowledge. Not only knowledge influences teachers' classroom actions, also their beliefs play a major role. In order to describe teacher professional development, the idea of changes in beliefs and in pedagogical content knowledge was therefore adopted. In section 2.1.1 teacher beliefs will be described and discussed, and section 2.1.2 addresses recent developments in research on PCK, and perspectives will be elaborated.

\subsubsection{Teacher beliefs}

Knowledge can be regarded as representations of facts, concepts, procedures and principles, while beliefs are based on evaluation and judgment of these knowledge components (Pajares, 1992). Not just teacher knowledge, but also teacher beliefs exert a powerful impact on the outcomes of teaching (A.T. Lumpe, Haney, \& Czerniak, 2000). Prospective teachers entering a professional preparation program bring with them personal beliefs on teaching and learning that appear to be based on early experiences as pupils. These beliefs and images 
are proven difficult to change and can have a strong impact on what teacher candidates learn during teacher preparation in university teacher training programs (Calderhead \& Robson, 1991). Teacher beliefs act like a filter through which new knowledge is interpreted and integrated and therefore play a major role in the development of practical knowledge (Pajares, 1992; Van Driel, Beijaard, \& Verloop, 2001).

Different studies highlighted the role of teachers' personal beliefs about content in relation to the implementation of a curriculum (Duschl \& Wright, 1989; Lantz \& Kass, 1987). Teachers did not implement curriculum materials that contradict their ideas about content and how this content should be taught (Cotton, 2006; J. Gess-Newsome, 1999 b). Materials were only used if they matched the teachers' perspectives, but were modified or discarded if they did not (Blake, 2002; Duffee \& Aikenhead, 1992). Cronin-Jones (1991) described four beliefs categories influencing curriculum implementation. These categories pertain to (a) teacher's own role, (b) the way students learn, (c) the abilities of particular student groups, and, (d) the relative importance of subject content topics. Teachers appeared to adapt a new curriculum during implementation according to their own beliefs. Even when teachers initially subscribed to a reform developed by others, there is no guarantee that the reform is implemented or sustained. Rousseau (2004) reported about a teacher community who started and later abandoned a reform. These teachers' beliefs about teaching and learning conflicted with their beliefs about their students. Teachers argued that their students' struggle to cope with the new curriculum demands required them to revert to old teaching habits. A similar course of events is reported in a case study by Van Veen et al. (2005) where an initially reform-enthusiast teacher because of personal, moral and social concerns developed negative emotions towards the most important aspect of the particular reform.

Bandura (1997) supposed that the students' learning results affected teacher self-efficacy beliefs. Self-efficacy in science teaching is defined as the perceived effectiveness of own teaching and the attitude towards natural sciences. Besides self-efficacy Bandura also distinguished school efficacy, including beliefs about school buildings and materials, students and parents, and political and cultural norms. Bandura's concepts are comparable to Ford's competence and context beliefs (1992). On empirical grounds from an inquiry involving 555 teachers, Friedman \& Kass (2002) proposed a new conceptualization for self-efficacy beliefs, differentiating between teacher self-efficacy in the classroom and in the school-organizational domain. The authors argue that teachers not only act with 
students but also function as a member of a group in a school organization. This definition acknowledges the different teacher competences.

Evers, Brouwers \& Tomic (2002) found that teachers in the Netherlands with strong self-efficacy beliefs seem to be more prepared to experiment with, and later to implement, new educational practices. This view is supported by the finding that the way teachers react to a reform is largely determined by whether "the teachers perceive their professional identities as being reinforced or threatened by reforms" (Van Veen \& Sleegers, 2006).

It is supposed that teacher self-efficacy beliefs positively or negatively affect the implementation of a new curriculum. Success experiences during the implementation phase, for example positive class experiences, may reinforce self-efficacy beliefs.

In times of educational reforms, aimed at changing teaching practices for the better, the intertwined nature of teachers' knowledge and beliefs, their emotions and cognitions, are revealed more prominently. Reform policies that affect their classrooms, give rise to more intense teacher emotions towards the reform (Schmidt \& Datnow, 2005). Imposing different normative beliefs on teachers in reforms may elicit actions of resistance (Kelchtermans, 2005).

\subsubsection{Pedagogical Content Knowledge (PCK)}

PCK was initially described by Shulman (1987) as 'knowledge for teaching'. In his conception, PCK included powerful subject matter specific analogies, illustrations, examples, demonstrations and other ways of making the subject comprehensible for others. Since Shulman, PCK has been studied by many researchers and been interpreted in different ways (Cochran, et al., 1993; J. Gess-Newsome, 1999; Grossman, 1990). Regardless the interpretation, PCK is thought to be such an amalgam of a teachers' knowledge that it influences their teaching for students' learning for understanding (Berry, Loughran, \& van Driel, 2008). Expert teachers have well formed PCK for all subject matter topics they teach. It is created through reflection, active processing, and integration of its contributing components. PCK is developed and shaped through teaching experiences (Clermont, Borko, \& Krajcik, 1994; Van Driel, et al., 1998).

Elaborating on Shulman's work, Grossman (1990) conceptualized PCK as the result of a transformation of knowledge from three domains: (a) subject matter knowledge and beliefs, (b) pedagogical knowledge and beliefs, and, (c) knowledge and beliefs about context. Each of these knowledge domains shapes PCK which 
development in turn influences the three contributing domains. Magnuson, Krajcik and Borko (1999), building on Grossman's work, described PCK for science teaching as consisting of five components: (a) orientations toward science teaching, (b) knowledge and beliefs about science curriculum, (c) knowledge and beliefs about instructional strategies, (d) knowledge and beliefs about students understanding of specific science topics, and (e) knowledge and beliefs about assessment in science. The authors explicitly address the knowledge and the belief characteristics of each PCK component. In our conceptualization of PCK we adhere to these five components and will use the following interpretations:

1. Orientations to science teaching encompass knowledge and beliefs about the purposes and goals for teaching science at a particular grade level. These orientations guide instructional decisions about teaching science. The purpose of employing a particular teaching strategy, not merely its use, distinguishes a teachers' orientation. Different goals of teaching science are reported in literature, for example: transmit facts of science, assist students to develop science process skills, engage students actively with "hands-on" experiences, and involve students in investigating solutions to authentic problems (Lantz \& Kass, 1987; Van Berkel, De Vos, Verdonk, \& Pilot, 2000).

2. Knowledge and beliefs about the science curriculum consists of mandated goals and objectives, plus specific curricular programs, activities, and materials used in meeting these goals and objectives. It includes knowledge teachers have about what students have learned in previous years and what they are going to learn in later years.

3. Knowledge and beliefs about instructional strategies is comprised of subject and topic specific strategies of instruction, including representations of specific concepts or principles to facilitate student understanding. Organizing, monitoring and evaluating students' cooperation is of special interest in context-based education. How to prepare and organize practical activities to foster student learning is one of the challenging tasks in chemistry education.

4. Knowledge and beliefs about students' understanding of specific science topics encompasses requirements for learning specific science concepts and areas of science students find particularly difficult. It also includes learning abstract concepts, problem solving and dealing with pre- and misconceptions.

5. Knowledge and beliefs about assessment in science is about dimensions of science learning important to assess, and knowledge of the methods by which learning can be assessed. 
PCK is a complex construct and not easily assessed (Baxter \& Lederman, 1999). It is developed and shaped in school practices through reflection-in-action and reflection-on-action (Park \& Oliver, 2008), active processing, and the integration of its contributing components. An expert teacher has well formed PCK for all topics taught (Abell, 2008; Clermont, et al., 1994). PCK is considered to be topic specific, but certainly also contains elements relevant for teaching different topics. In this sense it is considered to be subject specific (E. A. Davis \& Krajcik, 2005; Friedrichsen, et al., 2009). In times of a curricular reform, teachers have to bring their PCK in line with the reform demands.

\subsection{MODELS FOR TEACHER LEARNING}

Teacher change has long been seen as a result of training, as something done to teachers. In the traditional model, shown in Figure 2.1, in-service will lead to changes in teachers' knowledge and beliefs which in turn will lead to changes in classrooms that will positively affect learning outcome (Lewin, 1935).

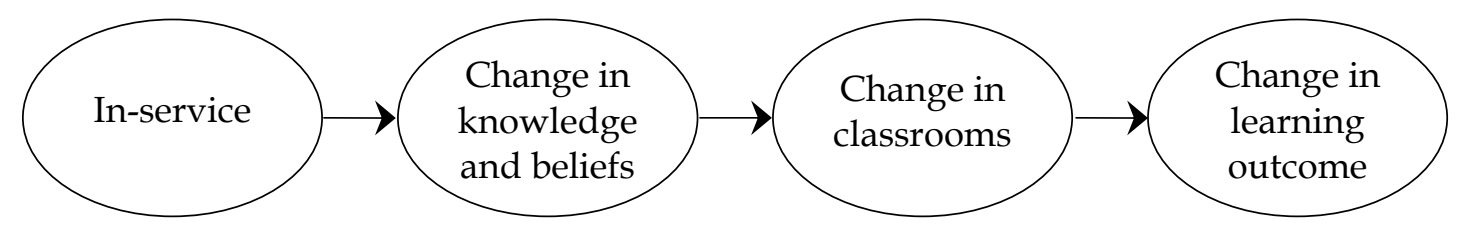

Figure 2.1 Traditional professional development model

In studies on the effectiveness of in-service programs, the sequence in this model proved to be inadequate, especially for experienced teachers. Guskey (1986) therefore presented the model shown in Figure 2.2, in which teacher changes in attitudes and beliefs occurs as a result of changes in classroom practice and student learning outcome. Since then the linearity of this model has been questioned, and cyclic models were proposed.

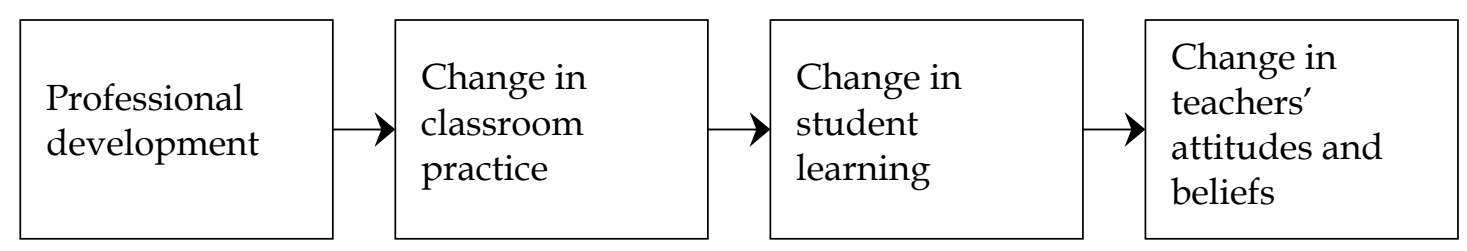

Figure 2.2 Guskey's teacher change model 
We conceptualise teacher change as growth or learning, as a natural and expected result of professional activities of teachers. Three frequently found models, each having a particular focus, portraying in-service teacher learning will be outlined below.

\subsubsection{Concerns Based Adoption Model}

When teachers prepare for a curricular reform, they have to unlearn or change certain teaching skills and have to learn how to use others. In doing so, teachers will go through a process of change. The Concerns Based Adoption Model (CBAM) by Hall and Loucks (1978) is considered a valuable model to describe where individual teachers go through during the process of innovation. The authors describe seven stages of concern teachers experience when reconstructing their teaching. These stages and typical expressions of concern about an innovation are shown in Table 2.1.

Table 2.1 Stages and expressions of concern, and phases about an innovation

\begin{tabular}{|c|c|c|}
\hline Stages of concern & Expressions of concern & Phases \\
\hline 1. Awareness & I am not concerned about it & Initiation \\
\hline 2. Informational & I would like to know more about it & Adoption \\
\hline 3. Personal & How will using the innovation affect me? & \\
\hline 4. Management & How do I get all materials ready? & Implementation \\
\hline 5. Consequence & $\begin{array}{l}\text { How is my use of the innovation affecting } \\
\text { learners? }\end{array}$ & \\
\hline 6. Collaboration & $\begin{array}{l}\text { How can I relate what I am doing to what } \\
\text { others are doing? }\end{array}$ & \\
\hline 7. Reorientation & $\begin{array}{l}\text { What ideas do I have and how could it work } \\
\text { better? }\end{array}$ & Incorporation \\
\hline
\end{tabular}

The first three stages will be accompanied by uncertainty and anxiety and therefore special attention has to be paid to the necessity of the change, the rationale behind it. Teachers then become concerned about the materials, and the impact of the innovation on students' learning. The last stages provide opportunities and time to exchange experiences. Each of these stages of concern is connected to a specific level of usage. For example in the awareness stage no usage will occur. This model specifically addresses questions teachers will focus on when confronted with change. Early questions are more self-oriented: what 
consequences does it have for me. Then, more task oriented aspects emerge and finally the focus will be on impact on students and other stakeholders.

\subsubsection{Joyce and Showers' training components}

Joyce and Showers (1988) described their vision for training as the means by which new knowledge is added to the teachers' professional repertoire. The authors argued that the following combination of components of a training program has proven to be successful: (a) theory: an explanation of the rationale behind the innovation; (b) demonstration: demonstration of the innovation facilitates learning; (c) practice: the practice under simulated conditions; (d) feedback: non-evaluative feedback from others as soon as possible after practice; (e) coaching: to take place in the workplace following initial training. Joyce and Showers (1988) see three general implications for the in-service training. First of all, participants must have ample opportunity to develop skills. Secondly, new content will need more extensive training than relative familiar content and finally for transfer of training follow up, such as coaching in the workplace, will be necessary. In a later version (Joyce \& Showers, 2002), the feedback phase has been removed from their model, the main reason being that learning to provide effective feedback needed extensive training. In addition to the remaining components, professional training should allow teachers to become more effective learners. Specific attitudes and skills, including persistence, understanding the transfer of training, and flexibility, are therefore needed.

\subsubsection{Interconnected Model of Teacher Professional Growth}

Clarke and Hollingsworth (2002) elaborated a model describing the growth of professional knowledge and skill, called the Interconnected Model of Teacher Professional Growth (IMTPG). This model is presented in Figure 2.3. The authors distinguished four domains: a Personal Domain where teachers' knowledge, beliefs and attitudes are located; the Domain of Practice containing all kinds of professional experimentation, including the enactment of learning material in class; the Domain of Consequence encompassing all salient outcomes of the experimentation domain; and the External Domain consisting of all sources of information or support. 
The Change

Environment

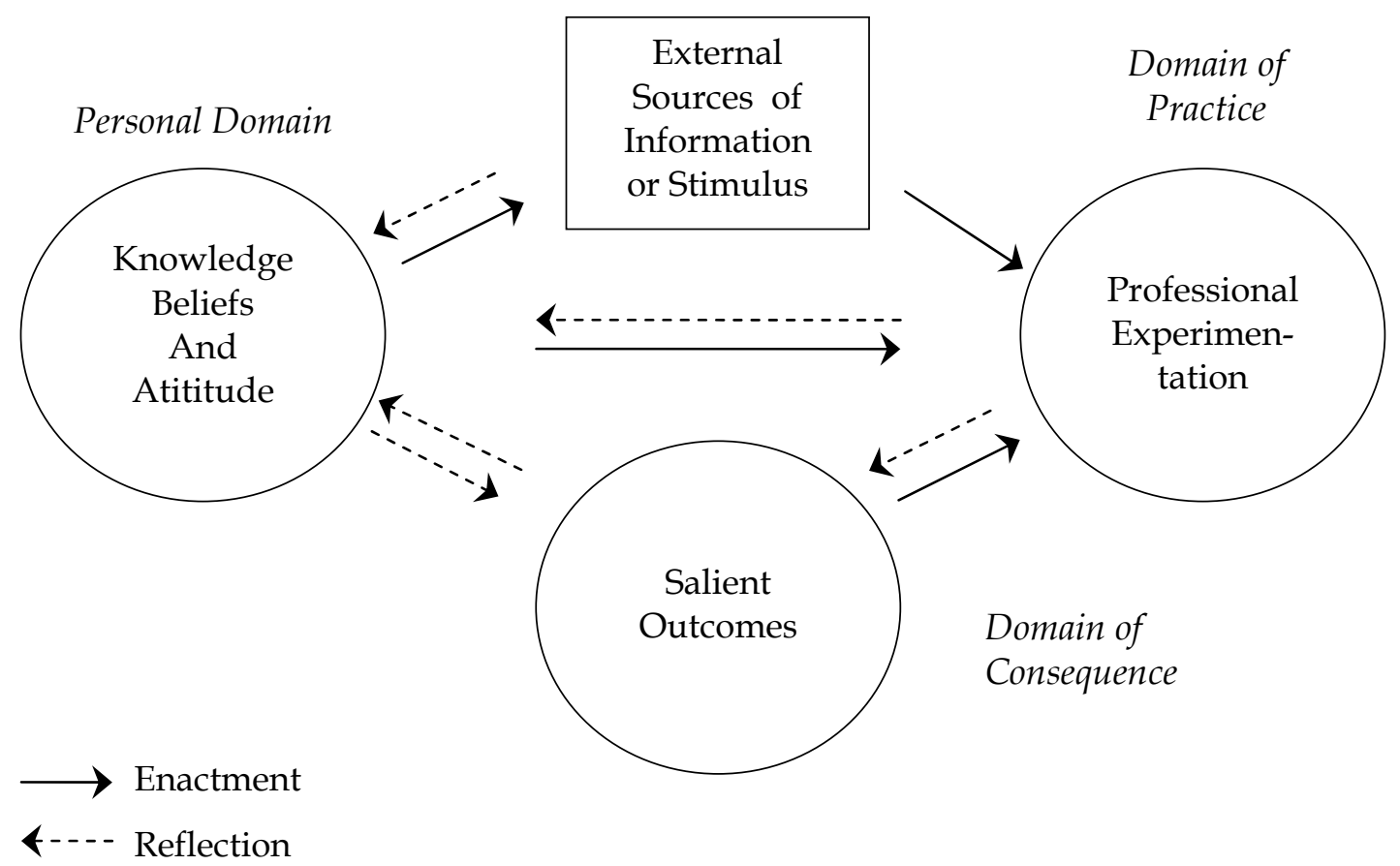

Figure 2.3 The Interconnected Model of Teacher Professional Growth (Clarke \& Hollingsworth, 2002)

These four domains can influence one another through mediation processes of 'reflection' and 'enactment'. The authors explain that: “The term 'enactment' was chosen to distinguish the translation of a belief or a pedagogical model into action from simply 'acting'." (2002, p. 951).

The process by which changes occur can, according to the authors, be represented by a "change sequence" consisting of "two or more domains together with the reflective or enactive links connecting these domains, where empirical data support both the occurrence of change in each domain and their causal connection" (p. 958). Where the occurrence of change is more than momentary, this change is seen as professional growth and the associated change sequence is termed a "growth network". Justi and van Driel (2006) used another criterion to distinguish between "growth sequence" and "change network". For them, "a 'change sequence' was characterized by the establishment of one or two relationships between different domains for a given aspect of teachers' knowledge" (p. 443). They interpret this as a superficial change. The term "growth network" was used when "the pictorial representation of the IMTPG of a given aspect consisted of more than two 
relationships between different domains" (p. 444). In their view this means more complex changes in teachers' knowledge.

This study is about how chemistry teachers professionally change. First of all we examined the changes in knowledge, beliefs and skills when teachers are placed in the role of developers of student learning material and subsequently enact this material in their classes. We then looked at the changes in knowledge, beliefs and skills of teachers who merely enact the developed materials in their classes. It is supposed that all teachers will go through a process of change, including the uncertainty and anxiety phases, making the stages of concern (CBAM) that Hall and Loucks proposed, relevant.

The teacher-developers did not receive any kind of training. They acted on the bases of guidelines in a network under supervision of a coach. The Joyce \& Showers model is especially suitable when an agency develops and delivers specific training for teachers. Although in this research, teachers themselves were the ones to take control over their own learning, the Joyce and Showers model might provide essential elements to be used during the development process. This model could certainly be of value when discussing the changes from teachers who just enacted the material.

Of special interest in this study was the question what activities the changes in teachers' knowledge and beliefs system would induce, and the possible differences between the two groups of teachers: the teacher-developers and the teachers. The IMTPG model from Clarke and Hollingsworth looked promising to describe the process.

In chapter 7 the relationship between these three models will be discussed and these models will be used to interpret and understand our findings.

\subsection{RESEARCH QUESTIONS}

In chapter 1.4 the four aspects of the research question were formulated, labeled (a) through (d). These were converted into specific research questions and each of these will be addressed in one of the chapters 3 till 7 .

Question (a) is the focal point of chapter 3. The research questions addressed here are: 1 . What are chemistry teachers' beliefs about the curriculum content, about their roles, about developing learning material, and about professional 
development? 2. Can these beliefs be taken as starting point for the development of a new chemistry curriculum?

Question (b) is dealt with in the chapters 4 and 5. In chapter 4 the focus is on the teacher- developers' perceived goals of chemistry education and on what they themselves reported to have learned during the development of student learning material. The specific research questions are: 1 . What are the teacherdevelopers' perceived goals of context-concept based chemistry education (a) before the development process (b) after the writing phase of the module, and (c) after class enactment of the module? 2. What did teacher-developers learn (a) during the writing phase (b) during the class enactment phase?

Chapter 5 looks into teacher learning in terms of PCK changes. The specific research question is: What changes in Teachers' Pedagogical Content Knowledge occur when teachers are engaged in the development and subsequent class enactment of context-based student leaning material, and to what phases within the development process can these changes be attributed?

Question (c) is looked into in chapter 6. The specific research question is: What changes in teachers' PCK take place when they class enact innovative learning material developed by teachers in a network

Question (d) finally is addressed in chapter 7, and the research question guiding this chapter is: How can the observed changes in teacher knowledge and beliefs be interpreted and understood in terms of the models of teacher learning?

\subsection{MeTHOD}

A multiple case study design (Yin, 2003) was used to answer the aforementioned specific research questions. The main reasons for choosing this design are that capturing a teachers' knowledge and beliefs system is highly complex (Pajares, 1992), and secondly that teacher learning is seen as idiosyncratic processes (Clarke \& Hollingsworth, 2002; Parke \& Charles, 1997). In Borko's words (2004, p.6): “Research using the individual teacher as the unit of analysis also indicates that meaningful learning is a slow and uncertain process for teachers, ........ Some teachers change more than others through participation in professional development programs". 
Different research instruments were used, for example interviews with semistructured interview guides, questionnaires, and transcripts from meetings. Teachers were invited to report and elaborate on all aspects they found relevant in answer to a specific general question. In each chapter the specific instruments used to answer the research questions are described in detail. Triangulation (Denzin \& Lincoln, 2000; Meijer, Verloop, \& Beijaard, 2002) was used if possible. For data analysis open coding was used (Gibbs, 2007). Details are provided in each chapter. 


\title{
CHAPTER 3
}

\section{Assessing teachers' beliefs to facilitate the transition to a new chemistry curriculum: what do the teachers want? ${ }^{1}$}

\begin{abstract}
In this article, we describe the results of a study of chemistry high school teachers' beliefs $(n=7)$ of the chemistry curriculum and their roles, their beliefs on the teacher as developer of materials, and their beliefs about professional development. Teachers' beliefs influence the implementation of a curriculum. We view the use of a new curriculum as a learning process, which should start at teachers' prior knowledge and beliefs. The results reveal that it is possible to develop a new curriculum in which teachers' beliefs are taken as a starting point. Promising approaches to prepare teachers for a new curriculum is to let them (co)develop and use curriculum materials: it creates ownership, and strengthens and develops teachers' PCK.
\end{abstract}

\subsection{INTRODUCTION}

Plans to develop a new chemistry high school curriculum in the Netherlands are in an advanced stage. The question is not whether a new curriculum will be introduced, but what characteristics such a new curriculum will have. Preparing teachers for a curriculum reform is seen as a complex learning process in which teachers actively shape their own professional growth. In any learning situation, the knowledge and skills the learners already have, are the starting point for the design and development of the learning processes to take place. This is also valid for teachers as learners. Curriculum developers will have to take account of teachers' knowledge, beliefs and skills in developing a

1 This chapter is a reprint from: Coenders, F., Terlouw, C., \& Dijkstra, S. (2008). Assessing teachers beliefs to facilitate the transition to a new chemistry curriculum: what do the teachers want? Journal of Science Teacher Education, 19(4), 317-335. 
new curriculum, otherwise it is unlikely that the curriculum will be implemented as intended (Cotton, 2006).

The question that guided this study was to establish what chemistry teachers consider to be a good curriculum, how they envisage their role as a teacher and what their beliefs are with respect to their preparation for a new curriculum. In the following paragraphs we will first look at the context of the study, then discuss the problems with curriculum reforms, after this explore what knowledge teachers draw on in their professional life and the relation between knowledge and beliefs, and we finally turn to teacher learning.

\subsubsection{Context of the study}

In 1999 the Dutch Ministry of Education introduced a new nationwide upper high school curriculum (for ages 16-18). The innovation was based on two main sets of requirements: (a) a new instructional design and teaching model; and (b) the inclusion of more exam subjects. In the new teaching model the teachers were no longer seen as information providers, but as facilitators of the students' learning processes. The teachers' role shifted from explaining content to coaching students. More subjects resulted in less class time per subject. Before the introduction of the new syllabus, students from the three upper high school classes had two, three and four chemistry periods per week. After the introduction of the new curriculum only two periods per class remained. As a consequence of the time reduction the existing examination syllabuses had to be adapted. The chemistry syllabus was mainly pruned, as a lot of topics were removed and only a few new ones added. The discontent that already existed amongst chemists about the curriculum was augmented after this operation. A discussion between stakeholders in chemistry education resulted in strategic guidelines to come to a major curricular change (Bulte et al., 2000), involving both the content and the teaching methodology. The need to redesign the curriculum was acknowledged by a committee appointed by the Dutch Ministry of Education (Van Koten, de Kruijff, Driessen, Kerkstra \& Meinema, 2002). In a follow up report (Driessen \& Meinema, 2003) recommendations for a new chemistry curriculum to be implemented in 2010 were suggested, and the crucial role the teachers play in a curriculum innovation was recognized. One of the new roles for teachers entails the development of learning materials for students. In the first stages it is envisaged that interested teachers in small regional networks develop learning material, validate this in their own classes and disseminate it to other teachers. After the introduction of the new 
curriculum, all teachers need to be able to develop new learning materials or at least adapt existing ones.

The purpose of this study was to solicit teachers' knowledge and beliefs with respect to the current and their ideal curriculum and classroom practices as a point of departure for the development of a new curriculum and for the design and development of a teaching staff development program. The research question was: what knowledge and beliefs do chemistry teachers hold with respect to the following areas: (a) the content of the current and their ideal curriculum; (b) teacher roles; (c) the teacher as developer of curriculum materials for class use and (d) training and support considered helpful before and during implementation.

\subsubsection{Curriculum reform}

The introduction of large scale science education reforms has often been problematic (Davis, 2003; Fullan 1998). Several reasons have been described in this literature for the interpretation of implementation difficulties. Many educational changes followed a model consisting of research, development and dissemination. The research and the curriculum development were carried out by specialists, the schools and the teachers were left to implement the prescribed curriculum (Olson, 2002). Innovations were often seen as organizational changes, something Fullan (1998) described as 'first-orderchange", ignoring the crucial role of the stakeholders, especially teachers. Another reason described by researchers for innovation problems is the fact that "dilution" and interpretational changes have taken place from the ideal curriculum in the head of the developers to the attained curriculum by students (Akker van den, 1988; Goodlad, Klein \& Tye, 1979). However the main reason found in the literature is that although it was widely recognized that teachers are the real driving forces in any innovation, the change agencies did not act accordingly. Despite good intentions the teachers were not or only sideways involved in the initiation, preparation, design and development of a new curriculum (Van Veen, Sleegers \& Van de Ven, 2005). Moreover, the change agencies presented the curriculum changes as improvements without having empirical evidence for this. When the new curriculum had been drawn up by specialists, teachers were required to update their knowledge and skills (Guskey, 2000) in accordance with the new curricular demands. In this perspective, change was seen as a repair program to eliminate deficits in teacher knowledge and skills. These programs consisted of "one-shot" 
workshops, aimed at teacher mastery of prescribed knowledge and skills. Research has shown that these one-off programs failed and this brought about a shift in focus on teacher change. Change is now seen as a complex process in which teachers are active learners shaping their professional growth (Clarke\& Hollingsworthe, 2002; Loucks-Horsley, Hewson, Love \& Stiles, 1998). Therefore the goal of this study is to examine the teachers' knowledge and beliefs, the teachers' learning processes, and the way these can be influenced in times of a curricular reform. Because the efficacy of a reform effort rests largely with teachers, their knowledge and beliefs need to be included in the development and implementation of a new curriculum (Ball \& Cohen, 1999; Keys \& Bryan, 2001; A.T. Lumpe, et al., 2000).

\subsubsection{Teacher knowledge}

The knowledge base for teaching has been the subject of many studies (Barnett \& Hodson, 2001; Cochran, DeRuiter \& King, 1993; Laplante, 1997; Loughran, Mulhall \& Berry, 2004; Shulman, 1987; Van Driel, Verloop \& de Vos, 1998; Veal, 2004; Yerrick, Park \& Nugent, 1997 (Laplante, 1997). A teachers' knowledge base consists of academic knowledge, pedagogical content knowledge, and experiential knowledge. Academic knowledge comprises science content knowledge, knowledge about the nature of science and knowledge about how and why students learn. Formal university courses were the main sources for teachers to acquire this academic knowledge. Pedagogical content knowledge, PCK, was initially described by Shulman (1987) as knowledge for teaching, developed from a teachers' knowledge of content and pedagogy. Elaborating on this work, Grossman (1990) conceptualized PCK as a knowledge domain drawing on subject matter knowledge, pedagogical knowledge and knowledge about context. The question whether PCK should be viewed as an amalgam of these knowledge domains or consists of a separate and unique knowledge domain has not been resolved (Gess-Newsome (1999 a). However, an expert teacher has well formed PCK for all topics taught, and this teaching knowledge is contextually bound. PCK is developed and shaped through teaching experience (Clermont, Borko \& Krajcik, 1994; Van Driel et al., 1998). It is created through reflection, active processing and integration of its contributing components. It can hardly be learned from a book or in a short course, but requires actual practice in classrooms. Experiential knowledge is defined as personal and situated knowledge about teaching and learning, acquired through experiences and to a great deal implicit or tacit. It is constructed in 
classrooms but also during informal staff room talks and in experiences with parents. Because of its nature experiential knowledge is highly situated.

A teachers' knowledge base is acquired and nourished through study and experience, and is under constant construction and modification. It is a highly complex construct and not easily assessed (Baxter \& Lederman, 1999). Teachers use their knowledge base in their daily work (Barnett et al., 2001). In this study attention was given to the teachers' knowledge base in relation to a curricular reform. In what content areas do teachers want to acquire new knowledge and how do they want support to be offered?

Beliefs play a major role in the development of practical knowledge in acting like a filter through which new knowledge is interpreted and integrated. (Pajares, 1992; Van Driel, Bijaard \& Verloop, 2001). Attention for beliefs and classroom practices is necessary in both pre- and in-service teacher training as a meaningful change in one requires change in the other and vice versa (Kupari, 2003).

\subsubsection{Teacher beliefs}

Tobin and McRobbie (1996) have identified four "cultural myths" that guide science teachers' classroom practice. The first myth concerns the belief that the transmission mode of teaching is more effective than the use of other teaching approaches. Another myth is that preparing students for the examinations dominates classroom practices. The third is the myth of efficiency, and the last myth is related to maintaining the rigor of the curriculum. From the innovation perspective these myths impede change.

Numerous studies highlighted the role of teachers' personal beliefs about content in relation to the implementation of a curriculum (Duschl \& Wright, 1989; Lantz \& Kass, 1987). Teachers did not implement curriculum materials that contradict their ideas about content and how this content should be taught (Gess-Newsome, 1999 b). Materials were used if they matched the teachers' perspective, but were modified or discarded if they did not (Blake, 2002; Duffee \& Aikenhead, 1992). Cronin-Jones (1991) described four beliefs categories influencing curriculum implementation. These categories concern the teacher's own role, the way students learn, the abilities of particular student groups, and the relative importance of subject content topics. Teachers appeared to adapt a new curriculum during implementation according to their own context and beliefs. Even when teachers initially subscribe to a reform developed by others, there is no guarantee that the reform is implemented or sustained. Rousseau (2004) reported about a teacher community who began and later abandoned a 
reform. These teachers' beliefs about teaching and learning conflicted with their beliefs about their students. Teachers argued that their students' struggle to cope with the new curriculum demands required them to revert to old teaching habits. A similar course of events is reported in a case study by Van Veen et al. (2005) where an initially reform-enthusiast teacher because of personal, moral and social concerns developed negative emotions towards the most important aspect of the particular reform.

Evers, Brouwers \& Tomic (2002) found that teachers in the Netherlands with strong self-efficacy beliefs seem to be more prepared to experiment with, and later to implement, new educational practices. This view is supported by the finding that the way teachers react to a reform is largely determined by whether "the teachers perceive their professional identities as being reinforced or threatened by reforms" (Van Veen \& Sleegers, 2006, p 106).

In times of educational reforms, aimed at changing teaching practices for the better, the intertwined nature of teachers' knowledge and beliefs, their emotions and cognitions, are revealed more prominently. Reform policies that affect their classrooms, give rise to more intense teacher emotions towards the reform (Schmidt \& Datnow, 2005). Imposing different normative beliefs on teachers in reforms may elicit actions of resistance (Kelchtermans, 2005). Because of their importance the main goal of this study was to solicit teachers' beliefs in relation to a curricular reform.

\subsubsection{Teacher learning and reform of practice}

Loucks-Horsley et al. (1998) argued that teachers need to experience for themselves the science learning that they want to engage their students in. The professional development program used by Jeanpierre, Oberhauser \& Freeman (2005) was based on this premise, and they found that it is possible to change a large part, though not all, of these teachers' educational practices. The success of the program was attributed to the presentation of deep science content and process knowledge with numerous opportunities for practice.

In another study teachers reverted to previously mastered teaching techniques and even retained subject content from previously taught classes (Lantz et al., 1987), when new teaching approaches were not accompanied by the mastery of knowledge and new patterns of practice (Hollon, Roth, \& Anderson, 1991). The authors therefore suggested that merging of aspects of a new curriculum with topics and practices teachers valued most from previous teaching experiences was required. 
A number of studies report about the use of curriculum materials to support teacher learning. A group of researchers developed teachers' guides containing "how-to-do" advice for teachers in potentially vulnerable areas like lesson preparation, lesson content, teaching role and evaluation (Akker, 1988; Roes, 1997; Voogt, 1993). The use of these materials with procedural specifications resulted in less implementation problems. Ball and Cohen (1996) proposed that curriculum materials for students should also be designed as educative for teachers, providing explicit support for learning about teaching. According to Schneider, Krajcik \& Blumenfeld (2005), the use of materials with detailed lesson descriptions, and specific, consistent support for teacher thinking can help with enactment, though this is not sufficient. In the authors' views, reform efforts must include professional development and effort to create systemic change in context and policy. One of the difficulties in the development of educative materials is the dilemma in the quantity of direction: give too much direction and teachers may lose any sense of ownership, give too little and teachers do not know what to do (Pintó, 2005).

As teachers' knowledge, experiences and beliefs greatly impact classroom practices, teacher learning must be a key ingredient in educative reform (Pintó, 2005). Just as for students, learning activities for teachers must take their knowledge, beliefs and skills into account (Lieberman, 1995). Professional development programs should attend to the diverse behaviors and beliefs of its participants (Luft, 2001). The teachers' professional growth is supposed to be a complex process, having an idiosyncratic nature (Clarke et al., 2002). It is not only important to find out what teachers think of a reform, but also to identify what they perceive to be their task and why (Olson, 2002).

The question that guided this study was whether it is possible to develop a new chemistry curriculum that takes the knowledge and beliefs of the teachers as a starting point, after these have been assessed. Researchers (Cronin-Jones, 1991; de Vries, 2004) have shown that beliefs teachers have with respect to curriculum content and teacher roles are important during curriculum reforms. These two aspects were therefore included in this study. As teachers are often codevelopers of learning materials for students, it was also of interest to assess their beliefs in this area. In any reform teachers will need to be trained and supported (Schneider et al., 2005) and we therefore also solicited the teachers' beliefs on professional development programs and activities. 


\subsection{METHOD}

\subsubsection{Participants}

Seven ${ }^{2}$ high-school teachers, employed at different schools throughout the country, three female and four male, were selected and interviewed, all having a chemistry masters degree and a teaching qualification. For the selection of the teachers four criteria were used: teachers should be familiar with the discussion on the new chemistry curriculum and with the main recommendations in the Van Koten report (2002) in order to be able to relate to these recent developments; as we wanted the teachers to comment on the curriculum content, they needed an open mind to new developments in chemistry and teaching; we wanted the teachers to assess the situation in chemistry classes and they should therefore be willing to reflect on their classroom practices; and teachers should have recent and up-to-date teaching experience. Of the selected teachers, six were very experienced, each having more than 20 years of teaching experience. Only one teacher was less experienced, having 2 years of experience. One teacher is a co-author of a chemistry high school book; one teacher was involved in the development of materials for practical work; one teacher was involved in the construction of evaluation questions; one has experience with the construction of curriculum materials and one teacher is involved in the development and use of prototype materials for 'chemistry in context'. Only one of the experienced teachers and the less experienced teacher had no specific expertise field outside the teaching profession.

All teachers were active teachers at the time they were interviewed, each having recent and up-to-date classroom experiences.

\subsubsection{Instruments}

In order to permit teachers to express their own ideas without guiding their responses, and because of the complexity of teachers' personalities and their belief structures, we decided to interview the teachers in stead of using a questionnaire. The interviews took between 60 and 90 minutes and were

2 Two teachers from different schools wanted to be interviewed together because they had as a team closely cooperated during the development of innovative classroom materials. This interview, in which the same issues were addressed as in the other interviews, resulted in one transcript. It is presented under teacher G. 
conducted in a period of six weeks. A semi-structured interview guide organized the interviews. Four areas were addressed:

1. Teachers' beliefs about the curriculum content. The following questions were raised: (a) what essential elements do you think should be present in assignments, exercises and other student activities, in order to facilitate students' knowledge construction? (b) what do you consider an ideal chemistry curriculum in terms of representative chemistry content?

2. Teachers' beliefs about their roles. The specific questions were: (a) what roles in relation to your students do you have as a chemistry teacher? (b) what roles do you have with respect to self-regulated learning?

3. Teachers' beliefs about the development of learning materials: (a) what kind of learning materials did you yourself develop so far? (b) what are your beliefs on teachers as developers of learning materials?

4. Teachers learning and reform of practice: (a) do you think you want support for: 1. chemistry content and chemistry didactical content? 2. the use of cooperative learning assignments? 3. evaluation of learning results? 4 . the use of information and communication technology (ICT) applications? (b) how would you like to receive this support? 1. as a course? 2. as exemplary material, containing procedural specifications? 3. in the form of developing educational materials with others? 4 . as teachers' guides?

\subsubsection{Data and data processing}

Data processing and analysis consisted of four phases. First, all interviews were transcribed verbatim. In order to establish common beliefs in the seven transcripts, a three step protocol analysis procedure was used (Coenders, 2003) In the first step, each transcript was examined to determine sentences or phrases considered characteristic for the given response. These characteristic phrases were highlighted in the transcripts, and subsequently tabulated in a created word table. This resulted in seven word tables containing the characteristic phrases per interview.

In the second step of the procedure the characteristic phrases from all the interviewees per question were organized in a new word table. This resulted in a word table for each question. Each table comprised of all the characteristic phases from all interviewees on that question.

In the third step, common elements were determined in each word table from step two in order to enable generalizations. These common elements were 
transferred to a new word table in which a plus $(+)$ sign was used to indicate that an interviewee had mentioned that element. Tables obtained after this step are shown in the results section.

\subsubsection{Determination of the reliability}

To determine the reliability of the data processing two tests were carried out, a test of the reliability of the results and the inter-rater reliability. Four chemistry teachers not involved in the research were requested to act as assessors and check the processed data against the interview transcripts. To limit their time investment, a representative sample check was carried out.

To determine the reliability of the results the assessors were given the data table that was obtained after step three of the data processing plus the corresponding interview transcripts. They were asked to indicate, comparing the table with the transcript, whether they could support or would reject the statement made in the table, and secondly, determine if statements were missing in the table. A random sample was selected per assessor, consisting of three processed tables and for each table the transcripts of two interviews. Of the items the assessors judged in this way, $91 \%$ was in full agreement, 3\% was partly supported and the other $6 \%$ were not agreed upon.

To establish the inter-rater reliability, all four assessors were asked to judge the processed data of one specific table against the transcripts of the same three interviews. This resulted in $94 \%$ full agreement.

\subsection{Results}

\subsubsection{Teachers' beliefs about the curriculum content: essential elements in assignments to foster knowledge construction}

As can be seen in Table 3.1, all teachers wanted a gradual shift from simple to more complex assignments. As one teacher said: "The cognitive aspect is first a matter of checking understanding of the content and if one can reproduce it that is sufficient. Then it should be applied or recognized in other situations."

Implicitly teachers also provided information on the content of the assignments. First of all assignments need to contain elements, which encourage students to look for relevant information in their textbook or some other information 
source, in order to reproduce this knowledge. After this the students need to be stimulated to apply the knowledge, first in a more or less familiar context. One of the teachers phrased it as follows: “Training exercises will always be necessary ........ The next phase would students require to apply what they learned to a context, for example a product label".

Three teachers explicitly mentioned the transition from closed to more open assignments. The goal of the open assignments is the integration of knowledge domains and skills acquisition, and not so much practicing specific content. As one teacher phrased it: "I find open assignments crucial, but the question is whether these do support knowledge construction or mainly the acquisition of skills?"

According to three teachers assignments need to support the construction of knowledge networks. Two of these teachers indicated that reflection on the learning results will also contribute to the creation of knowledge networks and to the development of meta-cognitive skills. One of the teachers mentioned how students can construct their knowledge network: "Assignments in which they do not have to apply the theory directly, but for which they need to show a helicopter view on the theory............ like the construction of a concept map."

Table 3.1 Essential elements in assignments and exercises to facilitate knowledge construction

\begin{tabular}{|c|c|c|c|c|c|c|c|c|}
\hline \multirow[b]{2}{*}{ Assignments and exercises need to } & \multicolumn{8}{|c|}{ Teacher } \\
\hline & $A$ & $B$ & C & $D$ & $E$ & $F$ & G & $\%$ \\
\hline $\begin{array}{l}\text { Start simple and gradually become } \\
\text { more complex }\end{array}$ & + & + & + & + & + & + & + & 100 \\
\hline $\begin{array}{l}\text { Support construction of a knowledge } \\
\text { network }\end{array}$ & & & + & & + & & + & 43 \\
\hline
\end{tabular}

Note. The plus (+) sign is used to indicate teachers who have mentioned the particular element. A letter is used to indicate the interviewed teacher.

\subsubsection{Curriculum content: Ideal chemistry curriculum}

Basic concepts, like chemical bonding, concentration, and organic chemistry, were mentioned by five of the respondents as typical components of an ideal curriculum (see Table 3.2). These teachers also indicated that some topics should be removed from the current curriculum: mass spectroscopy, redox reactions, entropy. Existing overlap between subjects (for example with biology in biochemistry) has to be reduced. 
There was support from five of the interviewees for the prominent place that positive developments in chemistry should have in a new curriculum. Negative aspects of chemistry application, like pollution and environmental damages, often appear in the news headlines. The important contribution of chemistry to our modern society needs a more prominent place in a new curriculum. Modern chemistry applications are indicative for the fact that six of the teachers especially wanted to incorporate state of the art chemistry developments in a new curriculum. One of these teachers formulated this as follows: "The positive developments in chemistry need to get a more central role. And then also the current developments."

Five of the teachers mentioned the students' practical activities as a characteristic of a chemistry curriculum. Three teachers stated that what students learn needs to influence their behavior.

\section{Table 3.2 Perceived characteristics of an ideal chemistry curriculum}

\begin{tabular}{|c|c|c|c|c|c|c|c|c|}
\hline \multirow{2}{*}{$\begin{array}{l}\text { Typical characteristics of an ideal } \\
\text { chemistry curriculum }\end{array}$} & \multicolumn{8}{|c|}{ Teacher } \\
\hline & $A$ & $B$ & C & $D$ & $E$ & $F$ & G & $\%$ \\
\hline $\begin{array}{l}\text { Basic concepts (bonding, concentra- } \\
\text { tion, particles); organic chemistry }\end{array}$ & + & + & & + & & + & + & 71 \\
\hline $\begin{array}{l}\text { Positive developments in chemistry in } \\
\text { a more prominent role }\end{array}$ & + & & + & + & + & & + & 71 \\
\hline Modern applications of the discipline & & + & + & + & + & + & + & 86 \\
\hline Practicals, skills, research & + & + & & & + & + & + & 71 \\
\hline $\begin{array}{l}\text { Aspects students will be confronted } \\
\text { with (later): knowledge must } \\
\text { influence behavior }\end{array}$ & & & + & + & + & & & 43 \\
\hline
\end{tabular}

\subsubsection{Current curriculum: general remarks made by the interviewees}

All teachers talked about the main difficulties in the current curriculum, although the interviewer did not bring this issue up. Lack of time was a complaint that emerged over and over again. Insufficient class time made it difficult to establish common ground with students: “.. you hardly see them (the students) because there is so little class time.." 
The school curriculum as a whole was considered to be overloaded. Teachers said that their students struggled with deadlines all the time as the number of assignments, for all subjects, was high: ".....because of the overburdening of the students as a result of all these practical assignments...."

Time was wasted because of insufficient coherence, both between the topics and between related subjects. Teachers expressed the feeling that during the development of this curriculum, the innovation, self-regulated learning of students, was not taken as a starting point, but the existing chemistry curriculum had only been pruned and polished.

The teachers attributed most problems the students encountered to requirements from outside the chemistry curriculum, not to difficult topics in the curriculum itself.

\subsubsection{Teachers' beliefs about their roles}

The role of instructor, in the sense of explaining content, was mentioned by five teachers (Table 3.3). Phrasing and answering questions was brought up by four of the respondents. These two roles are directly related to the subject matter content.

Making students enthusiastic was mentioned by four teachers and maintaining a pleasant working atmosphere by two. Three teachers talked about the role of managing the students' learning processes; four did not mention this role explicitly.

Four teachers believed to have a guiding or coaching role. One of these teachers decidedly mentioned the upbringing task as the most important school objective, especially for this age group. In his opinion these students have to be guided through adolescence, a difficult period in their lives: “... your students grow older and you play a role in this." This teacher also considered relating chemistry to students' life world more important than teaching subject content per se: "...... something should start living in students; they should be able to relate it to something familiar..." 
Table 3.3 Perceived roles as chemistry teacher

\begin{tabular}{|c|c|c|c|c|c|c|c|c|}
\hline \multirow[b]{2}{*}{ Perceived teacher roles } & \multicolumn{8}{|c|}{ Teacher } \\
\hline & $A$ & $B$ & C & $D$ & E & $F$ & G & $\%$ \\
\hline Explain content; instructor & + & + & & & + & + & + & 71 \\
\hline Phrase or answer questions & + & & + & & + & & + & 57 \\
\hline Make students enthusiastic & & + & + & & & + & + & 57 \\
\hline $\begin{array}{l}\text { Maintain a pleasant working } \\
\text { atmosphere }\end{array}$ & & + & & + & & & & 29 \\
\hline Manage the learning process & + & & + & & & + & & 43 \\
\hline Guide - coach & & & & + & + & + & + & 57 \\
\hline
\end{tabular}

Only three teachers mentioned teach how-to-learn and teach how-to-plan as clear tasks within chemistry education (Table 3.4). However it is unclear how this should be carried out in practice. As one teacher said:

"So the students you think would require a lot of your coaching role, do not make use of this ........... My task is to see to it that students do have questions. I don't know yet how to do this. That is learning and the uncertainty I now have myself".

Table 3.4 Perceived teacher roles with respect to self-regulated learning

\begin{tabular}{|c|c|c|c|c|c|c|c|c|}
\hline \multirow{2}{*}{$\begin{array}{l}\text { Role with respect to self- } \\
\text { regulated learning }\end{array}$} & \multicolumn{8}{|c|}{ Teacher } \\
\hline & $A$ & $B$ & C & $D$ & E & $F$ & G & $\%$ \\
\hline $\begin{array}{l}\text { No explicit role in chemistry } \\
\text { education }\end{array}$ & + & + & & & & & & 29 \\
\hline Teach how-to-learn & & & & + & + & & + & 43 \\
\hline Teach how-to-plan & & & + & & + & & + & 43 \\
\hline
\end{tabular}

\subsubsection{Teachers' beliefs about the development of learning materials}

The responses to the questions are summarized in Table 3.5. Teachers were encouraged to mention whatever they perceived as development tasks. In the second question a broad description for development task was adopted, from making worksheets with exercises to describing student practicals and writing of complete topic chapters.

All teachers expressed that a full teaching load in the current school practice leaves insufficient time for the development of learning materials. 
Experience with the development of materials was diverse as can be seen in Table 3.5. Four teachers have developed open assignments, and made adaptations in existing materials. Only two teachers have written complete topic chapters.

With respect to beliefs about the teacher as developer five teachers reported to find development tasks in combination with teaching motivating, under the condition that sufficient time is available. One of these teachers phrased this as follows: “... maybe about 10-15\%. I like developing new things but it should not become my main task."

Two teachers expressed that the development of learning and teaching materials should be left to professionals; these professionals could however be teachers who can spend "minimal one day per week for development tasks" as part of their teaching profession, which would certainly require a major reduction in teaching load.

Table 3.5 Development work carried out and beliefs about the teacher as developer

\begin{tabular}{|c|c|c|c|c|c|c|c|c|}
\hline \multirow[b]{2}{*}{ Developed learning materials } & \multicolumn{8}{|c|}{ Teacher } \\
\hline & $A$ & $B$ & C & $D$ & $E$ & $F$ & G & $\%$ \\
\hline Open assignments & + & + & & & + & & + & 57 \\
\hline Just adapting materials & + & & + & & + & + & & 57 \\
\hline Complete chapters & & & & & + & & + & 29 \\
\hline Beliefs about teacher as develope & & & & & & & & \\
\hline $\begin{array}{l}\text { Combination developer-teacher is } \\
\text { motivating }\end{array}$ & & + & + & & + & + & + & 71 \\
\hline $\begin{array}{l}\text { Professionals have to do the } \\
\text { developing }\end{array}$ & & & & + & & & + & 29 \\
\hline
\end{tabular}

\subsubsection{Teachers' learning and reform of practice}

As can be seen in Table 3.6, most teachers expressed to appreciate support in the four areas mentioned by the interviewer, the duration and extent depending on the depths and breaths of the innovation. Three teachers said that they considered assistance in ICT applications only useful when the support offered had a direct bearing on their teaching and when the course was offered at school. These teachers also acknowledged the fact that students are more computer literate than they are and the difference is widening. 
Table 3.6 Perceived areas of support in preparation of a new curriculum

\begin{tabular}{lllll|l|l|l|l}
$\begin{array}{l}\text { Support areas to prepare for } \\
\text { a new curriculum }\end{array}$ & A & B & C & D & E & F & G & $\%$ \\
Content (plus didactical) & + & + & + & + & - & + & + & 86 \\
$\begin{array}{l}\text { Cooperative learning } \\
\text { assignments }\end{array}$ & + & + & - & + & + & + & & 71 \\
Evaluation of learning results & + & + & + & + & + & + & & 86 \\
ICT & + & \pm & \pm & - & + & \pm & & 71
\end{tabular}

In Table 3.7 the kind of support teachers would like to receive is reported. Of the four alternatives offered, a course was preferred when specific knowledge and skills need to be acquired, especially when the course could be held at school. The advantage of the latter would be that all materials and computer programs are in place and in working condition, and can be used even after the course. One teacher reported to be happy with a course offered at school: "We had a course in school with about twenty colleagues under supervision from someone from a college and I consider this a good way of in-service training."

Merely written resources were less appreciated. Exemplary material, containing specifications for class use, was new to most teachers. They had never used it and characteristics had to be explained to them before they could answer the questions. Three of the respondents considered exemplary materials helpful. The use of teachers' guides was appreciated by four of the teachers.

All teachers believed involvement in the development of learning materials as a strong opportunity to get ready for a new curriculum.

Table 3.7 Perceived ways of support in preparation of a new curriculum

\begin{tabular}{|c|c|c|c|c|c|c|c|c|}
\hline \multirow{2}{*}{$\begin{array}{l}\text { Ways of support in preparation } \\
\text { of a new curriculum }\end{array}$} & \multicolumn{8}{|c|}{ Teacher } \\
\hline & $A$ & $B$ & C & $D$ & $E$ & $F$ & G & $\%$ \\
\hline Course & \pm & + & + & + & + & + & + & 100 \\
\hline Exemplary material & + & + & & & + & & & 43 \\
\hline $\begin{array}{l}\text { Develop (with others) educational } \\
\text { material }\end{array}$ & + & + & + & + & + & + & + & 100 \\
\hline Teachers' guides & + & + & & & + & + & & 57 \\
\hline
\end{tabular}




\subsection{Discussion}

\subsubsection{Teacher knowledge}

Teachers appear to be self-knowledgeable. They spoke frankly about their qualities and their strong and weak sides, and were able to indicate in what areas they need to acquire knowledge and skills. Teachers use the syllabus requirements to determine whether or not their knowledge and skills are sufficient, and they compare their own school practice with practices of colleagues.

Surprisingly teachers felt uneasy when asked about their role in stimulating self-regulated learning. They do not know how to realize this in their own practice. As self-regulated learning was one of the pillars of the 1999 curriculum renewal, this aspect of that reform could be assessed as being little successful.

Although the proposed context-concept approach by Driessen et al. (2003) can count on cautious approval, teachers felt uneasy about the implications for the students' learning processes. They wonder whether their knowledge will be adequate to support students when they engage in a learning process based on a context-concept approach. The academic and pedagogical content knowledge domains need to be updated.

\subsubsection{Teacher beliefs}

The teachers recognize the fact that the current curriculum is outdated and share the belief that a curriculum overhaul is necessary. The data show that teachers hold strong beliefs about the conditions a chemistry curriculum should meet in terms of assignments and exercises. The student activities must start simple and gradually become more complex. Teachers first want to assess students' knowledge and understanding of basic principles before moving on to more complex learning situations as applications and open assignments. Scaffolding activities to construct a knowledge network, and activities to foster reflection on the learning process and learning results should be incorporated in students' learning activities.

The results further show that all the teachers have firm beliefs about the content of a chemistry curriculum. Positive developments in chemistry and state-of-theart applications, the covering of basic concepts and the use of experiments all require a prominent place. It is not so much the specific topics featuring in the curriculum that teachers are worried about, but more the class time available to 
cover the content and the rationality within the science curriculum as a whole. One of the ways to achieve more coherence is to reduce the overlap with the related subjects biology and physics. Because of the nature of chemistry, the students' practical work requires a prominent place in the curriculum. Practical work is believed to be not merely important because of the acquisition of practical and investigative skills, but also to instigate the integration of knowledge domains. As practical work is time consuming, sufficient class time is a prerequisite. There are two possible ways to realize adequate class time. A reduction of the number of subjects in a new curriculum will create more study time per subject. Or, if the first option is politically unacceptable, a reduction of the examination syllabus for chemistry will also create time for students to do experiments. This second option can also count on teacher approval.

Based on these conditions, it seems possible to develop a new chemistry curriculum that is acceptable to all the teachers. It should be flexible in nature to leave room for teachers to make choices according to own preferences.

How teachers perceive their roles has a direct bearing on what happens inside the classroom (Schmidt et al., 2005). Changing classroom practices therefore requires at least a reflection on possible roles. The data on the teacher roles show that all the interviewed teachers belief to have different roles. Each teacher mentioned two or more roles; they all belief that teaching is a multifaceted profession in which teachers have to take up different responsibilities and tasks. Teachers' beliefs on their roles pertain to the three domains from the teachers' knowledge base. From the academic knowledge domain, intertwined with the pedagogical content knowledge domain, teachers mentioned: explaining content and instructing students, phrasing and answering questions, and making students enthusiastic for the discipline. That these three roles were often mentioned is not surprising as these teachers were educated for these roles during their teacher preparation programs and, being very experienced, have used these in their classes for a long time. A typical role from the experiential knowledge domain, maintaining a pleasant working atmosphere, is only mentioned twice. Almost all of the teachers belief to play a role in managing the learning process and guiding or coaching students. Both these roles are partly new for these teachers as they only received explicit attention in the new curriculum introduced in 1999. One teacher holds very outspoken beliefs about the upbringing of the students. Raising children is in 
this belief by far the most important task for a teacher and a school: students first of all need to be guided to become responsible citizens.

Because learning materials have to be used in classrooms, it is necessary to take teachers' beliefs regarding these materials into account (Cotton, 2006; Rousseau, 2004). One way of achieving this is to involve teachers in the development of these materials (Kupari, 2003). All interviewed teachers developed their own performance tests and all considered this a normal teacher task, also for the future. The skills teachers have acquired in this area can be broadened to develop learning materials and learning activities.

Although nearly all teachers have developed some kind of learning materials for class use, a large variety exists in the depth and breadth of these developed materials. Some teachers have adapted existing materials to their specific situation. Others have developed comprehensive innovative materials comprising texts, assignments and practical activities for students, including teachers' guides for teachers and teaching assistants.

The teachers, who, next to a part-time teaching load, were engaged in the development of more comprehensive learning materials, perceived it very rewarding and looked forward to continuing this in future. Especially the combination of teaching and writing curriculum materials is considered valuable. A writer needs to know what fascinates students and how they learn and think. A teacher has direct contact with students and experiences how they acquire knowledge and skills. Teacher-writers combine these two sides, and are in the position of testing materials in a very early development stage with their students. In a school setting in which teachers have a full teaching load, insufficient time for development activities is available. Teachers indicated to be interested in having more of these tasks as part of their normal working load, at the same time acknowledging the requirement of professionalism.

\subsubsection{Teacher learning and reform of practice}

Teachers hold strong beliefs about the usefulness of different kinds of assistance. For ICT, a course at school is believed to be the most valuable. Teachers not only learn how to use the materials, but all materials, including hard- and software, will be locally available during and after completion of the course. Offering inservice courses at school for a whole team of teachers will contribute to the growth of the teacher self-efficacy (Evers et al., 2002; Friedman and Kass, 2002) 
and foster cooperation between the teachers (Davis, 2003). Explicit attention to the situation in the school can be given, making the course gain in practicality.

When it comes to chemistry content, knowledge typically from the academic knowledge domain, the interviewed teachers prefered a course. This reflects how teachers acquired this kind of knowledge in the past.

\subsubsection{Toward a new curriculum}

People's beliefs are powerful motivation agents. If teachers belief something to be true they are likely to act accordingly. To attend to both beliefs and practices is essential as a change in one requires a change in the other (Kupari, 2003). Teachers' understanding of the curriculum materials, their beliefs about what is important, and their beliefs about the roles of the students and the teachers all strongly shape their practice (Ball et al., 1996). The uncertainty teachers experience in times of curriculum change (Van Veen et al., 2006) clearly emerged from these interviews. The concerns teachers expressed are related to their own practices and experiences. Teachers wonder how they can play a supportive role in ICT as they observe that their students' computer skills are far better developed than their own.

Fullan (1998) described change as a learning process and as a journey. An effective learning process presupposes that teachers' prior knowledge and beliefs be taken as the starting points. Change agents need to be aware of what teachers already know, can and belief.

Teachers need to become more aware of and reflect on their beliefs and understanding about learning, teaching, students and the subject matter (Davis, 2003; Pinto, 2005). Confidence needs to be built as teachers have to take risks in enacting a new way of teaching (Ball et al., 1999; Guskey, 2000). Consensus exists between the interviewed teachers about the subject content of a new curriculum. The recommendations and directions as indicated by Van Koten et al. (2002) and Driessen et al. (2003) find approval. Also with respect to support before and during a curriculum change general accordance exists.

A possible learning process, in which teachers' prior knowledge and beliefs are taken seriously, can therefore have the following characteristics. The starting point is the idea to let teachers develop curriculum materials for class use. This requires reflection on own practices, creates at the same time ownership (Pintó, 2005; Fullan, 1998), boosts teacher self-efficacy, and teachers develop new PCK during class use. In this scenario teachers are (co) producers of innovative practices (Evers et al., 2002). Conditions for 'teacher as developer' are the 
allocation of sufficient time for the development tasks, support for teachers to clarify and learn new teacher roles, and support in specific content areas. If the curriculum reform requires the acquisition of academic knowledge, the organization of a course at the school of the participating teachers will be effective. Teacher personal growth can now really be an amalgam of practice, meaning and context (Clarke et al., 2002).

\subsubsection{Implications for further research}

One of the limiting factors in this research is the fact that the number of interviewed teachers is relatively small. This in combination with the strategy to let teachers speak out freely with a limited number of guiding questions hampers generalizations. We intend to use the results of this work to follow a few teachers involved in the development of classroom materials more closely during a longer period.

The scenario of teachers as developers of (part of) their curriculum materials looks promising though the issues of quality control, acceptance of the materials by colleagues, and clarification of what the developers learn in this process all need further research. 


\title{
CHAPTER 4 \\ The effects of the design and development of a chemistry curriculum reform on teachers' professional growth, a case study ${ }^{3}$
}

\begin{abstract}
A curriculum innovation requires new learning material for students and a preparation program for teachers, in which teacher learning is a key ingredient. In this paper we describe how three experienced teachers, involved in the development and subsequent classroom enactment of student learning material for context-based chemistry education, professionalized. For data collection a questionnaire, three interviews and discussion transcripts were used. Our results show that: (a) teachers, cooperating in a network under supervision of an expert, can develop innovative learning material; (b) the development of learning material can be seen as a powerful program to prepare teachers for an innovation; and (c) teachers' knowledge increases in all five pedagogical content knowledge (PCK) domains during the development and class enactment phases.
\end{abstract}

\subsection{INTRODUCTION}

A rather recent curriculum change in chemistry in several countries is the development and introduction of context-based education. In this type of education, appealing contexts for students are used as a starting point for learning, not merely to demonstrate science applications in daily life at the end of a topic. Context-based science education adopted the view that science content is negotiated within realities, evolving and flexible (Bencze \& Hodson, 1999), and not just a set of rules and principles to be memorized. Specific forms of contextbased approaches were developed in chemistry curriculum renewal schemes in,

3 This chapter has been accepted by JSTE in January 2010: Coenders, F., Terlouw, C., Dijkstra, S., \& Pieters, J. (2010). The effects of the design and development of a chemistry curriculum reform on teachers' professional growth, a case study. Journal of Science Teacher Education. 
for example, 'Chemistry in the Community' in America (Schwartz, 2006), in 'Salters Advanced Chemistry' in the United Kingdom (Bennett \& Lubben, 2006) and in 'Chemie im Kontext' in Germany (Parchmann et al., 2006). A similar context-based curriculum change was initiated in the Netherlands (Driessen \& Meinema, 2003), under the name "context-concept" approach. This reform, which will be discussed in a next section, is seen as a complete renewal of the chemistry high-school curriculum, touching upon the educational goals, the subject content and the pedagogy. Successful implementation of such a curriculum requires attention for students and teachers. For students, new learning material has to be developed, a process often performed by professional developers. Teachers need to understand and be prepared and equipped for this context-based education, as they are the ones to enact it in their classes. Development of student learning material and teacher preparation can be combined through the involvement of teachers in the development of the material. This study is about professional growth of three teachers during the development and subsequent class enactment of student learning material for a context-based chemistry curriculum. In the following sections we will first look at teacher learning to prepare for a reform, next at the teacher as developer of student learning material, and finally describe the context in which this study is embedded.

\subsubsection{Teacher learning in preparation of a reform}

What teachers do in class is largely influenced by their knowledge and beliefs about teaching and learning (Sanders, 1993; Walberg, 1991). In turn, experiences in class influence teachers' knowledge and beliefs (Veal, 2004). In their daily work teachers use their practical knowledge (Barnett \& Hodson, 2001) of which pedagogical content knowledge, PCK, is an essential part. Shulman (1987) initially described PCK as knowledge for teaching. Since Shulman, PCK has been studied by many researchers and been interpreted in different ways (Cochran, et al., 1993; J. Gess-Newsome, 1999). Park and Oliver (2008) define PCK as "teachers' understanding and enactment of how to help a group of students understand specific subject matter ....", and it is therefore shaped in school practices through reflection-in-action and reflection-on-action. PCK can be characterized comprising five components: (1) knowledge of science curricula, (2) knowledge of students' understanding of science, (3) knowledge of assessment, (4) knowledge of instructional strategies, and (5) orientation to teaching subject matter (Abell, 2008; Grossman, 1990; Magnusson, et al., 1999). 
An expert teacher has well formed PCK for all topics taught, developed and shaped in teaching practice through reflection, active processing and integration of its components (Clermont, Borko, \& Krajcik, 1994; Van Driel, Verloop, \& De Vos, 1998). Teachers' beliefs act like a filter through which new knowledge is interpreted and integrated (Pajares, 1992).

As teachers' knowledge and beliefs greatly impact classroom practices, expanding and changing these must be a key ingredient in any educative reform (Pintó, 2005). Different intervention programs to prepare teachers for a curriculum change have been described in literature. Some studies focused on in-service activities to train teachers for a renewal (Fullan, 1998). In general these activities were not effective. Therefore, Lumpe (2007) called on science educators to stop one-shot workshop models of professional development as teachers seldom put into practice in their classrooms what they had learned. Other studies let teachers experience the learning they wanted to engage their students in for themselves (Jeanpierre, Oberhauser, \& Freeman, 2005; LoucksHorsley, Hewson, Love, \& Stiles, 1998). These studies showed that deep science content and process knowledge plus opportunities for practice did help some teachers to take the renewal into their classes. Other scholars reported on the use of curriculum materials to support teacher learning for a renewal (Van den Akker, 1988; Voogt, 1993). It appeared from these studies that the use of material with detailed lesson descriptions and specific support for teacher thinking, can help implementation but is still insufficient with respect to the renewal intentions (Schneider, Krajcik, \& Blumenfeld, 2005). Furthermore, teacher characteristics such as knowledge, beliefs, and dispositions towards reflection, also limit the effectiveness of curriculum material used for teacher learning (Davis \& Krajcik, 2005). In all these intervention programs, the centerperiphery model of curriculum development was used (Guskey, 2000; Stronkhorst \& van den Akker, 2006) in which teachers are at best involved in the process of piloting curriculum material developed by others.

A complicating factor is that reform policies affecting teachers' classrooms can give rise to emotions towards the reform (Schmidt \& Datnow, 2005), may elicit actions of resistance (Kelchtermans, 2005), and might be threatening to teachers' professional identities (Van Veen \& Sleegers, 2006). In the Dutch chemistry curriculum renewal scheme described in the next section, resistance and feelings of threat may arise, because the current chemistry teachers have not been educated to teach, nor have experience with, context-based chemistry (De Vos \& Verdonk, 1990). These aspects are addressed when teachers are engaged 
in the curriculum change process from the beginning, for example through participation in the development of student learning material (George \& Lubben, 2002; Tal, Dori, Keiny, \& Zoller, 2001).

\subsubsection{Teacher as developer of learning material}

Dutch teachers consider the combination of teaching and developing curriculum material as valuable (Coenders, Terlouw, \& Dijkstra, 2008). In their day-to-day work teachers experience how students learn and what fascinates them, and they can use this knowledge when they act as learning material developers.

Teachers' beliefs regarding learning material need to be taken into account (Cotton, 2006; Rousseau, 2004), and this is provided for by placing teachers in the role of developers of learning material. When the learning material has to be innovative, developers need to be able to draw on external resources for new ideas. Clarke and Hollingsworth (2002) called these resources the External Domain in their interconnected model of teacher professional growth. Different kinds of external resources can be used. For example, someone with specific expertise can be consulted or included in a development team. Literature is another potential external source. Reflections on teaching experiences can also act as sources, internal for the reflective teacher personally, and external for other teachers. The idea behind the teacher-as-developer is that the design and development of learning material suitable for their own students can be considered as professional development for the teachers involved (Ball \& Cohen, 1996). It is supposed that this process creates ownership of the learning material, boosts confidence, and stimulates deliberate reflection on action (Valli, 1992). Collaborative interactions in which teachers work together to examine and improve their practice, are powerful (Borko, 2004). In this approach, teacherdevelopers do not need in-service programs before implementation, because they can immediately employ the material in their classes as the preparations for class enactment have taken place concurrently with the development of the learning material. Elements previously to be included in traditional in-service training programs (Joyce \& Showers, 1995), like explanation of the rationale and goals of the innovation, demonstration of vulnerable aspects, and practice with the material, can now become attention points and discourse themes throughout the process of developing learning material. 


\subsubsection{The context of the study}

A committee, installed by the Dutch Ministry of Education, to investigate problems and shortcomings of the current chemistry curriculum (Van Koten, de Kruijff, Driessen, Kerkstra, \& Meinema, 2002) published recommendations for a new curriculum (Driessen \& Meinema, 2003). The major recommendations were: (1) the chemistry content should appeal to all students, not only those who want to pursue a career in chemistry; (2) contemporary chemistry and societal challenges should be included in the curriculum; and (3) the introduction of the context-concept approach in pedagogy. Teacher networks would be set up to develop the new student learning material. To avoid confusion, in the rest of this paper the term 'teacher-developer' will be used for those teachers who, in addition to performing normal teaching tasks in their own school, are involved in the development of student learning material in a network.

A teacher network consisted of three to five teacher-developers from different schools, plus a coach who acted as a chair and served as the liaison between the network and the national coordination. The schools employing the teacherdevelopers facilitated the development process by releasing these teacherdevelopers from part of their teaching tasks, and agreed to test the initial version of the learning material. The mission of the network was to develop and test student learning material, in the form of a complete module, in line with the national recommendations, in particular the context-concept approach. A complete module comprises of all texts, exercises and assignments, practical activities, and other student learning activities, ready for direct class use. A framework of the development process of a module is depicted in Figure 4.1. In this development process two distinctive phases for teacher learning were distinguished: a writing phase and a class enactment phase. During the writing phase of the module, all texts, exercises and assignments, practical activities, and other learning activities were developed. After completion, the module was enacted in class and the resulting experiences were used to revise the module.

\begin{tabular}{|c|c|c|c|}
\hline $\begin{array}{l}\text { National level: } \\
\text { - curriculum } \\
\text { change } \\
\text { - development } \\
\text { guidelines }\end{array}$ & $\begin{array}{l}\text { Self regulatory } \\
\text { network } \\
\text { developing student } \\
\text { learning materials } \\
\text { (a module): writing } \\
\text { phase }\end{array}$ & $\begin{array}{l}\text { Class use of } \\
\text { the module } \\
\text { by the } \\
\text { developers: } \\
\text { enactment } \\
\text { phase }\end{array}$ & $\begin{array}{l}\text { Revision: } \\
\text { tested } \\
\text { module } \\
\text { ready for } \\
\text { other } \\
\text { schools }\end{array}$ \\
\hline
\end{tabular}

Figure 4.1 Framework of the development process of a module 
Networks received the following instructions: (1) The module has to be suitable for Form 3, the first year students (of about 15 years of age) take a chemistry course in secondary school. (2) The interaction between an interesting context for students and a number of chemistry concepts present in this context needs to be the central element (the context-concept approach). (3) The network bears responsibility for the selection of the context and of the concepts students have to learn. (4) Concepts should follow "naturally" from the context as was exemplified in the Salters materials (Campbell et al., 1994). Rigid following of syllabus objectives or of a subject content structure should be avoided. (5) The four stages used by Chemistry in Context in Germany (Parchmann et al., 2006) had to be applied in the module: (a) the teacher first introduces the context; (b) students are made curious and plan their investigations; (c) students carry these out and process the results; and (d) finally all knowledge is brought together. (6) The module should be appropriate for approximately 8 to 10 periods of 50 minutes each. Within these guidelines, a teacher network had freedom to decide on a context, on learning activities and materials, on pedagogy, and on assessment methods of student learning results. Process variables like the members' task allocation within the network, the number of face-to-face meetings, and the communication between the meetings were also left to the discretion of a network. Several teacher networks were established throughout the country.

\subsubsection{Aims of the study}

This study concerns the professional development of teachers: to what extend do the knowledge and beliefs of the teacher-developers change during the development and the subsequent class enactment of a new chemistry module? The following specific research questions were addressed: 1 . What are the teacherdevelopers' perceived goals of context-concept based chemistry education (a) before the development process (b) after the writing phase of the module, and (c) after class enactment of the module? 2. What did teacher-developers learn (a) during the writing phase (b) during the class enactment phase?

\subsection{METHOD}

A multiple case study design (Yin, 2003) was used, because the purpose was to thoroughly investigate the changes each teacher-developer goes through. To 
address internal validity we employed different data collection instruments. This multi-method approach (Meijer, et al., 2002) is inherently time consuming but teachers' knowledge and beliefs system are complex (Pajares, 1992), and developments in this system difficult to assess.

\subsubsection{Participants}

This particular network, which had a similar composition and operated like all the others, was chosen for purely practical reasons: the teachers were employed by three different schools not too far from the university of the researchers. The network consisted of three experienced chemistry teachers, all having a masters' degree plus teaching qualification in chemistry, and more than five years of teaching experience. We will name these Pete, Lisa and Ed. A male coach employed by the teacher training department from a university was chair of the network. The coach, an experienced author of chemistry textbooks, contributed to the discussions by bringing in new ideas, alternative teaching approaches, literature, and he advised during the writing up phase. All teachers were currently teaching and participated on a voluntary base in this development process for which they received a reduction in teaching load of half a day per week from their school.

\subsubsection{Instruments}

Different instruments were used at various stages in the development process. Two instruments were used before the development activities in the network started: a questionnaire $\left(\mathrm{A}_{1}\right)$ and an interview a few weeks later $\left(\mathrm{A}_{2}\right)$. After the writing phase, each teacher-developer was interviewed (B), and once again after class enactment of the module (C). For each interview a semi-structured interview guide was used. Figure 4.2 depicts where the different instruments were employed in the process. In the appendix the instruments $\mathrm{A}_{1}, \mathrm{~A}_{2}, \mathrm{~B}$ and $\mathrm{C}$ are shown.

During the interviews more questions were posed than used for this article, they will be reported elsewhere. Questions of $A_{1}, A_{2}, B$, and $C$ referring to the perceived goals of chemistry education were used to address research question 1 about the beliefs teacher-developers have with respect to the goals of chemistry education. 


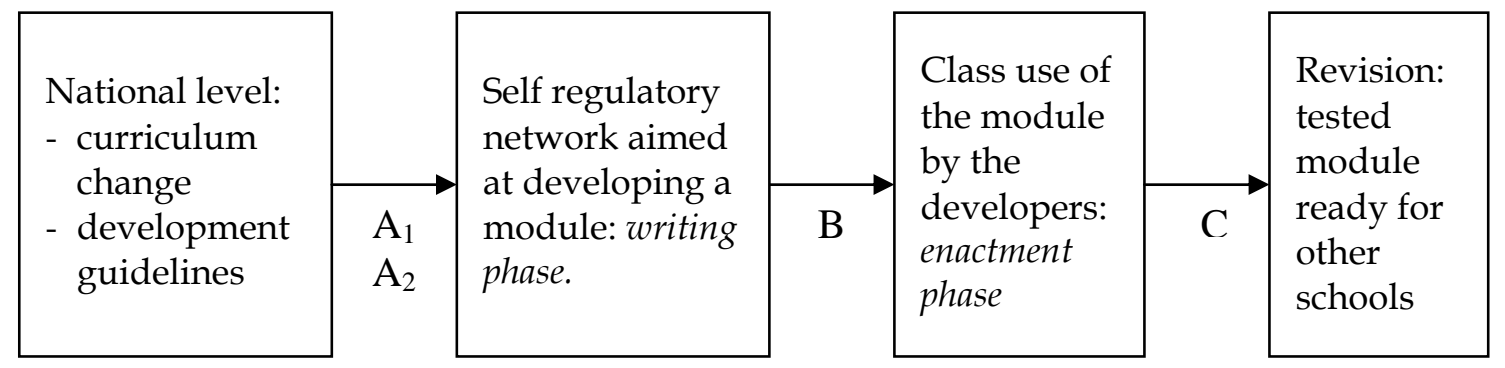

Figure 4.2 Data collecting timing (A1, A2, B, C refer to data collection instruments) within network development activities

To answer research question 2 on what teachers have learned, in both interview B and $\mathrm{C}$ teacher-developers were asked what they had learned. Some questions provided indirect information on research question 2. For example what the teacher-developers considered new aspects in the module in comparison to their "traditional" chemistry education, and why they considered this new. The different instruments in relation to the research questions are shown in Table 4.1.

Table 4.1 Data collection instruments in relation to the research questions

\begin{tabular}{|l|ccccc|} 
& \multicolumn{5}{c|}{ Research question } \\
\hline Instrument & $1 a$ & $1 b$ & $1 c$ & $2 a$ & $2 b$ \\
\hline $\mathrm{A}_{1}$ (questionnaire before) & $\mathrm{X}$ & & & & \\
\hline $\mathrm{A}_{2}$ (interview before) & $\mathrm{X}$ & & & $\mathrm{X}$ & \\
\hline $\mathrm{B}$ (interview after writing) & & $\mathrm{X}$ & & & $\mathrm{X}$ \\
\hline $\mathrm{C}$ (interview after class use) & & & $\mathrm{X}$ & & \\
\hline
\end{tabular}

\subsubsection{Procedure}

The complete development process lasted one school year. The first face-to-face meeting was held in September 2004, the last in June the following year. In total nine meetings took place, varying in time between two to four hours. In between the meetings e-mail correspondence occurred.

The module was developed from scratch. A brainstorm session to identify potential contexts and concepts within these contexts initiated the beginning of the development process. Several themes were discussed in light of the main criterion that the context should be appealing to all students. At the end 'Baking' was selected, and the specific context became 'Baking a cake'. The concepts emerging from this context were not new to the teacher-developers as they were 
part of the existing syllabus. However the way students were introduced to these concepts starting from the context was new. Network meeting transcripts show that after intensive discussions it was agreed that cooperative learning, including the use of students' roles with specific tasks within the group, and the use of a group logbook, would be used. The envisaged advantage was that students could work more independently in cooperative groups and would require less teacher assistance. These could spend more time on organizational issues and on monitoring learning progress. Cooperative learning, using group roles and a logbook, was new to all three teacher-developers.

\subsubsection{Analysis}

All interviews, $A_{2}$, B and $C$ from each teacher-developer were first transcribed verbatim. In each transcript, passages that exemplify ideas related to the research questions were identified and highlighted. These characteristic phrases from each questionnaire were then tabulated in a created word table. The results for research question 1, related to beliefs on goals of chemistry education, are shown in Table 4.2. Analysis of the characteristic phrases with respect to teacher-developer learning, research question 2, resulted in two categories in which learning occurred: teaching methodology, and learning materials and chemistry content. Learning during the writing phase is reported in Table 4.3, during enactment in Table 4.4.

To ensure the reliability of the data processing, a researcher, not previously involved in this research, was asked to perform two tests. The first one served to confirm the presence of each of the characteristic phrases in the transcribed interviews. A second to determine whether all sentences considered characteristic were indeed identified and tabulated. This resulted in first instance in $85 \%$ agreement. Disagreement occurred with two characteristic phrases not confirmed by the second researcher, who added also eight new ones. Parts not agreed upon were discussed and verified against the transcripts. The outcome of this process was that one characteristic phrase was changed and that seven were added to the original set. 


\subsection{Results}

We will first describe relevant context for each of the three teacher-developers and then present the results to address the research questions.

Pete. At the start of the network Pete had neither experience with the development of student learning material, nor had he used contextualized material in his classes.

His main reason to participate in this network was personal: he wanted to grow further as a teacher. He found it important to continuously professionalize as "the world constantly changes".

He used the module in two of his classes, but did make some minor changes to the material before class use, because he did not have sufficient time to enact the module as planned.

Lisa. Lisa had no experience with the development of learning materials for students of these levels, and had never used context-based materials.

Her main reason for participation in this network was change. She wanted to get away from teacher-centered teaching and she sought to develop an alternative with colleagues.

She slightly adapted the module before class use. At her school, two teachers not involved in the development process, wanted to use the module also in their classes and negotiated with Lisa about adaptations to be made in the module.

$E d$. Ed had been involved in the development at national level of practical assignments for students, but had no experience in developing context-based materials. He had not previously used context-based materials.

His main reason to join the development process was triggered by a discussion he had with a non-science colleague at school who had no idea how chemistry contributed to his life, something Ed considered an imperative goal for chemistry education. 
He used the module in his class, as did a colleague at his school not involved in the development. A few minor changes were made in the material before class use.

Ed, being the advocate of a role-play to model a chemical reaction, had his students perform this role-play in class.

\subsubsection{Perceived goals}

A summary of the data to answer these teacher-developers' perceptions of the goals of chemistry education, research question 1, are presented in Table 4.2.

Pete's initial goals of chemistry education were rather vague and general. According to Pete, the relevance of chemistry should be emphasized using news items from newspapers or magazines. Students also need to become enthusiastic for chemistry and have to realize that chemical concepts are close to their own life world. The following phrase, in which Pete talked about decomposition, a common chemistry concept, illustrates this: "Students need to be able to apply acquired concepts in a new context and should recognize decomposition during a barbeque". Concrete contexts should be transferred into abstract concepts: "students have to consider what happens at molecular level during decomposition at the barbecue".

During class enactment of the module, he experienced that students did not acquire concepts from a context automatically. This will require explicit attention both in the material and from the teacher in class. As another goal of context-based chemistry education, Pete now mentioned that students should be able to link acquired concepts. He noticed that students did not do this by themselves and he said: "Students need to learn this; it is a skill to discover structure in chemistry concepts".

Before the development process started, Pete's goals of chemistry education were general in nature, and in his view students would be able to pick up the concepts easily from a context. Class enactment showed that students did not automatically discover concepts, and did not learn how to link the concepts they acquired. In these aspects Pete's goals evolved. 
Table 4.2 Perceived goals of chemistry education for students in their first year chemistry according to Pete, Lisa and Ed

\begin{tabular}{|c|c|c|}
\hline \multirow{4}{*}{ 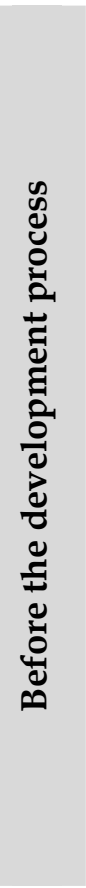 } & & Students should: \\
\hline & Pete & $\begin{array}{l}\text { 1. become enthusiastic for chemistry. } \\
\text { 2. be able to acquire and built up basic knowledge of chemistry. } \\
\text { 3. use actuality (newspaper etc). } \\
\text { 4. be able to use acquired concepts in new contexts. } \\
\text { 5. be able to transfer concrete contexts into abstract concepts. }\end{array}$ \\
\hline & Lisa & $\begin{array}{l}\text { 6. develop an interest in chemistry. } \\
\text { 7. experience chemistry as an important factor in life. }\end{array}$ \\
\hline & $E d$ & $\begin{array}{l}\text { 8. understand selected concepts. } \\
\text { 9. experience chemistry as fun and meaningful. } \\
\text { 10. develop a more positive feeling about chemistry, also those students } \\
\text { not taking up this subject in their further education. } \\
\text { 11. acknowledge the importance of chemistry for our daily life. } \\
\text { 12. see the logic of chemistry and experience the possibility to develop } \\
\text { personal theories. } \\
\text { 13. feel and understand chemistry from within, as natural processes. } \\
\text { 14. be given the opportunity to partly control their learning process. }\end{array}$ \\
\hline \multirow{3}{*}{ 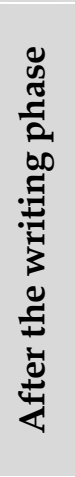 } & Pete & $\begin{array}{l}\text { 15. experience that chemistry deals with their life environment. } \\
\text { 16. be stimulated and become enthusiastic }\end{array}$ \\
\hline & Lisa & $\begin{array}{l}\text { 17. be able to work independently, and to carry out independent group } \\
\text { work, including group research activities. } \\
\text { 18. enjoy what they do in chemistry. }\end{array}$ \\
\hline & $E d$ & $\begin{array}{l}\text { 19. be given the opportunity to differentiate, especially students who do } \\
\text { and do not take up chemistry in their further education. } \\
\text { 20. be able to deduce concepts themselves. } \\
\text { 21. find end of the year chemistry education pleasant. }\end{array}$ \\
\hline \multirow{3}{*}{ 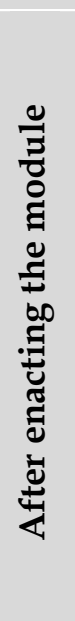 } & Pete & $\begin{array}{l}\text { 22. be able to develop concepts from contexts. This needs to be explicitly } \\
\text { incorporated in the learning materials. } \\
\text { 23. be able to discover structure in chemistry and build on this. This skill } \\
\text { needs explicit attention in the materials and from the teacher. }\end{array}$ \\
\hline & Lisa & $\begin{array}{l}\text { 24. develop concepts and be able to associate and link up concepts to one } \\
\text { another. }\end{array}$ \\
\hline & $E d$ & $\begin{array}{l}\text { 25. be able to think from concrete to abstract and vice-versa. } \\
\text { 26. be able to start with concrete interaction when learning from a } \\
\text { context. } \\
\text { 27. be given the opportunity to differentiate. } \\
\text { 28. gain confidence with respect to finishing the school. } \\
\text { 29. acquire knowledge themselves. }\end{array}$ \\
\hline
\end{tabular}

Lisa formulated the goals of chemistry education at the start of the development process in very general educational terms. For her, students should learn to appreciate chemistry and the role it plays in people's life. She 
said: "students should develop the idea that one always deals with chemistry, and not perceive it as a weird and compulsory subject".

After the writing phase she translated the goals in more concrete terms as is illustrated by the following phrases: "I hope that students can work independently and will enjoy what they do. They can work on own small research projects, for example to separate colors from sweets". She also acknowledged cooperation within student groups as a specific goal, but this at the same time frightened her as she was concerned to lose control. Lisa was aware of the gender differences: "students being more independent can do things they appreciate, but how girls experience it is to be seen, although the context 'baking' looks promising".

Class enactment showed that students did not learn what was anticipated. The activities were carried out, but the students did not get the chemistry concepts clear. Lisa formulated this as follows: "students became quite independent but did not always see what was meant. I think that this needs to be added, a kind of a summary of the concepts." A bit later Lisa said: "students hardly link concepts, also not previously learned concepts. Before this module students had learned a lot about safety in the lab, but did not link this to safety issues in this module". Looking at the complete development process, Lisa's beliefs about goals changed noticeably: from very general notions initially, to more pedagogic goals after the writing phase, to goals associated with learning at a conceptual level after class enactment.

Ed's goals of chemistry education initially focused on meaningful chemistry and how chemistry positively contributes to people's lives. He was quite outspoken in this as he formulated quite a number of broad goals. In the interview Ed said that he wanted "students to learn more naturally in order to get more feeling and understanding from within towards the subject, which will create more ownership and sympathy".

During the writing phase another goal emerged: the notion of differentiation and personal concept deduction. He said: "students should be given the opportunity to develop the concepts themselves, I have some experience with it and it worked out well". As the developed module was meant for the last term of the school year, Ed added as specific goal that students need to end the year pleasantly.

Finally his classroom experiences strengthened the differentiation goals, and the concept development goals concretized as the students' ability to transform concrete interaction with materials to an abstract level. Ed said about this: "So 
this concrete, the interaction between the concrete and the abstract is extremely important". In his view another goal would be to foster student's confidence in the sense that they should experience being able to acquire knowledge themselves, something that can be elicited by starting from a concrete situation. Ed's beliefs about the goals of chemistry education changed and matured during the complete development process.

\subsubsection{Teacher-developer learning}

The following section is devoted to what Pete, Lisa and Ed learned, research question 2. We will first present teacher learning during the writing phase, then in the class enactment phase.

Teacher learning during the writing phase. Two categories of answers emerged: (a) about teaching methodology, and (b) about learning materials and chemistry content. A summary of the results is presented in Table 4.3.

\section{Table 4.3 Teacher learning during the writing phase}

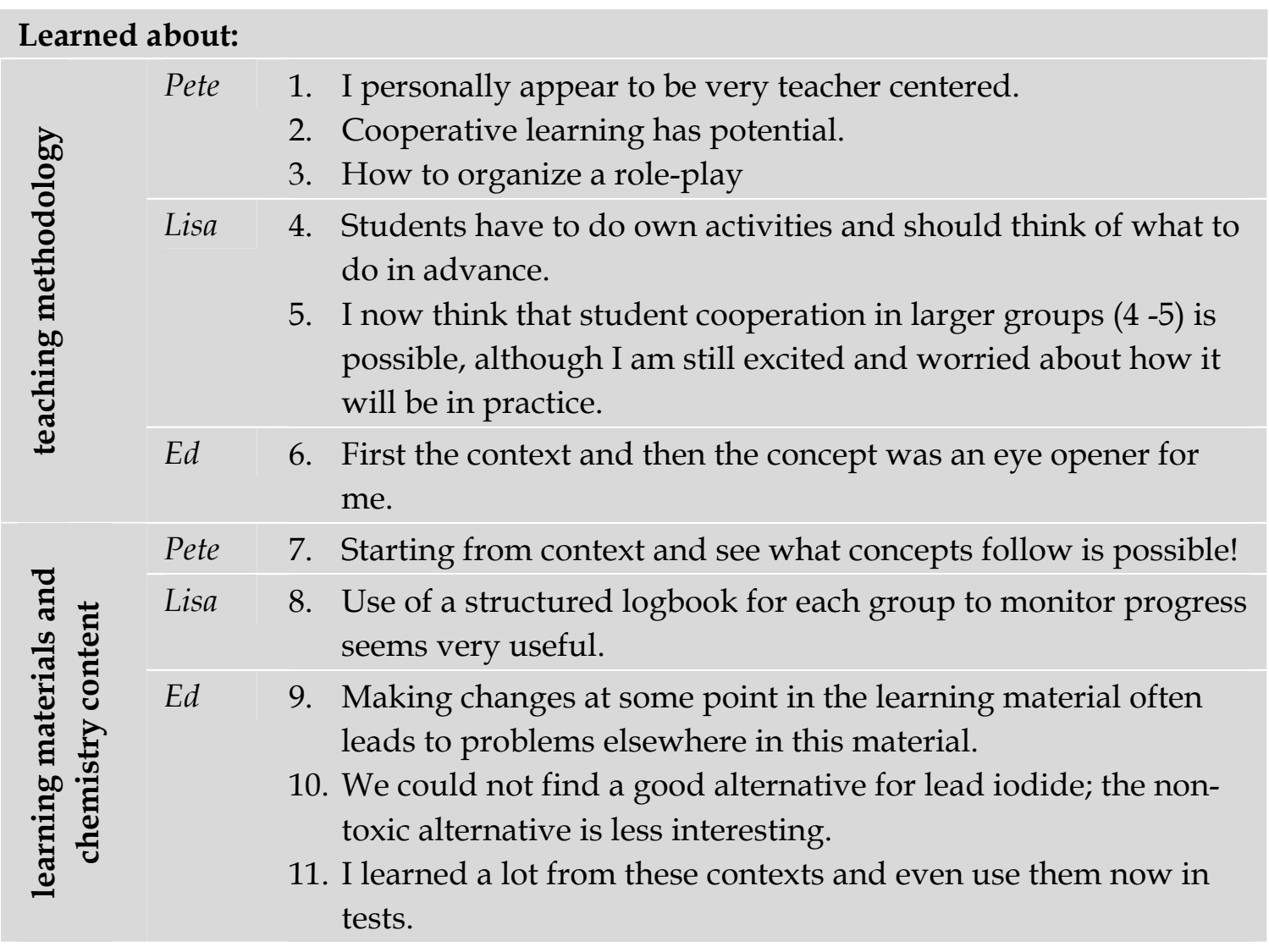


Pete discovered cooperative learning as a methodology: "specific attention for cooperative learning processes as such and the reflection that is explicitly incorporated is for me renewing". A bit earlier Pete said: "I intend to use cooperative learning, including the group member roles and the logbook, and want to use the T-cards to teach cooperative skills". This use of cooperative learning will enable him to move away from teacher centered classes: "Looking back I have been very teacher centered, in this module students will get more control".

At a network meeting Pete said "I do not feel comfortable with the role-play where students act as atoms, join hands to represent molecules, and then cannot pass a door". A bit later he said: "I would like to experience, to feel, how it is to do a roleplay, can Ed demonstrate this for us?" Ed then explained the role-play and the teacher-developers performed it, and it was decided to include it in the material.

Pete also learned that starting with a context has potential or in his words: "I have forced myself to start with a context in the material and see what concepts will emerge.......... I am excited to see what it will bring for the students".

Lisa focused on methodological issues in her responses. Although network meetings' discourse continuously focused on student learning, Lisa was anxious about class enactment, or in her own words:

I find it a bit scary. Education was teacher controlled and now students have to come up with group activities themselves. In your own lessons you know from experience this will go like this and that like that, and students have difficulties with that section. Now you don't have this knowledge in advance and honestly I have no idea where students are going to end up!

So far her students did not work in groups, and in the interview before class use Lisa said: "I have never been enthusiastic about students working in larger groups, but these rotating group roles is an excellent idea". At a network meeting, she also clearly articulated the advantage of larger groups for her own role in class: "The advantage of groups of 4-5 students is that it is easier. When groups are small and all come with questions to you, you get nuts".

With respect to the learning material two issues are of importance to Lisa. First of all the use of a student logbook to monitor progress and to keep track of the student roles: "For each lesson one page. First students indicate the date of the period, the roles of all students in that lesson, planning, answers to questions etc." 
A bit later she said: "It also helps students themselves to monitor the process and they can say, hey you were supposed to do this and did not do it". A second important aspect for the learning material is the inclusion of open practical assignments. In the interview she said: "What I noticed last year is that during practical activities everything is ready and students sit down and look around to what the others are doing and copy this". A bit later: "In the past students used all the things that were prepared .... but now they need to think in advance about what to do and what materials are needed for this. That is attractive".

Ed's responses indicated that he learned it was possible to start from a context. It is not necessary to first explain the principles and then demonstrate these using a daily life example, as he often had done in the past as he observed in the interview:

.....the concrete must precede other things. So first the context and then the concept and never the other way around. Yes, this was an eye opener and I must use this more often and I am doing this already. I no longer start with the tricks and thereafter the applications.

With respect to the learning material he noted that it is not always possible to find a good alternative for experiments: "I tried to find an alternative for the poisonous lead iodide, but did not succeed. Each alternative had shortcomings". Ed also experienced that it was not easy creating and keeping internal consistency in the learning material, because a change at some point affected the rest.

Teacher learning during the class enactment phase. To organize the data the categories 'teaching methodology' and 'learning materials and chemistry content' were used. A summary of the results is presented in Table 4.4.

Pete was especially happy about cooperative learning, enabling him to assist individual groups. Although he noted that students initially did not cooperate effectively, and did not divide the tasks at hand:

I noted that three students watched a colleague who poured a solution in a beaker, another solution in a test tube and then mixed these in the beaker. Eight eyes then saw that the color changed to yellow. This took 10 minutes, and for four students this is not very effective. 
Table 4.4 Teacher learning during the class enactment phase

\begin{tabular}{|c|c|c|c|}
\hline \multicolumn{4}{|c|}{ Learned about: } \\
\hline \multirow{3}{*}{ 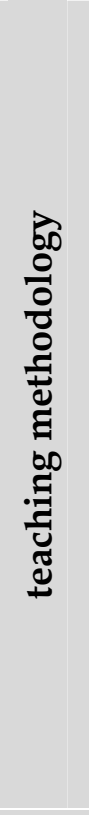 } & & Pete & $\begin{array}{l}\text { 1. Looking back by the students at the previous period is very } \\
\text { positive for their learning process. The logbook facilitated this. } \\
\text { 2. Cooperative learning in combination with the use of a group } \\
\text { logbook creates time for teachers to assist individual groups. } \\
\text { 3. Students can within limits determine their own learning route. }\end{array}$ \\
\hline & & Lisa & $\begin{array}{l}\text { 4. Students have to do a lot of small researches and work busy } \\
\text { and enthusiastic on these. } \\
\text { 5. Attractive for students is the context, the freedom to do own } \\
\text { activities, to work at own pace. } \\
\text { 6. Needs to be diversity in class approach: group work should not } \\
\text { extend to a whole year. } \\
\text { 7. Leveling out of students' grades occurs when grading group } \\
\text { work. }\end{array}$ \\
\hline & & $E d$ & $\begin{array}{l}\text { 8. Thinking to and from models by students is disappointing. I } \\
\text { should restrict the number of models and role-play. }\end{array}$ \\
\hline \multirow{3}{*}{\multicolumn{2}{|c|}{ 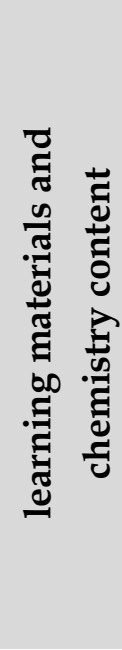 }} & Pete & $\begin{array}{l}\text { 9. Linking up with students' experiential world creates } \\
\text { enthusiasm. } \\
\text { 10. Clear instruction in the materials reduces intervention time in } \\
\text { class. } \\
\text { 11. Use of a logbook to record all communication (tasks, answers } \\
\text { to questions, problems encountered) provides the teacher } \\
\text { powerful intervention opportunities. }\end{array}$ \\
\hline & & Lisa & $\begin{array}{l}\text { 12. The marking of the logbook to control and monitor the learning } \\
\text { process of the group did really help me, and it enabled the } \\
\text { students to start immediately at the beginning of each lesson. }\end{array}$ \\
\hline & & $E d$ & $\begin{array}{l}\text { 13. The learning material has to be more explicit, from step to step } \\
\text { with lots of opportunities to practice. }\end{array}$ \\
\hline
\end{tabular}

Learning cooperative skills requires time and specific attention, as he said: "After some time cooperation did go better. Students knew their roles and adhered to these". After each period he collected the logbooks and went over each of them. He marked the answers to questions, commented on performed activities, wrote down suggestions for the next period and question marked passages he was dissatisfied with. What struck him was that each group at the beginning of a period first looked at his comments and then rectified or supplemented those parts he had marked. He noted that "connecting to and building upon what students had done in the previous period occurred therefore automatically".

Pete did not use the role-play because he argued that by the time his students reached this section he believed it would not contribute to students' learning. 
An innovative element in the material for Pete was that: "The module does connect to students' life world". Pete's students were very positive about the module and worked enthusiastically and hard, "Sir, can't we do this more often, and why didn't we do this earlier" was one of the expressions used by students. Pete mentioned another strong aspect in the material: "Students had to look back at what was done, they had to sit down and consider whether they had done what was required, and if not think of how to solve it.......... there was feedback on their own action". Students also had to carry the consequences when they were not properly prepared, so when students came to Pete asking what to do, he responded: "Well, that is something you should have done yesterday afternoon".

He learned that written instructions in the material need to be explicit and clear, if not students need extra teacher support: "What I noticed is that when the material contains clear instructions, you only need half the manpower. That is what I really learned". Also with respect to cooperation in the groups the material has to be clear as Pete in a network meeting said: "What you see is that some students manage to behave in such a manner that the work is done by others. The assignments should be formulated in such a way that each member takes responsibility for it".

Because of time constraints, assessment of the leaning outcomes was not possible. The groups prepared a poster and presented this to their colleagues, but no time was left for a written test.

Lisa was particularly satisfied about the cooperative group work, both about the process and about the opportunities it provided for the teacher to monitor the content of the group work, or in her words: "The fact that the students had to consult the group and then continued working, and this cooperation worked out quite well". The enthusiasm of her students strengthened her opinions regarding the usefulness of context-concept learning and cooperative group work. After each period she collected the logbooks, went over the students' answers and made comments about the content and the progress: "In the logbook I jotted down how satisfied I was with their work." She assessed students' answers to the module questions by marking their logbooks after the module was completed. This resulted in leveling out of the final grades.

Lisa did not let her students do the role-play in her classes, as she did not think it would lead to a better understanding of the concept of chemical reaction, and she feared unrest in class during the role-play activity. 
With respect to the learning material she noted that the logbook is important as it enabled the groups to work rather independent from the teacher. She also noted that all groups were very active and enthusiastic, and attributed this to the open practical activities in the material.

For Ed, class use did provide insights that could not have been anticipated before. Ed did not use group roles, and also left the formation of the groups to the students themselves. This resulted in groups of two and groups of five, and one student even worked on her own. Ed decided not to let his students use the group logbooks, instead, the students could use their own personal way of presenting their answers. At a network meeting he said about the logbook: "This should be kept short, from such an administration one gets nuts or it will take a lot of time". Ed assessed this work after completion of the module. To monitor and influence the learning processes in class he sat down with groups and observed their discussions.

Although Ed advocated the use of a role-play to model a chemical reaction, his opinion has changed due to students' reactions to this activity. He discovered that students' ability to think in terms of models was poorly developed: "I don't know whether students find it difficult or not, but they don't switch between reality and a model". The role-play did not contribute to a better understanding of the concept of chemical reaction. It did create class unrest as students had to walk around.

Learning material needs to explicitly solicit for concepts, if not little learning will take place. Ed said about this in the interview: "Students do not reflect on experiences. And it was not called for to do so, so the material needs to explicitly ask for this."

Assessment of the final learning results was oral; the marking of the students' answers after completion of the module also played a role in the final grade.

Teacher learning during the complete development process. Pete's conception about the locus of control in class changed during the development process. He was initially teacher-centered, but he agreed to try cooperative learning where the control of the learning process lies within the groups. After class enactment he was very positive about cooperative learning, especially the use of a logbook which offered him a strong intervention tool to monitor and direct the groups' learning. His comments and marks in the students' logbook enabled each group to continue with the module without constant teacher intervention. He learned 
that student centered education can be effective, and that students' motivation increased when they perceive ownership of their learning process. Linking chemistry with students' experiential world created enthusiasm.

Pete used his initial general beliefs, for example about students acquiring a concept in a specific context and applying this in another context, to develop concrete student activities. In class, he experienced that students had difficulties developing the concepts and discovering structure between these concepts. This calls for scaffolding activities in the module or teacher interventions in class. After class enactment he realized that clear instruction saves teachers' time as students can continue their activities without help. His initial skepticism with respect to the feasibility of students developing concepts 'naturally' from a context has disappeared, as he is now convinced that this approach is possible. The network discussions during the writing phase contributed in this transition process, but the turning point was clearly the way students responded to the module.

Lisa's views on cooperative learning changed. Although she wanted to be less teacher-centered, she was initially hesitant because of the freedom students had. She learned that students were able to work rather independently in cooperative groups, and that the group logbooks helped her to monitor progress. She was however critical about two aspects. Firstly, in her practice, student results leveled out, meaning that there was little variation in the final grades, and these grades were different from those obtained by individual students on previous chapters. Therefore she proposed to change the grading system. Secondly, she felt that other teaching methodologies besides cooperative learning should be used in a school year to ensure diversity to accommodate differences in learning styles between students.

Her confidence to engage in unknown teaching adventures received a boost.

Contrary to Pete and Lisa, Ed did not use cooperative learning. Instead he used a question-answers method in class to reveal student learning. This could be the reason that he did not mention to have learned something from cooperative learning as teaching methodology.

He advocated the use of a role-play during the writing phase, used it in class, but was disappointed about the learning outcome. In future, he intends to use this as an activity for those students who need additional support to grasp a specific concept. 
To start a learning process from a context was the largest eye opener for him. He was not sure how students would respond to it, but it worked out very well, not only the learning results were as expected but student motivation was also high.

\subsection{Discussion}

The journey of developing student learning material and subsequent class use provides learning experiences for the teacher-developers. Our data mirror Borko's (2004) words: "Research using the individual teacher as the unit of analysis also indicates that meaningful learning is a slow and uncertain process for teachers, ............... Some teachers change more than others through participation in professional development programs (p. 6)."

In this study we showed that the teacher-developers changed with respect to the goals of chemistry education and with respect to teaching methodology and learning material. We see these changes as a learning process. In the next section we will first discuss teacher learning as the result of the writing and class enactment phases, and then turn to teacher learning and the five PCK domains.

\subsubsection{Teacher learning during the development and enactment of learning material}

Our results show that developing a module can be seen as a training program in which personal characteristics, like knowledge, beliefs and dispositions toward reflection, form the starting point (E. A. Davis \& Krajcik, 2005). When teachers are not familiar with an innovation, they need to become equipped, for example through a training program (Joyce \& Showers, 1995) in which the goals are elucidated, vulnerable and difficult aspects are explained and discussed, opportunities for practice with materials is provided, and practicalities are exchanged. From our data we conclude that these aspects are addressed when teachers 'in a network' develop learning material. The two phases of the development process as indicated in Figure 4.1, the writing phase and the enactment phase, were instrumental in these teacher-developers learning.

Writing phase. During the writing phase of the learning material, teachers learn by using the following five sources: (1) the written documents from the committee that initiated this context-concept renewal (Driessen \& Meinema, 2003); (2) the coach and in particular his specific expertise as a textbook writer; 
(3) experiences from each teacher who acted as inspiration for the others: teacher-developers build up an attitude of inquiry into one's own practice, and engaged in deliberate reflection about a number of aspects of teaching and learning (Valli, 1992); (4) discourse during network meetings about produced materials and envisaged class use; and (5) specific literature (e.g. on cooperative learning). These five sources constitute the components of what Clarke \& Hollingsworth (2002) called the External Domain in their model. The teacherdevelopers constantly envisaged how their students will react to learning activities, what they will learn from these, and how practical problems can be solved. One can argue that the writing phase prepared teachers in an excellent way for class use of these materials.

Having quality learning material for students does not guarantee high-quality class enactment. Some scholars (Van den Akker, 1988; Voogt, 1993) had therefore included detailed lesson descriptions in their curriculum materials. This research demonstrates that developing a module provides the teacherdevelopers sufficient 'how-to-do' advice for their specific group of students. Practical advice about what to prepare, how to take it to class, how a logbook can be used to monitor student learning, and how to react to students, was over and over sought for and discussed in the network meetings. During such a process of discourse, writing, and reflecting, each teacher-developer becomes familiar with the operationalization of the educational goals in the instructional material and resources for own class use.

An innovation affecting classroom practices involves emotions (Schmidt \& Datnow, 2005). All teacher-developers were initially hesitant about the potential of the context-concept approach because it was perceived as a threat to their professional identities (Van Veen \& Sleegers, 2006). Initially they wondered whether it would be possible to develop context-based learning material for students to acquire concepts. Through discussion, their knowledge of the strong and weak aspects of the context-concept approach gradually increased and their beliefs changed. They wondered and conceived of how their students would react to a certain teaching methodology and how and what students would learn from a specific learning activity. The discussions about activities, the logbook and its possible use, and the simulation of the role-play during the network meetings, reduced anxiety as it demonstrated how these activities could be carried out in class. Before taking the module to class teacherdevelopers were convinced that it would be valuable for their students. This shows that the development of the module provides teacher-developers with 
ample opportunities to cope with emotional aspects of this specific reform, and prepares them for classroom practice.

The goals for chemistry education these three teacher-developers find important, like increasing students' motivation, creating enthusiasm, and providing a learning motive by showing students how chemistry relates to daily life and what the relevance of the subject is, are in line with these of context-based approaches in other countries. Increasing students' sense of ownership (Gilbert, 2006) by providing learning process autonomy also becomes an important goal for these teacher-developers, as mirrored in the produced module in two ways. Students had to design and carry out their own research projects and report on their findings. One teacher-developer phrased it as follows: "you have to give the students the idea that they are the stationmaster". Secondly the organization in cooperative groups, with substantial group control on the learning process and product, makes exploring the module their own venture.

Class enactment phase. Traditionally, lesson preparation entails familiarization with the content and ways to engage students with assignments, all in a teacher controlled setting without much space for differentiation. In the new situation, students are guided by the learning material and the logbook, and can continue studying without constant teacher guidance. Each cooperative group designs its own research activities. This requires reflection on possible teacher roles (Coenders, Terlouw, \& Dijkstra, 2008), and calls for a different kind of lesson preparation, in which a teacher establishes for example the feasibility of the groups' research proposal in terms of materials, possible outcomes and safety. In traditional classes teachers talk to individual students, in this new setting groups will be addressed. A logbook is used to monitor group work.

Class enactment, after being involved in the development of the material, reinforces knowledge and beliefs learned during the writing phase, but we also noticed that in specific cases it can lead to incongruous experiences, as with the role-play. Ed observed that the role-play did not contribute to student learning. He now believes that a role-play will only contribute to learning in specific circumstances.

These three teacher-developers spent over six months developing a module, which for each of them contained innovative aspects. It was expected that the writing process and network discourse would create sufficient sense of ownership (Fullan, 1998; Guskey, 2000) to implement the module "as-is". However, all decided to make changes before introducing the module in class, 
or changed it during class use. All had specific reasons for the changes made. Teacher-developers redesigned the module in accordance with their beliefs: ownership is at the end created personally, not in a group process.

\subsubsection{Teacher learning and the five PCK domains}

Teacher learning can be expressed in the five PCK domains mentioned in the introduction:

1. Knowledge of science curricula. Initially, before the development process started, the reported goals are rather general and vague, in terms of providing a learning motive (Gal'perin, 1992), and permit different directions for their transfer to concrete learning material and teaching approaches. The nature of these goals are basically philosophical, of rationale and mission kind, and fit in the ideal curriculum representation from Goodlad (1979) and Van den Akker (1998). The articulated goals after the writing of the module, a process that involved the translation of the general ideas and notions into concrete learning activities and material for students, are more concrete, and reflect the written and the perceived curriculum. After the enactment of the module in class, the goals have shifted towards operational and experiential curriculum representations. These goals reflect the experiences from the interaction of students with the learning activities and material, and focus on what students should be able to do for learning and to reach understanding. For example, teachers express concerns about students' ability to link up different concepts and the way this is regulated in the learning material and assignments. The construction of a coherent conceptual network by students is therefore mentioned as an important goal for chemistry education at this level.

2. Knowledge of students' understanding of science. Also with respect to student learning teacher-developers' practice required scrutiny. In the current 'normal' curriculum, teachers, through year long experiences, know well what students learn, what is considered difficult, and how their own behavior, the textbook and other learning material all contribute to student learning. In the new module this is no longer obvious. Monitoring of the learning process and learning outcome on a daily basis is now imperative, not only to assess their own students, but also to improve the module. 
3. Knowledge of assessment. New ways of assessment suitable to establish student learning outcomes in context based education, like the logbook and posters, surfaced during the development of the module, and were put into practice in class.

4. Knowledge of instructional strategies. Our results also show a conceptual change in general pedagogical terms during the development process. Cooperative learning, the pedagogy used in this specific module, was extensively discussed at network meetings. Even though initially hesitant, teacher-developers gradually became more enthusiastic as the specific advantages of cooperative learning surfaced, and class practicalities were resolved. The use of the logbook was something that was shaped in practice (Clermont, et al., 1994; Van Driel, et al., 1998) as the three teachers, after the writing phase, decided to use it in their classes in a specific and personalized way.

5. Orientation to teaching subject matter. The conceptualization of science teaching and learning in epistemological terms has also changed. In their previous educational experiences, teacher-developers used learning material in which students learned concepts based on the subject matter structure (De Vos \& Verdonk, 1990). Now they developed and used materials starting from a context, in which students selected and discussed concepts from the experiences of their own research projects. Although this was one of the main reform goals (Driessen \& Meinema, 2003), teacher-developers were initially not convinced that it would be possible and would lead to meaningful learning. After class use they experienced the potential of this approach: students were enthusiastic, active, linked up chemistry with daily life, and acquired concepts. Of course the materials were not perceived perfect as can be seen in the recommendation to strengthen the construction of a coherent conceptual network by students.

In conclusion, teacher-developers' practical knowledge (Barnett \& Hodson, 2001) and especially their knowledge in all five PCK domains (Grossman, 1990; Magnusson, et al., 1999) increases during the cycle of development of learning material and its use in class (Figure 4.1).

In this study the development process was left to the group of teacherdevelopers and their coach. They decided on the manner in which the group operated. The focus of the network was on the development of student learning 
material. As a by-product the process served as a learning experience for the teacher-developers themselves. The question that surfaces is whether it is possible to design a development process of learning material that maximizes teacher learning and if so what distinctive qualities would such a process have?

\subsection{APPENDIX}

Questionnaire A1

1. What are according to you important goals for the module to be developed for Form 3 Junior High? What is it the students need to learn?

2. What roles do you see for yourself as teacher using such a module, and what activities will you carry out?

3. What roles do you see for your students? What do you want your students to do?

4. How would you like to evaluate the learning results?

5. Do you already have possible contexts in mind?

Interview guide A2

1. What do you consider goals for chemistry education?

2. How do you see your own role in this? What are your tasks?

3. How do you see the role of your students in this?

4. What can you say about the content of chemistry education:

- What is the relation between context and concept?

- What kind of teaching methodology do you consider appropriate?

- What assessment techniques do you think are appropriate?

5. Did you previously develop teacher guides?

6. Did you use innovative materials developed by others?

Interview guide B

1. What do you hope the module will bring:

- For yourself?

- For your students?

2. What do you consider your role in this?

3. What are for you the strong aspects of the module?

4. What do you consider difficult, of critical aspect of the module?

5. Why do you consider this module innovative?

6. Did you learn yourself something during the writing phase about:

- Pedagogy?

- Tips to be used in class?

- Chemistry content?

7. Are you going to use cooperative learning, including logbook and student roles? 
Interview guide $\mathrm{C}$

1. What was your reason to participate in the development of the module?

2. In what classes did you use the module?

3. How many periods did you use?

4. Did you make any changes in the module beforehand?

5. How did the students respond to the module?

6. What is your opinion about the module? Would you use it again next year?

7. What do you consider now to be innovative in the module?

8. Did you use the role-play? If yes, what did it bring? If not, why not?

9. Cooperative learning:

- How were the groups formed?

- Did you use the logbook?

- Did you use roles for group members?

- Would you do the above aspect again a next time?

10. How did you assess the learning results?

11. How were the learning results, also compared to previous chapters and topics?

12. Did you yourself, during the class enactment phase, learn something about:

- Pedagogy?

- Chemistry content?

- Other things?

13. How do you see the context-concept approach now?

14. Anything you would like to add? 


\title{
CHAPTER 5 \\ Preparing chemistry teachers for a curriculum renewal through development and class enactment of student learning material: a case study of teachers' Pedagogical Content Knowledge (PCK) changes ${ }^{4}$
}

\begin{abstract}
This paper details the changes in teachers' pedagogical content knowledge when three experienced chemistry teachers developed and class enacted student learning material for a context-based chemistry curriculum. Semi-structured interviews, a questionnaire and discussion transcripts solicited teachers' knowledge and beliefs. Our results show changes in teachers' knowledge and beliefs in three domains: (a) context-based chemistry, (b) cooperative learning, and (c) requirements for context-based chemistry. These changes can be attributed to two phases in the development process. The writing phase, for the production of learning material and the concurrent preparation phase for class enactment, turned out to be powerful for learning. The subsequent class enactment phase reduced teachers' anxiety towards the feasibility of the material, and served to build new teaching routines.
\end{abstract}

\subsection{INTRODUCTION}

A new chemistry high school curriculum, to be implemented in the Netherlands in 2012, is under construction. Compared to the current curriculum, particularly changes in the educational goals and objectives and in the pedagogy are proposed. Teacher preparation for such a renewal is seen as a complex learning process (K. S. Davis, 2003; Fullan, 1998) in which teachers have to be actively

4 This chapter has been submitted: Coenders, F., Terlouw, C., Dijkstra, S., \& Pieters, J. (2010). Preparing chemistry teachers for a curriculum renewal through development and class enactment of student learning material: a case study of teachers' Pedagogical Content Knowledge (PCK) changes. 
involved. Teachers have to learn to understand the new goals (Pintó, 2005), learn to use the innovative student learning materials in class, and reflect on their different roles (Olson, 2002). The teachers' knowledge and their beliefs (Cotton, 2006) have to be taken into account, otherwise it is not likely that implementation will occur (Rousseau, 2004; Van Driel, et al., 2001). One way to both expand a teachers' knowledge base as well as connect to their current knowledge and beliefs, is to involve teachers from the beginning in the development process of curricular materials (George \& Lubben, 2002; Guskey, 2000; Parke \& Charles, 1997).

This study focuses on what, and through what activities, teachers learn when they develop student learning material for this new chemistry curriculum and subsequently enact it in class. In the next section teacher learning for a curriculum renewal will be conceptualized, we then turn to the context of this study, and finally the knowledge base for teaching impinged on in this curriculum renewal will be described.

\subsubsection{Teacher learning for a renewal}

Teacher professional development, targeted at assisting teachers to implement a new curriculum, needs to focus on both teacher learning and student learning: teachers need to experience for themselves the science learning into which they want to engage their students (Jeanpierre, Oberhauser, \& Freeman, 2005; Loucks-Horsley, Hewson, Love, \& Stiles, 1998). Attention for beliefs and practices is essential as a change in one requires a change in the other and vice versa (Ball \& Cohen, 1996; Kupari, 2003). Participation in a study group or involvement in the development process is one way to professionally prepare teachers for an implementation as it provides in-depth engagement. (Guskey, 2000; Loucks-Horsley, et al., 1998; Penuel, Fishman, Yamaguchi, \& Gallagher, 2007). This kind of participation is more effective for professional development than the traditional workshop model. Penuel et al. (2007) have identified other factors in order to prepare teachers for change in practice. One of these is time to allow for multiple cycles of presentation and reflection on knowledge. A second factor is that teachers need to be comfortable with both the new content and the new pedagogy and these therefore have to be addressed. Lastly, teachers' interpretations of activities aimed at professional development, and not just the design itself, seem to be important for the effectiveness of these activities. A similar view at curriculum level has been described in terms of five curricular representations (Goodlad, 1979; Van den Akker, 1998). Teachers' 
interpretation of the formal, written, curriculum leads to a personalized version of the operational curriculum enacted in class.

We conceptualize the growth of professional knowledge and skills as a process in which teachers themselves have to be actively involved. One way of doing this is by letting teachers develop student learning material and enact it in their classes. This scenario looks promising as the factors for professional preparation described above can be accommodated, the gap between formal and operational curriculum can be reduced, and also because Dutch chemistry teachers fully support the concept of 'teacher-as-developer of learning material' (Coenders, et al., 2008).

Before examining the teachers' knowledge and beliefs at stake in this curriculum renewal, the context of this study will be highlighted.

\subsubsection{The context of this study}

In 2002, a curriculum renewal for high school chemistry was initiated in the Netherlands (Driessen \& Meinema, 2003; Van Koten, et al., 2002). Important characteristics of this renewal were that contemporary chemistry content and societal challenges had to be included in the curriculum, and that chemistry should appeal to all students. To achieve this, a context-based approach, in which students learn concepts and the relations between these concepts starting from an appealing context, was adopted (Gilbert, 2006). From the beginning teachers were involved in the change processes in order to facilitate preparation and implementation. For the development of student learning material, teacher networks were set up. Each teacher network comprised two or three teachers from different schools and a coach who acted as the chair and as the liaison between the different networks. Teachers participated voluntarily. Their schools supported them through a reduction of their teaching load and facilitated the enactment of the material in class. Each network was to develop learning material in the form of a module, comprising all texts, exercises, practical and other learning activities, for approximately 8 - 10 periods. Subsequently the teachers had to enact this learning material in their classes, discuss the outcomes and improve the module for use by other interested teachers. In order to avoid confusion the term "teacher-developer" will be used for those teachers who, next to being a teacher, were involved in the development of student learning material in a network. The framework of the development process of student learning material is shown in Figure 5.1. 
Several teacher networks were established throughout the country, one of these participated in this study. This network received the following instructions: (a) Design a module suitable for Form 3, the first year students (of about 15 years of age) take up chemistry in secondary school; (b) The central element must be the interaction between an interesting context for students and a number of chemistry concepts present in this context (context-based approach); (c) Concepts should follow "naturally" from the context as was exemplified in the Salters' materials (Campbell, et al., 1994) and rigid following of syllabus objectives or of a subject content structure must be avoided; (d) To structure the module, the four stages from Chemistry in Context in Germany (Parchmann, et al., 2006) have to be used, these are: (i) the teacher first introduces the context, (ii) students are made curious and plan their investigations, (iii) students carry these out and process the results, and (iv) all knowledge is brought together. The selection of the context and of the concepts emerging from this context and to be explored by the students, as well as the kind of learning activities and materials, the pedagogy, and the assessment methods of student learning results, were the responsibility of the network. Each network also had substantial freedom with respect to the organization of their work like the number of face-to-face meetings, the communication between the meetings, and the task allocation to the network members.

The material to be developed by the network of this study will not contain new chemistry content for the teacher-developers. Familiar concepts will feature but the way these will be presented to and learned by students will be different. This means that the teacher-developers of student learning material in the context described above, who subsequently enact this material in their classes, will probably expand their Pedagogical Content Knowledge (PCK). PCK and its components will be elaborated in the next section.

\subsubsection{Pedagogical Content Knowledge}

Teaching is a complex cognitive activity in which the teacher has to apply knowledge from different domains (Barnett \& Hodson, 2001; Cochran, et al., 1993; Resnick, 1987): (a) subject matter knowledge, (b) pedagogical knowledge, and, (c) pedagogical content knowledge (PCK). An amalgam of content and pedagogy to foster students' learning for understanding is seen as the foundation of PCK. Shulman (1987) conceptualized PCK in terms of the ways of representing and formulating the subject to make it understandable for others, 
subject matter is transformed for pedagogical purposes. Building on Grossman's (1990) work, PCK for science teaching is seen as consisting of five components (Magnusson, et al., 1999): (a) orientations toward science teaching, (b) knowledge and beliefs about the science curriculum, (c) knowledge and beliefs about students' understanding of specific science topics, (d) knowledge and beliefs about assessment in science, and (e) knowledge and beliefs about instructional strategies for teaching science. PCK encompasses both teachers' understanding and their enactment. We adopted this general conception of PCK in this study using the following interpretations.

1. Orientations to science teaching encompasses teachers' knowledge and beliefs about the purposes and goals for teaching science at a particular level, and therefore guide instructional decisions about teaching science. Important aspects in context-based education will be the relation between the chosen context of the learning material and the concepts to be learned, and also the role of chemistry in society in relation to teaching chemistry content per se.

2. Knowledge and beliefs about the science curriculum include specific goals and objectives, and activities and curriculum materials to be used in meeting these. The curricular saliency (Geddis, Onslow, Beynon, \& Oesch, 1993), the importance of various topics relative to the curriculum as a whole, is part of this component. This also shows the tension often felt in education between "having to cover the curriculum" and "teaching for understanding".

3. Knowledge and beliefs about student understanding incorporates requirements for learning specific topics and areas the students find difficult. This component includes knowledge about learning difficulties, learning style, and requirements for developmental levels.

4. Knowledge and beliefs about assessment deals with dimensions of science learning important to assess and the methods by which this can de done. It includes knowledge of specific instruments, approaches and activities for assessment. Context-based education might require other assessment methods and instruments than traditional education.

5. Knowledge and beliefs about instructional strategies includes subject and topic specific strategies of instruction. Subject specific strategies are more general approaches such as practical activities and inquiry-oriented instruction. Topic specific strategies refer to instructional strategies to teach particular topics, such as the use of models in teaching organic chemistry. Context-based education often uses cooperative learning as the instructional strategy to enable students to explore the context and develop the concepts without the need for regular teacher intervention. 
PCK is a complex construct and not easily assessed (Baxter \& Lederman, 1999). It is developed and shaped in school practices through reflection-in-action and reflection-on-action (Park \& Oliver, 2008), active processing, and the integration of its contributing components. An expert teacher has well formed PCK for all topics taught (Abell, 2008; Clermont, et al., 1994; Henze, van Driel, \& Verloop, 2008; Van Driel, et al., 1998). PCK is considered to be topic specific, but certainly also contains elements relevant for teaching different topics. In this sense it is considered to be subject specific (E. A. Davis \& Krajcik, 2005; Friedrichsen, et al., 2009). In times of a curricular reform, teachers have to bring their PCK in line with the reform demands. Can the process of development and class enactment bring about the required change? The following research questions guided this study: What changes in teachers' PCK occur when teachers are engaged in the development and subsequent class enactment of context-based student learning material, and to what phases within the development process can these changes be attributed?

\subsection{METHOD}

\subsubsection{Participants}

Three teachers participated in this study, one female teacher which will be called Lisa, and two male teachers, Pete and Ed. All are experienced teachers having between 5 and 30 years of teaching experience, and all had a master's degree in chemistry plus a teaching qualification. The teachers were employed by three different schools, and were released by their school for half a day per week to contribute to the development process. The network was chaired by a coach, who was a staff member from a University teacher training department, and had been a high school teacher himself with yearlong experience as a high school chemistry textbook author. This particular network was chosen on practical grounds as it was not too far from the researchers' university.

\subsubsection{Development procedure of learning material}

For almost a full school year the network participants collaborated. A complete module was developed from scratch, starting with a brainstorm session to reveal and explore possible contexts. After its development the module was 
enacted in teacher-developers' own classes. The network members than discussed the outcomes and the module was revised for use by other teachers. The participants had nine meetings under the chair of the coach, all of several hours in which they discussed issues at hand. In between the meetings, regular e-mail contact took place. The e-mail content varied from a continuation of the discussion to sending attachments with ideas, half-products of the module, or copies from articles or books.

Network members themselves determined the content of the module, the instructional strategies to be used and the way of assessment of the learning results. After a brainstorm session, 'Baking a cake' emerged as the context. Concepts that surfaced from this context were for example: what is a chemical reaction and how can one determine whether a (baking) process is a chemical reaction, the law of conservation of matter, and the use of process charts both on paper and by using a computer program. A cooperative learning environment was proposed. The students were organized into small groups of four to five students. They then worked through the assignments until all group members did successfully understand and complete these. Each period group members were assigned different roles, such as chairperson and writer. Specific tasks related to these roles were incorporated in a group logbook that was especially designed for this module. In this logbook, that had the form of a small booklet, for each period ample space to write down specific information was provided, both related to content and process. With respect to the content, student groups had to answer the questions in the module, jot down the observations of experiments, the work plans for investigations, and the problems encountered. Related to the process, each group had to indicate for every period the role each member had, whether all members had completed the self- imposed homework, and how the cooperation was perceived. Paying explicit attention to teaching cooperative skills using T-cards was discussed (Ebbens, et al., 1996). One T-card addresses one specific cooperative skill on a practical level.

Some advantages were envisaged for cooperative learning: (a) students could work more independently and would require less teacher assistance, (b) the students could learn from each others' efforts and (c) the teacher could focus on the learning process and on organizational issues. Cooperative learning was new to all teacher-developers. They were familiar with all concepts in the module; however the way students were going to learn these concepts, starting from a context, was new. 


\subsubsection{Research instruments}

In this study data were gathered using different instruments and sources and during specific periods in the development process as depicted with the letters A through $\mathrm{C}$ in Figure 5.1.

\begin{tabular}{|c|c|c|c|c|c|c|}
\hline \multirow{2}{*}{$\begin{array}{l}\text { National level: } \\
\text { - curriculum } \\
\text { change } \\
\text { - development } \\
\text { guidelines }\end{array}$} & & \multirow{2}{*}{$\begin{array}{l}\text { Self regulatory } \\
\text { network aimed } \\
\text { at developing a } \\
\text { module: writing } \\
\text { phase. }\end{array}$} & & \multirow{2}{*}{$\begin{array}{l}\text { Class use of } \\
\text { the module } \\
\text { by the } \\
\text { developers: } \\
\text { enactment } \\
\text { phase }\end{array}$} & & \multirow{2}{*}{$\begin{array}{l}\text { Revision: } \\
\text { tested } \\
\text { module } \\
\text { ready for } \\
\text { other } \\
\text { schools }\end{array}$} \\
\hline & $\begin{array}{l}\mathrm{A}_{1} \\
\mathrm{~A}_{2}\end{array}$ & & B & & $\mathrm{C}$ & \\
\hline
\end{tabular}

Figure 5.1 Framework of the network development activities, and timing of data collection (A1, A2, B, C refer to data collection instruments)

As can be seen in Figure 5.1, data were collected before the start of the development process (A1, A2), after the development of the module but before class enactment (B), and after class enactment (C). A1 was a written questionnaire. $\mathrm{A} 2, \mathrm{~B}$ and $\mathrm{C}$ were semi-structured interviews, all lasting between one and two hours. The specific questions used in the different instruments are shown in the appendix in 5.5. One opposing viewpoints question was used in the questionnaire and in the last interview (appendix 5.5, A1 question 5 and C question 10) and was of the "forced choice" response type as we wanted teachers to weigh the two viewpoints and then select the one they considered most important.

The results from the network meetings were used to supplement and validate the findings from the interviews. From the first four meetings a written report was made, and the last five network meetings were audio recorded.

The developed learning material itself acted as a research instrument. A lot of learning activities and pedagogical and practical issues were discussed at network meetings. The material showed what was finally incorporated.

\subsubsection{Design and Analysis}

As we were interested in possible changes in teacher PCK, a multiple case study design was used (Yin, 2003), including the levels of questions. The main data sources were the instruments A1, A2, B, and C. Network meeting transcripts and learning material itself were used as triangulation instruments (Denzin \& 
Lincoln, 2000; Meijer, et al., 2002). Results will first be reported for each individual case, followed by cross-case conclusions.

All interviews were transcribed verbatim. Using open coding (Gibbs, 2007, p. 50), passages that exemplify thematic ideas related to the PCK components were identified. When all transcripts and the questionnaire were coded, it turned out that redefining the domains would make it easier to understand changes in teachers' PCK. This process of axial coding resulted in three domains to organize the data: (a) knowledge and beliefs on context-based chemistry education, (b) knowledge and beliefs on cooperative learning, and (c) knowledge and beliefs on requirements for context-based learning. The coded passages were transferred to word tables and organized under the appropriate category. To report on changes in the "forced choice" questions (see appendix 5.5, A1 question 5 and C question 10), we used the idea of a conceptually ordered matrix (Miles \& Huberman, 1994, p. 183). The results of this matrix (Table 5.4) were used to validate the findings reported in the word tables.

To ensure data processing reliability, a research assistant not previously involved in the research, checked the reported passages resulting from the written questionnaires and all transcripts. Immediate agreement transpired for $98 \%$ of the passages. The ones not agreed upon were discussed and reformulated until consensus was reached.

\subsection{RESUlts}

In the following section results will be reported for each teacher-developer separately in the three domains indicated above: knowledge and beliefs on context-based chemistry, on cooperative learning, and on requirements for context-based learning. The opposing viewpoints question is tabulated for all three teacher-developers, and shown in Table 5.4. Finally a summary of the results is given to facilitate the search for patterns across the three cases.

\subsubsection{Pete}

Pete's knowledge and beliefs on the three domains at the different moments in the development process, that is before and after the writing phase and after class enactment (Figure 5.1), are shown in Table 5.1. 
Table 5.1 Pete's knowledge and beliefs on context-based education, on cooperative learning, and on requirements for learning during the three phases of the development process

\begin{tabular}{|c|c|}
\hline & Pete's knowledge and beliefs on context-based chemistry education \\
\hline $\begin{array}{l}\text { Before } \\
\text { writing }\end{array}$ & $\begin{array}{l}\text { - Normally, I think in concepts and try to identify suitable contexts. I want to } \\
\text { change this now knowingly. I consider this a "leap in the deep". } \\
\text { - Students should learn basic concepts from contexts. How to do this? } \\
\text { - Concepts should be close to students' life. For example at a barbeque, when } \\
\text { - Aood turns black, students should recognize the concept decomposition. } \\
\text { For example students need to question what happens at molecular level during } \\
\text { - decomposition at a barbeque. }\end{array}$ \\
\hline $\begin{array}{l}\text { After } \\
\text { writing }\end{array}$ & $\begin{array}{l}\text { - Students should experience that chemistry has to do with their lives. } \\
\text { - I am excited as the starting point is a context, but I wonder what will happen in } \\
\text { class. }\end{array}$ \\
\hline \multirow[t]{2}{*}{$\begin{array}{l}\text { After class } \\
\text { enactment }\end{array}$} & $\begin{array}{l}\text { - The chosen context did appeal to students' life world and created enthusiasm. } \\
\text { - For me it was an experiment, I went into unknown adventures, and getting } \\
\text { used to it needs time. } \\
\text { - Context-based approach is possible, but it is important that the concepts } \\
\text { become clear and that students relate these concepts and build up a concept } \\
\text { structure. }\end{array}$ \\
\hline & on cooperative learning \\
\hline & $\begin{array}{l}\text { - I want to use cooperative learning with mutual dependence, although I have } \\
\text { no experience with this. } \\
\text { - Differentiation (selecting specific tasks) should be possible, but students also } \\
\text { need to do activities others find relevant. } \\
\text { - Teacher needs to introduce topic, challenge students, enthuse, stimulate } \\
\text { curiosity, monitor quality, facilitate for students, address student effort, and } \\
\text { answer questions and maps out the road. }\end{array}$ \\
\hline $\begin{array}{l}\text { After } \\
\text { writing }\end{array}$ & $\begin{array}{l}\text { Attention for group processes with explicit attention for reflection is a strong } \\
\text { aspect in the material. } \\
\text { - Want to use T-cards to teach cooperative skills, and group roles in cooperative } \\
\text { learning. } \\
\text { - Want to let students use the logbook. }\end{array}$ \\
\hline $\begin{array}{l}\text { After class } \\
\text { enactment }\end{array}$ & $\begin{array}{l}\text { - Cooperative learning: } \\
\text { - I composed groups myself, } \\
\text { - Students used the group roles, } \\
\text { - I hardly used T-cards, } \\
\text { - I marked each group logbook after every period. } \\
\text { - Marking the students' logbooks made students look back at the previous period. } \\
\text { Students corrected mistakes or made additions and naturally established a } \\
\text { connection between the content of the previous and the current lesson. } \\
\text { - Reflection by students in the groups on what was agreed upon to work on and } \\
\text { - } \text { - Coophat was done at home and in class is a strong aspect. } \\
\text { - Instruction for students is different, I had to get used to this. }\end{array}$ \\
\hline
\end{tabular}




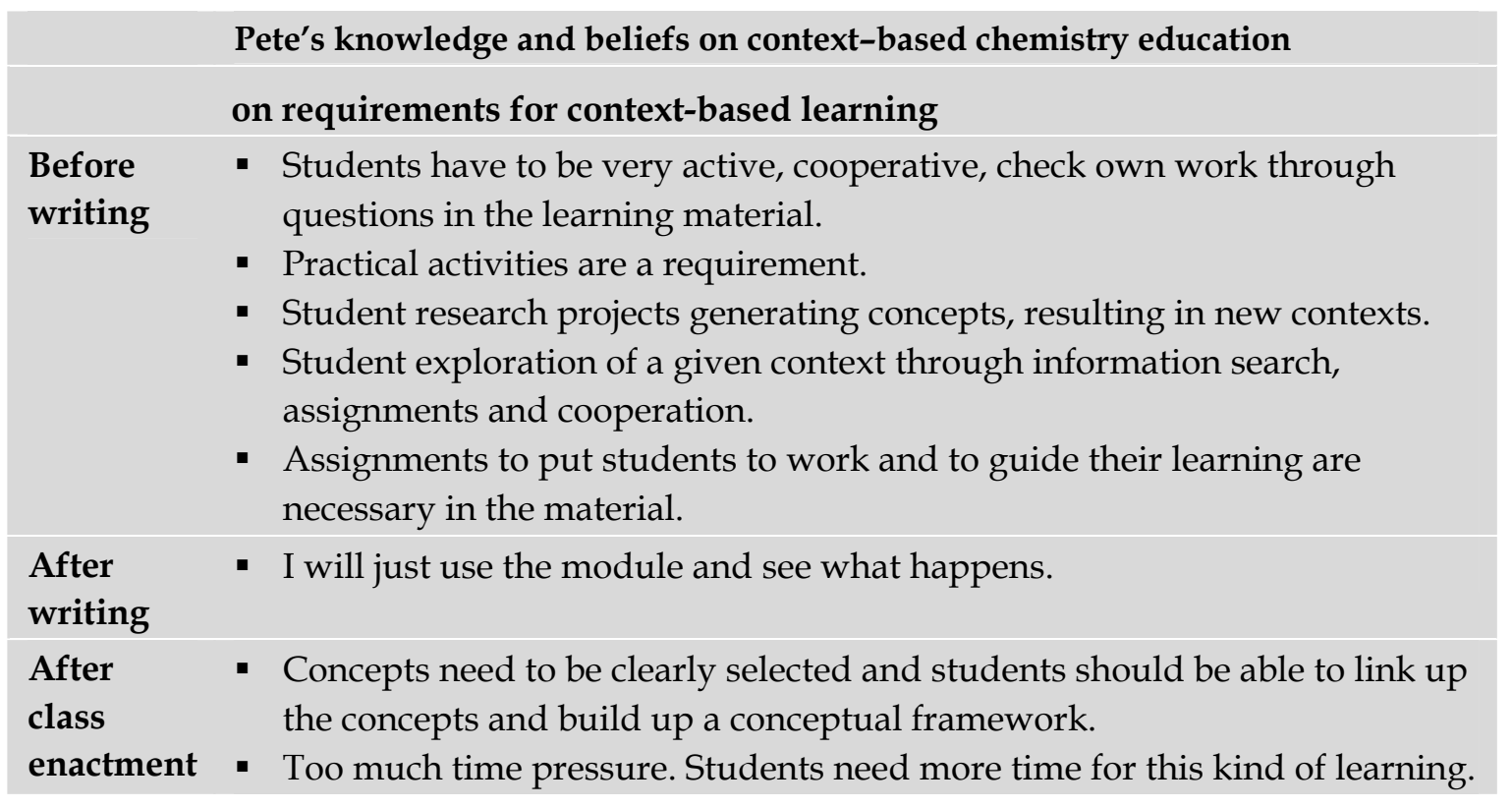

\section{Changes in knowledge and beliefs on context-based chemistry}

During the writing phase Pete learned how to develop student learning material starting from a context in which the concepts addressed are close to students' life. Pete learned to design and develop specific assignments and practical activities to foster student learning. However,

after the writing phase Pete did not know how students were going to react in class, and what and how they were going to learn. In the interview before class enactment Pete noted: "Is the module challenging enough for the students? For my feeling I would start with concepts and find a suitable context. I find it an exciting endeavor". Through year long experience he did know students' reaction in his 'normal' teaching approach, but now class enactment felt for Pete as an adventure.

Class enactment of the module did influence his beliefs as he now considered concepts more important than a context, although he perceived starting a learning process with a context positive as it created students' engagement with activities and enthusiasm. This change from context to concept is related to his observation that students find it difficult to link up the concepts they learned, and he therefore wants to equip his students with the necessary skills (see also Table 5.4, viewpoints 1 and 3). 


\section{Changes in knowledge and beliefs on cooperative learning}

During the writing phase Pete learned the why and how of elements of cooperative learning. Network discussions and specific literature on cooperative learning provided the necessary ideas for effective class enactment. During one of the network meetings Pete said that " ........... in the teachers' guide attention should be given to the use of T-cards". In the same meeting he wondered whether there is an instrument to monitor student (group) learning and argued that "we can ask them (the students) to fill out separate paper sheets but we also need to go towards some sort of assessment of the module". This discussion resulted in the development of a specific group logbook. In the last network meeting the use of T-cards was again discussed, especially in relation to cooperation within the groups as Pete wondered whether a few students were going to do all the work whilst others would not take responsibility for the group activities. In the interview before class enactment, Pete indicated that student roles in a group, the use of T-cards to discuss cooperative skills, the logbook and how to use it, and reflection on group work by the students, were incorporated into the material and he intended to use all these. He said: "Specific attention for group processes and the explicit reflection in the module are renewing elements in the material". In the same interview Pete noted that "Looking back I have been very teacher centered". In the module, students have substantial freedom for their learning: they can design and carry out own small research projects and the cooperative groups can operate rather independently. In class, Pete hardly used the T-cards although he noted that students needed time to get used to work in cooperative groups, he said: "Initially three students watched one student pour a solution in a test-tube in his right hand into another solution in a beaker in his left and all observed a color change, this took 10 minutes, that was not very effective". Class enactment showed that the logbook can play an even more prominent role than anticipated during the development of the learning material. Pete marked the group logbooks and this stimulated students' reflection on both the process as on the content. Granting 
the groups more responsibility worked out well in class, the students worked enthusiastic and hard and the learning results were good. Pete noticed that students themselves were well capable of acquiring knowledge (see also Table 5.4, viewpoint 5).

\section{Changes in knowledge and beliefs on requirements for context-based learning}

Pete learned that that the quality of the learning material, especially the formulation of texts and the description of assignments, has an impact on the degree in which groups can work independent from the teacher. Pete noted: "What I saw is that using clear instruction in the material can reduce manpower in class by half." Unclear wording requires the teacher to clarify texts or explain what students are supposed to do. Initially Pete said that practical activities were necessary for students to explore the context. Practical activities from a recipe had his preference.

After class enactment he noted that open research experiments (see also Table 5.4, viewpoint 9) created students' enthusiasm. However, concept development did not occur automatically but needed scaffolding, especially in the form of a better selection of concepts, and activities to establish relationships between these concepts, as Pete said in the interview after class enactment: "I wanted to have more time at the end to reflect with the students on the concepts learned. And I would have loved to have more concepts in this context." A bit further on he reflected on past experiences: "I used to make a concept map with the students of all concepts learned so far And I found that very effective. ........ I would love to include this in the module".

\subsubsection{Lisa}

Lisa's knowledge and beliefs on the three domains at different moments in the development process are shown in Table 5.2. 
Table 5.2 Lisa's knowledge and beliefs on context-based education, on cooperative learning, and on requirements for learning during the three phases of the development process

\begin{tabular}{|c|c|}
\hline & Lisa's knowledge and beliefs on context-based chemistry education \\
\hline $\begin{array}{l}\text { Before } \\
\text { writing }\end{array}$ & $\begin{array}{l}\text { - I first want to have the concepts clear myself, and then generate ideas } \\
\text { how to offer these in an interesting way to students. } \\
\text { - The context should raise students' interest by showing that chemistry is } \\
\text { not alienating but all around us. }\end{array}$ \\
\hline $\begin{array}{l}\text { After } \\
\text { writing }\end{array}$ & $\begin{array}{l}\text { Normally I know where students will have difficulties and how things } \\
\text { will run in class. Now this is all new, I don't know where they will be } \\
\text { stranding. }\end{array}$ \\
\hline \multirow[t]{2}{*}{$\begin{array}{l}\text { After } \\
\text { class } \\
\text { enactment }\end{array}$} & $\begin{array}{l}\text { Context-based approach was motivating for students. A difficult aspect } \\
\text { was isolating the concepts and linking these with other concepts (also } \\
\text { with some previously learned). }\end{array}$ \\
\hline & on cooperative learning \\
\hline $\begin{array}{l}\text { Before } \\
\text { writing }\end{array}$ & $\begin{array}{l}\text { I want to use group work, small groups of } 2 \text { to } 3 \text { students, but also } \\
\text { individual work. } \\
\text { - Students need to be able to acquire information, and learn to work with } \\
\text { limited substances and limited directions. } \\
\text { - Teacher needs to teach basic skills, stimulate, and guide students while } \\
\text { looking for answers. } \\
\text { - Teacher at the end needs to discuss and resolve difficulties in a class setting. }\end{array}$ \\
\hline $\begin{array}{l}\text { After } \\
\text { writing }\end{array}$ & $\begin{array}{l}\text { - I have never been enthusiastic about larger groups, but now see the } \\
\text { advantages. Still wonder how it will be in class, and I am a bit scary to be } \\
\text { honest. } \\
\text { - Students will work in cooperative groups, including roles and a group } \\
\text { logbook. I also want to use the T-cards. } \\
\text { - Students have to think about what to do next, this is challenging. In } \\
\text { traditional classes they could carry out the experiments using the } \\
\text { prepared materials. } \\
\text { - My task is to monitor, pose questions and see what happens. } \\
\text { - Have to mark the logbook (I would have loved to use an electronic version). }\end{array}$ \\
\hline $\begin{array}{l}\text { After } \\
\text { class } \\
\text { enactment }\end{array}$ & $\begin{array}{l}\text { Cooperative learning: } \\
\text { a. I selected group members myself randomly. } \\
\text { b. I used T-cards, and this was a positive experience. I could refer to } \\
\text { specific cooperative skills on these cards during classes. } \\
\text { c. Students used the group roles. } \\
\text { d. I commented in group's logbook after every period, did not grade it. } \\
\text { Commenting helped as students worked more accurately. } \\
\text { - Attractive for students, and for me, was that they could consult within } \\
\text { their cooperative group and start working. Student learning did not } \\
\text { depend on my intervention. } \\
\text { - Students participated actively and were enthusiastic. I am going to use } \\
\text { cooperative learning more often. }\end{array}$ \\
\hline
\end{tabular}




\section{Lisa's knowledge and beliefs on context-based chemistry education}

- I sat down with groups and observed the learning process, and gave hints when necessary. Was interesting.

- Organization of group activities was difficult especially when one has different classes. I lost the overview of where students were working on.

- Do not let students work in groups a whole year, but variation is necessary.

\section{on requirements for context-based learning}

$\begin{aligned} & \text { Before } \\ & \text { writing }\end{aligned}$
$\begin{array}{ll}\text { - At the end of the cycle select and discuss learning difficulties in whole class. } \\ \text { - Students need to be active through assignments, computers and especially } \\ \text { internet. }\end{array}$
$\begin{array}{ll}\text { After } & \text { - I think that my task will be to guide groups, walk around in class and see } \\ \text { writing } & \text { what happens. Learning material should permit students to work in } \\ \text { groups without constant teacher intervention. }\end{array}$
$\begin{array}{ll}\text { After } & \text { - The concepts have to be more clearly extracted by the students. Having } \\ \text { class } & \text { them make a concept list could be helpful. } \\ \text { enactment } & \text { - Class summary and review at the end is necessary, also to check the } \\ & \text { concept list. }\end{array}$

\section{Changes in knowledge and beliefs on context-based chemistry}

During the writing phase Lisa learned that it is possible to start from a context. Before writing she said: "I want to have the concepts clear first, I want to know (when using a context) where (with what concepts) I am going to end." But the development started with a brainstorm session to determine the most suitable context and from there the concepts gradually emerged. Before class enactment she was not confident that it would work out well as she said: "I hope that the student groups can work independent and that they love working on the module, but I find it a bit scary to be honest".

Lisa experienced in class that the context-based approach is motivating and does lead to student learning, which was her initial anxiety. After class enactment Lisa said: "students loved it. ........... They worked hard, and even had the stuff they had to bring from home." A bit further on she noted: "the learning results were in line with previous chapters". How students can get the concepts clear remains challenging, she said: "That is missing in the module, a concept list." A bit further on she said: "Linking concepts with one another is not something students do automatically".

Lisa also said to need time getting used to the context-based approach as she said: "I liked it but it is strange, you begin somewhere but you don't know where it will end." 
During the complete process Lisa's conception of what she thought was more important, context or concept, and knowledge of the role of chemistry or knowledge of chemistry content changed (see also Table 5.4, viewpoints 1 and 2).

\section{Changes in knowledge and beliefs on cooperative learning}

Lisa envisaged a substantial role for herself in presenting knowledge as she did not have much confidence in students' acquiring own knowledge After the development of the learning material she is willing to let students explore the module themselves, and to take on the teacher role of monitoring and questioning. For Lisa cooperative learning, using T-cards to teach students cooperative skills, roles for group members and a group logbook, was new. During the writing phase Lisa learned a lot about cooperative learning. In a network meeting she said: "The advantage of larger groups is that it becomes easier for the teacher. When students working in pairs have questions and come to you for help, you become overwhelmed". A bit later when the issue of cooperation within the group was discussed she noted: "Changing group roles and having them write down what they did this period and what they are going to do the next period makes it better. Everyone is in turn in charge and students who do not contribute will be addressed". In the next network meeting the design of the logbook was discussed and Lisa noted: "For each lesson there is one sheet per group. On top is indicated what lesson it is, the date, who is the chief, who the writer etc. and then planning, what needs to be done". A bit later she indicated about the use of the logbook: "It also serves for the group itself so that can be seen what each member should have done". The network discussions, in combination with the developed materials, prepared her well for class enactment.

Class enactment confirmed previous opinions. Students did acquire knowledge in their groups rather independent from teacher intervention and her opinion on this changed (see also Table 5.4, viewpoints 5 and 6). The cooperative groups worked well. Lisa experienced that she had time to sit down with groups to observe their discussions and other activities. However, some practical aspects were not foreseen: she had difficulties keeping the overview as groups were doing own research projects, and she experienced organizing the group activities complicated. 
Changes in knowledge and beliefs on requirements for context-based learning Lisa's beliefs on what to incorporate in the learning material and on how to put students to work were quite outspoken: assignments, computer and internet use, excursions, practical work and especially own research projects. These aspects were all to some extend incorporated in the material.

After class enactment Lisa experienced that students do learn a lot from own experiments (see also Table 5.4, viewpoint 9). She experienced that the learning material needs to be of high quality, if not, teacher intervention for clarification, is repeatedly necessary. Lisa felt that concepts should have been more noticeable for students at the end of the module. In the last interview she said: "I think that the teacher has to mention, has to make a sort of a summary and indicate that these are the concepts that we met in this module. That is missing, a concept list".

\subsubsection{Ed}

Ed's knowledge and beliefs on the three domains at different moments in the development process are shown in Table 5.3. 
Table 5.3 Ed's knowledge and beliefs on context-based education, on cooperative learning, and on requirements for learning during the three phases of the development process

\begin{tabular}{|c|c|}
\hline & beliefs on context-based chemistry education \\
\hline $\begin{array}{l}\text { Before } \\
\text { writing }\end{array}$ & $\begin{array}{l}\text { - A context must be concept generating. But can students draw sufficient } \\
\text { - A good context, in combination with the right questions and problems, will } \\
\text { lead to students developing theory. } \\
\text { - I hope that if we bombard the students with the reality they will start } \\
\text { drawing concepts from it. } \\
\text { - Through observations students learn to understand. } \\
\text { - A must of this program is that students learn the natural sciences' way of } \\
\text { thinking and reasoning. }\end{array}$ \\
\hline $\begin{array}{l}\text { After } \\
\text { writing }\end{array}$ & $\begin{array}{l}\text { - The concrete must precede the rest, so first the context and then the } \\
\text { concepts and never the other way around. }\end{array}$ \\
\hline $\begin{array}{l}\text { After class } \\
\text { enactment }\end{array}$ & $\begin{array}{l}\text { - Start with a context, develop a concept en bring this back to reality, to a } \\
\text { context. It could be the same context but also a different one. } \\
\text { - Students need to be able to switch between the concrete and the abstract. } \\
\text { - Teacher needs to rediscover the content. }\end{array}$ \\
\hline \multicolumn{2}{|r|}{ on cooperative learning } \\
\hline $\begin{array}{l}\text { Before } \\
\text { writing }\end{array}$ & $\begin{array}{l}\text { - Independent work; if group work is necessary then groups of } 5 \text { students. } \\
\text { another. } \\
\text { - Teacher needs to make students enthusiastic and assist on request. }\end{array}$ \\
\hline $\begin{array}{l}\text { After } \\
\text { writing }\end{array}$ & $\begin{array}{l}\text { - Will not use a structured logbook, no roles, no T-cards. } \\
\text { - In class I will go along with students' ideas and see where this leads to, if } \\
\text { necessary I will redirect students through questioning. } \\
\text { - I will form mixed ability groups of } 3 \text { - } 4 \text { students. }\end{array}$ \\
\hline $\begin{array}{l}\text { After class } \\
\text { enactment }\end{array}$ & $\begin{array}{l}\text { - I formed the groups myself; I mixed able and less able students. } \\
\text { - Did not use T-cards nor logbook, students used their own notebook in their } \\
\text { own preferred manner. Left roles to the groups, is for me not important. } \\
\text { - Teacher is busy coaching and leading Socratic conversations with groups. }\end{array}$ \\
\hline \multicolumn{2}{|r|}{ on requirements for context-based learning } \\
\hline $\begin{array}{l}\text { Before } \\
\text { writing }\end{array}$ & $\begin{array}{l}\text { - Teacher needs to guide students. This is interesting and requires } \\
\text { "Fingerspitsengefühl" as students need to get help without prompting. } \\
\text { - Practical work and especially own research projects are necessary as } \\
\text { students need to develop reasoning skills and a scientific way of thinking. } \\
\text { - Assignments to put students to work, assignments can be open or descriptive } \\
\text { depending on the goals. The use of computers (animations) and internet. }\end{array}$ \\
\hline $\begin{array}{l}\text { After } \\
\text { writing }\end{array}$ & $\begin{array}{l}\text { - Socratic way of developing content (a strategy I love). So far students have } \\
\text { acquired knowledge without much thinking on the bases of the textbook, } \\
\text { but that will change in this module. }\end{array}$ \\
\hline $\begin{array}{l}\text { After class } \\
\text { enactment }\end{array}$ & $\begin{array}{l}\text { - Socratic conversations were wonderful. } \\
\text { - Students had to be active. } \\
\text { - Students explored things and appreciated this. }\end{array}$ \\
\hline
\end{tabular}


Changes in knowledge and beliefs on context-based chemistry

Ed learned during the writing phase that it is possible to start chemistry education in the concrete, in a context, and have students discover concepts and elaborate these. Context-based chemistry must be a cyclic process in which students from the context develop a concept and bring this back to a context. Then another concept is explored etc.

This was confirmed in class (see also Table 5.4, viewpoint 1 ). In the interview after class use he said: "You start with a context, extract concepts from it and bring these back in a context. This can be the same or a different context." A bit later he said: "....but it must be meaningful, you do not let students brew alcohol just to have them practice balancing a chemical equation".

Ed noticed in class that students learn better when they enjoy what they are doing, his opinion in this changed (see Table 5.4, viewpoint 4). Ed in class also noticed that students had problems using models as he said in the interview after class use: "They (the students) find it difficult, this thinking to and from models. We need to be more cautious in using models and make sure students make each step explicitly."

\section{Changes in knowledge and beliefs on cooperative learning}

Ed hardly changed in this domain, as he did not use those aspects of cooperative learning he was unfamiliar with, but instead had students follow their own preferences. During a meeting he said about the logbook: "It is important to keep these things short. Such administration makes you nuts or will cost a lot of time". A few minutes later he added: "This is typically nothing for me". A viewpoint he lived by because he did not let his students use a logbook.

Initially he did not advocate group learning. However, before class enactment he does want to make groups, and actually used these in class (see also Table 5.4, viewpoint 6). He noted that group work has potential because students can discuss content issues without teacher presence. But even after class enactment he said: "I don't think that it is important that we teach students cooperative skills, students however do learn together."

\section{Changes in knowledge and beliefs on requirements for context-based learning}

Ed's focus is on skills like exploring and reasoning. According to Ed, students want to acquire knowledge and had lost the ability to reason, for which he blamed the text books. In this new approach these reasoning skills and the scientific way of thinking were back, something he applauded. Learning material 
needs to have suitable questions and problems for the student groups to work on. Suitable in his opinion means using the latest technologies as he said in a network meeting: "If I imagine myself in the position of students I would prefer to use the computer. Spread sheet use is not the goal but the means. It can be done by hand but I think students prefer computer use." Students should have the opportunity to develop theories themselves, and only thereafter be confronted with existing theories. With the help of a teacher to pose the right questions, students can go a long way. This process takes time but it leads to better understanding. Ed was a very outspoken advocate of the use of a Socratic conversation. In the interview before enactment of the material in class he said: "Socratic learning. That is no prompting, go along with students' ideas and then see where the ship strands and where it can be redirected".

Class enactment confirmed his belief with respect to the scientific way of thinking. In the interview after class enactment he said: "So the concrete, the interaction between the concrete and the abstract is extremely important". Therefore skills are important (see also Table 5.4, viewpoints 3 and 5). About the Socratic conversations he noted in the same interview: "Not prompting anything, but reformulating the question and divide in chunks. It worked out very well and I went to these classes with great pleasure".

In Table 5.4 the three teachers' responses on the opposing viewpoint questions before and after class enactment are shown. The number 1 or 2 in the table means that a teacher both before as well as after class use had a preference for the first (1) or the second (2) viewpoint. The notation "Yes plus arrow" signifies a shift in viewpoint; the arrow indicates the direction of the change.

The results of the opposing viewpoints question (Table 5.4) will be used in the summarizing conclusions below. 
Table 5.4 Teacher-developers' responses to the opposing viewpoints questions

\begin{tabular}{|c|c|c|c|c|}
\hline \multirow[b]{2}{*}{ Domain } & \multirow[b]{2}{*}{ Opposing viewpoints } & \multicolumn{3}{|c|}{ Changed after class enactment? } \\
\hline & & Pete & Lisa & Ed \\
\hline \multirow{4}{*}{$\begin{array}{l}\text { Context- } \\
\text { based }\end{array}$} & 1. Context or concept & Yes $\rightarrow$ & Yes $\leftarrow$ & Yes $\leftarrow$ \\
\hline & $\begin{array}{l}\text { 2. Knowledge of the role of } \\
\text { chemistry or subject (chemistry) } \\
\text { knowledge. }\end{array}$ & 1 & Yes $\leftarrow$ & 1 \\
\hline & 3. Knowledge or skills. & Yes $\rightarrow$ & 2 & 2 \\
\hline & $\begin{array}{l}\text { 4. Concept learning or students } \\
\text { enjoy learning. }\end{array}$ & 2 & 2 & Yes $\rightarrow$ \\
\hline \multirow[t]{4}{*}{$\begin{array}{l}\text { Cooperative } \\
\text { learning }\end{array}$} & $\begin{array}{l}\text { 5. Teacher presents knowledge or } \\
\text { students acquire knowledge. }\end{array}$ & $\mathrm{Yes} \rightarrow$ & Yes $\rightarrow$ & 2 \\
\hline & $\begin{array}{l}\text { 6. (Learn to) cooperate or } \\
\text { independent work. }\end{array}$ & & & \\
\hline & & 1 & Yes $\leftarrow$ & Yes $\leftarrow$ \\
\hline & $\begin{array}{l}\text { 7. Offer identical content to all } \\
\text { students or students choose } \\
\text { their own subject matter. }\end{array}$ & 1 & 2 & 2 \\
\hline \multirow[t]{2}{*}{$\begin{array}{l}\text { Requirements } \\
\text { for learning }\end{array}$} & $\begin{array}{l}\text { 8. Experiments/ practical work or } \\
\text { paper assignments. }\end{array}$ & 1 & 1 & 1 \\
\hline & $\begin{array}{l}\text { 9. Practical from a recipe or open } \\
\text { research experiments. }\end{array}$ & Yes $\rightarrow$ & Yes $\rightarrow$ & 2 \\
\hline $\begin{aligned} \text { Note: } & \rightarrow: \text { Repr } \\
& \text { the seco } \\
& \text { mention }\end{aligned}$ & $\begin{array}{l}\text { sents a shift from the first to the second } \\
d \text { to the first viewpoint; } 1 \text { or } 2 \text { : the firs } \\
d \text { both before as well as after class enact }\end{array}$ & $\begin{array}{l}\text { iewpoint; } \\
\text { (1) or the }\end{array}$ & $\begin{array}{l}\text { epresen } \\
\text { nd (2) }\end{array}$ & $\begin{array}{l}\text { hift from } \\
\text { oint was }\end{array}$ \\
\hline
\end{tabular}

\subsubsection{Summarizing conclusions}

All three teacher-developers modified the module they had developed before or during class enactment to suit personal preferences.

Context-based approach. During the writing phase all three learned how to develop learning material starting from a context in which students explore concepts using multiple activities. Ed said that he had to rediscover the content. Pete and Lisa were after development of the material still anxious about class enactment. In class, all three teacher-developers experienced the potential of the contextbased approach. They assessed the context as motivating. The main problem 
encountered was that students had difficulties getting the concepts clear and not automatically liked up concepts nor connected to previously learned concepts. Each of the teachers made suggestions to improve this aspect.

Pete and Lisa said to need time to get used to the different teacher role they had in class. Ed used his Socratic conversations approach he was familiar with. This shows that building up teaching routines is important.

Each of these teacher-developers changed with respect to two of the four opposing viewpoints (Table 5.4, viewpoints 1 to 4 ). Their views on context or concept changed. After the complete process they agreed on the remaining three, as all consider knowledge of the role of chemistry, skills, and students enjoy learning to be most important.

Cooperative learning. During the writing phase all three teacher-developers acquired knowledge and skills with respect to the why and how of cooperative learning. Group roles, the use of T-cards and of a logbook were discussed and hand in hand materials for class use were developed.

In class, Ed only grouped his students, but did not use the cooperative elements like group roles, a group logbook or T-cards. He therefore did not learn anything regarding cooperative learning. Lisa and Pete did implement cooperative learning in their classes. Both were positive about the use of changing group roles and especially about the use of the logbook. They learned that marking or commenting the logbook stimulated student reflection on what had been done the previous period. Lisa also used the T-cards and was positive about this as it helped her students to acquire and use cooperative skills. Lisa and Pete said that both their students and they themselves had to get used to cooperative learning.

Some viewpoints also changed as can be seen in Table 5.4, viewpoints 5 to 7 . After class enactment there seems to be consensus about the emphasis on students acquire knowledge and on cooperation.

Requirements for context-based learning. During the writing phase the teacherdevelopers experienced that learning material needs to have different kinds of activities for students to explore the context and get the concepts clear. They also experienced that the quality of the material is important. Assignments should be challenging but feasible, and the wording is important. If not, teachers have to spent substantial time explaining the meaning. 
Class enactment revealed that concept learning, and especially connecting concepts, needs explicit attention in the material. Pete calls for the inclusion of concept maps for this. Lisa wants time for a summary and a concept list.

All three teacher-developers agree on the need for practical work. After class enactment they also prefer to have students do own research experiments, in this Pete and Lisa changed of opinion as they experienced that their students are well capable of doing own research experiments (Table 5.4, viewpoints 8 and 9).

\subsection{Discussion}

This study in the context of a curriculum renewal focuses on changes in chemistry teachers' knowledge and beliefs. The research question is: what changes in teachers' PCK occur when teachers are engaged in the development and subsequent class enactment of context-based student learning material, and to what phases within the development process can these changes be attributed? In the next section we will first answer what changes in teachers' PCK occur, and then turn to attribution of changes to the phases of the development process. Finally implications of this study and suggestions for follow-up studies are discussed.

\subsubsection{Changes in teachers' PCK}

Data coding resulted in a change in the description of the teacher's Pedagogical Content Knowledge: three instead of five domains emerged. The three domains in which teacher learning can take place are identified as: knowledge and beliefs on (a) context-based chemistry, (b) cooperative learning, and (c) requirements for context-based learning. These domains do not coincide with the five PCK components from the introduction, illustrating the intertwined and complex nature of teacher learning. The following example demonstrates this. "Knowledge and beliefs on context-based chemistry" is partly situated in the PCK component 'orientations to science teaching', for example when it comes to the purpose for chemistry education. But this is also situated in the 'knowledge and beliefs about the science curriculum' component, for example with respect to teaching for understanding and the activities and materials in meeting the specific goals. 
The results clearly show that all three teacher-developers experience the potential of context-based education, although initially they are skeptical about its feasibility in practice. The module is motivating for the students and they work intensely on the activities and assignments. The teacher-developers also experience that learning concepts starting from a context needs scaffolding. Students do not get the concepts clear automatically. The teacher-developers experience to have different roles in class in context-based chemistry and need to get used to the new role requirements. They are no longer mainly information providers explaining content and pacing instruction, but become facilitators of student groups attending to their learning activities. Teachers also have to link concepts previously learned for example when students think that the gas formed in the dough might be hydrogen the teacher reminds the students on the experiment to verify the presence of hydrogen. Monitoring progress and the cooperation within the groups, and posing questions, for example "why does the dough rise", to assist the learning processes become new tasks teachers have to get used to. After class, their tasks also differ: they no longer have to prepare the lesson content for the next period, but instead go over the group logbooks.

Cooperative learning, new to all three teacher-developers, is used as the instructional strategy by two of them. During the writing phase they learn what cooperative learning entails, develop specific materials for class enactment, like the logbook with student group roles, and discuss how these can be used, and class enactment proves its strength in practice. Class enactment also shows that students working in groups are able to acquire knowledge themselves.

In the domain "requirements for context-based chemistry", the teacherdevelopers experience that the quality of the learning material is important. Both the wording of texts, activities, and assignments, as well as its degree of complexity need attention, if not, students just do not understand these and the teacher has to do a lot of 'translation' in class. How to learn concepts starting from a context also needs special attention, this is a learning result from class enactment. Practical work and especially student groups doing own research projects are also seen as requirements in context-based chemistry.

Summarizing we can say that teachers' PCK does change when they are engaged in the development and class enactment of context-based learning material. These changes were as expected idiosyncratic, which is in line with previous findings (Borko, 2004; Park \& Oliver, 2008; Parke \& Charles, 1997)). 


\subsubsection{Teacher learning for a new curriculum}

Two distinctive phases are distinguished in the development process, the writing phase and the class enactment phase (Figure 5.1). These phases will be elaborated to examine whether changes in teacher PCK can be attributed to one of these phases.

Writing phase. The writing phase constitutes two functions: to produce innovative student learning material, and to prepare teachers for class enactment. The development of learning material will probably support the teachers' change of PCK. Teacher-developers can draw on the following typical sources to nurture their learning: (a) specific literature, for example on cooperative learning and on baking a cake; (b) the expertise of the coach as a chemistry textbook author; (c) experiences from each teacher for the others, and especially class experiences with learning materials; and (d) network meeting discourse about draft materials and how these can contribute to student learning. In both (c) and (d) the reflection-on-action component proves to be powerful. Describing personal class experiences to others can be seen as reflective processes, in which the questions posed catalyze deep reflection (Penuel, et al., 2007). Network meeting discourse can have a similar reflective function, and will also contribute to getting grip on practical aspects of the learning materials. In this last sense teachers become empowered for class enactment.

The second function of the writing phase, preparing teachers for class enactment, will also support the teachers' learning. Preparing for class enactment in a teacher-developer network goes hand in hand with the development of learning material as teachers immediately wonder what the implications will be when enacting a certain activity in class, that is what their role will be and how their students will respond to the activity. A similar pattern occurs when discussing instructional strategies like cooperative learning. Teachers first critically discuss advantages and disadvantages of cooperative learning in relation to their students' learning, then examine their role, and finally develop the materials needed to facilitate these roles. This is both an iterative as well as a cyclic process.

At the end of the writing phase all teachers are happy about the developed module. However, the teacher-developers are still anxious and uncertain about how their students are going to perceive this module.

Class enactment phase. The class enactment phase is especially important to reduce teacher anxiety and uncertainty. Teachers have to experience that their students respond well to the module before they feel confident about it. Class 
enactment is also important to start building routines, both on organizational issues within the classes as with respect to their new roles, a process that takes time as these teachers express.

Practice is different from design and development and teachers do not always enact what was agreed upon and incorporated in the material. For example Pete hardly uses the T-cards to teach cooperative skills, Lisa does not grade the group logbooks, and Ed does not use cooperative learning at all. Ed's position is interesting. He is the most experienced teacher of all three, and has strong beliefs about instruction: he advocates the Socratic way of teaching. His preferences and beliefs make him use the Socratic Method, and because he believes that this method interferes with cooperative learning he does not use the latter. These examples illustrate the idiosyncratic position toward class implementation.

The entire process. Using teachers' initial knowledge, beliefs and practices as a starting point is a strong aspect of the teacher-as-developer concept. Advantages of this concept can also be seen at curriculum level. The development process, as organized in this study (Figure 5.1), ensures that the dilution between the ideal curriculum as indicated in the documents at National level, the written curriculum developed by the network, and the operational curriculum as enacted in class, will be minimal (Goodlad, 1979; Van den Akker, 1998).

\subsubsection{Implications}

The results of this study clearly show that developing learning material, its class enactment and the way students react, are instrumental for teacher learning. This implies that if we want to prepare teachers for a curriculum change affecting class room practices, a preparation program should have the following characteristics. Let three or four teachers under the guidance of a coach, develop learning material on a topic for their own students. The coach should be an experienced teacher, preferably with expertise on the domain of developing learning material. Start the process by discussing the main characteristics of the renewal. The ideal curriculum should be clear to all. It is necessary to discuss specific content to be included in the material. One way of starting this is by using the Content Representation (CoRe) tool (Loughran, et al., 2004) to identify important features of the content from the perspective of the teachers. Special attention should be given to the design of the development 
process as this determines the degree of innovativeness of the material. Time to allow for multiple cycles of discussion is essential, not just for the incorporation of renewal elements in the material, but also to prepare well for class use.

Letting teachers develop learning material is on the one hand a time-consuming and particularly costly way to professionalize teachers, leading on the other hand to endurable changes in the pedagogical content knowledge of the teachers involved. It would be interesting to examine if and what changes in teachers' PCK occur, when teachers not involved in this development process, would enact this material in their classes.

\subsection{APPENDIX}

Questionnaire A1

1. What roles do you see for yourself as teacher using such a module, and what activities will you carry out?

2. What roles do you see for your students? What do you want your students to do?

3. How would you like to evaluate the learning results?

4. Do you already have possible contexts in mind?

5. What do you consider most important with respect to the following opposing viewpoints:

a. Context or concept

b. Knowledge or skills

c. Concept learning or students enjoy learning

d. Knowledge of the role of chemistry or subject chemistry knowledge

e. Practical from a recipe or open research experiments

f. (learn to) cooperate or independent work

g. Teacher or material present knowledge or students acquire knowledge

h. Offer identical content to all students or students choose their own subject matter

i. Experiments or practical work or paper assignments

Interview guide A2

1. How do you see your own role in a new chemistry curriculum? What are your tasks?

2. How do you see the role of your students in this?

3. What can you say about the content of chemistry education:

- What is the relation between context and concept?

- What kind of teaching methodology do you consider appropriate?

4. Did you previously develop teacher guides?

5. Did you use innovative materials developed by others? 
Interview guide B

1. What do you hope the module will bring:

- For yourself?

- For your students?

2. What do you consider your role in this?

3. What are for you the strong aspects of the module?

4. What do you consider difficult, of critical aspect of the module?

5. Why do you consider this module innovative?

6. Did you learn yourself something during the writing phase about:

- Pedagogy?

- Tips to be used in class?

- Chemistry content?

7. Are you going to use cooperative learning, including logbook and student roles?

Interview guide $\mathrm{C}$

1. What was your reason to participate in the development of the module?

2. In what classes did you use the module?

3. How many periods did you use?

4. Did you make any changes in the module beforehand?

5. How did the students respond to the module?

6. What is your opinion about the module? Would you use it again next year?

7. What do you consider now to be innovative in the module?

8. Cooperative learning:

- How were the groups formed?

- Did you use the logbook?

- Did you use roles for group members?

- Would you do the above aspect again a next time?

9. How were the learning results, also compared to previous chapters and topics?

10. What do you consider most important with respect to the following opposing viewpoints:

a. Context or concept

b. Knowledge or skills

c. Concept learning or students enjoy learning

d. Knowledge of the role of chemistry or subject chemistry knowledge

e. Practical from a recipe or open research experiments

f. (learn to) cooperate or independent work

g. Teacher or material present knowledge or students acquire knowledge

h. Offer identical content to all students or students choose their own subject matter

i. Experiments or practical work or paper assignments

11. How do you see the context-concept approach now?

12. Anything you would like to add? 


\section{CHAPTER 6 \\ The effect of class enactment of innovative chemistry learning materials on teachers' Pedagogical Content Knowledge ${ }^{5}$}

Curricular innovations require teachers to bring their Pedagogical Content Knowledge (PCK) in line with the reform demands. This paper describes the PCK changes of five chemistry teachers when they class enact multi-faceted innovative learning material, developed by colleague teachers. Three conclusions demonstrating the idiosyncratic nature of teacher learning materialized: (a) Teachers adapt materials, and consequently do not experience how students would react to the original innovative material; (b) teachers skip activities they personally consider insignificant, even though explicitly incorporated in the material; (c) students' perception of learning activities impacts on a teacher' belief system. Theoretical and policy implications are discussed.

\subsection{INTRODUCTION}

It is widely acknowledged that teachers play a crucial role in the implementation of a curricular reform as they are the ones to take the new curriculum to their students (Fullan, 1998; A. T. Lumpe, 2007). As teachers' knowledge, beliefs and experiences greatly impact classroom practices, teacher preparation for a new curriculum is seen as a learning process (Pintó, 2005). Teachers have to understand the new curriculum, adopt the new goals and objectives, and familiarize themselves with the new student learning material, the instructional strategies for class use, and the evaluation methods to

5 This chapter has been submitted: Coenders, F., Terlouw, C., Dijkstra, S., \& Pieters, J. (2010). The effect of class enactment of innovative chemistry learning materials on teachers' Pedagogical Content Knowledge. 
determine the learning outcomes (Guskey, 2000). Teachers' professional growth is a complex process having an idiosyncratic (Clarke \& Hollingsworth, 2002) and a situational nature (Borko, 2004). Further complicating factors are that teachers' educational beliefs act like a filter through which new knowledge is interpreted and integrated (Pajares, 1992), and that emotions are involved especially when a reform affects classroom practice (Kelchtermans, 2005; Schmidt \& Datnow, 2005).

Different intervention programs and materials to prepare teachers for a new curriculum have been reported in literature. One group of researchers let teachers experience for themselves the science learning into which they want to engage their students (Jeanpierre, et al., 2005; Loucks-Horsley, et al., 1998). Others used curriculum materials to support teacher learning (Ball \& Cohen, 1996; E. A. Davis \& Krajcik, 2005; Schneider, Krajcik, \& Blumenfeld, 2005; Van den Akker, 1998). In another approach, teachers were actively involved in the change process through participation in the development or redevelopment of curriculum materials (George \& Lubben, 2002; W. Penuel, et al., 2008; Tal, Dori, Keiny, \& Zoller, 2001). All these intervention programs where designed to let teachers acquire knowledge and skills useful for their classroom practice, and all were partly successful.

We conceptualize teacher preparation for a curriculum renewal as a learning process in which teachers have to be actively involved (Garet, Porter, Desimone, Birman, \& Yoon, 2001; Penuel, et al., 2007). In a previous study (Author, 2009a; 2009b) we reported on a teacher preparation program for a curriculum innovation, in which teachers in a small network, under the guidance of a coach, developed student learning material and subsequently enacted this in class. Although powerful in terms of teacher learning, there was one major limitation: the development of the learning material turned out to be time consuming, and therefore costly. The question arising is: does a similar kind of teacher learning occur when teachers, who are not involved in the development of the material, use it in their classes? To answer this question, the learning material plus a teachers' guide produced by the small network was introduced to other teachers who volunteered to use it in their classes. This study is about how these teachers' knowledge and beliefs with respect to context-based chemistry developed through class enactment. First the context of the study will be portrayed. 


\subsubsection{The context of this study}

In 2002, a high school chemistry curriculum renewal was initiated in the Netherlands (Van Koten, et al., 2002). Three important characteristics for this new curriculum were formulated (Driessen \& Meinema, 2003): (a) chemistry had to be meaningful for all students, not just those who pursue a career in chemistry; (b) societal challenges and contemporary chemistry should be incorporated; and (c) a context-based approach was adopted, in which students acquire concepts and the relations between them starting from an appealing context (Gilbert, 2006; Parchmann, et al., 2006). Active student engagement through the use of meaningful activities, group work, and cooperative learning was seen as another important characteristic of this new curriculum. In order to facilitate preparation and implementation, teacher networks were set up in which two to three teachers under the guidance of a coach developed student learning materials in the form of modules. A module consisted of all texts, assignments, practical activities, exercises and other learning activities, based on the context-based approach, for approximately 8-10 periods. The National Steering Committee requested teachers interested in the actual development process to register, but also teachers only interested in class enactment of innovative modules for this context-based chemistry curriculum were invited.

In this study five teachers participated who were only interested in class enactment of one of the two modules developed by one specific teacher network. The two modules differed in both context and concepts and were suitable for the end of the school year of Form 3, the first year secondary education students take chemistry in the Netherlands. Both modules were innovative by the use of the context-based approach and of cooperative learning. In each teachers' guide the objectives and some guidelines for effective use of four cooperative learning elements were addressed. The concepts addressed in the modules were wellknown to the teachers who enacted the module, and teachers do not need to acquire new concepts but have to engage students in a different learning process. Therefore, teacher learning during enactment will be situated in the Pedagogical Content Knowledge (PCK) domain.

\subsubsection{Pedagogical Content Knowledge}

In their daily work teachers integratively draw on their content knowledge, knowledge of pedagogy and knowledge about the context (Barnett \& Hodson, 2001; Veal, 2004). The resulting amalgam is called Pedagogical Content 
Knowledge (PCK) and was first described by Shulman (1987). PCK is considered as a dynamic entity, shaped in practice, and under constant revision (Abell, 2008; De Jong, Van Driel, \& Verloop, 2005). A number of researchers have since elaborated on PCK (Berry, et al., 2008; Grossman, 1990). It is considered to be topic specific, but certainly also contains elements relevant for teaching different topics. In this sense it is supposed to be subject specific (E. A. Davis \& Krajcik, 2005; Friedrichsen, et al., 2009).

Building on previous work (Magnusson, et al., 1999), we distinguish five PCK components for this study, which were interpreted for context-based education:

1. Orientations toward science teaching, comprising knowledge and beliefs about the purposes and goals for teaching science at a particular level, and therefore guiding instructional decisions about teaching science. In contextbased education the use of the context and the role of chemistry in society will be important.

2. Knowledge and beliefs about the science curriculum, encompassing specific goals and objectives, plus activities and materials to be used in meeting these. Not just the goals of context-based chemistry, but also the materials might differ substantially from goals and materials from 'traditional' education.

3. Knowledge and beliefs about instructional strategies for teaching, in which subject and topic specific strategies of instruction are located. In contextbased education, cooperative learning is often used, an approach requiring specific materials.

4. Knowledge and beliefs about students' understanding of science topics, comprising requirements for learning specific topics and areas that the students find difficult. In context-based education the concepts are familiar to the teachers, but the way these are instructed will be different.

5. Knowledge and beliefs about assessment in science, consisting of the dimensions important to assess and the suitable methods for this. Other assessment methods might be more suitable to assess student learning in context-based chemistry than the ones used in 'traditional' education.

PCK is developed and shaped in school practices through active processing and the integration of its contributing components (Berry, et al., 2008; Rollnick, Bennett, Rhemtula, Dharsey, \& Ndlovu, 2008), and through reflection-on-action and reflection-in-action (Bindernagel \& Eilks, 2009; Park \& Oliver, 2008). An expert teacher has well developed PCK for all topics taught within a specific curriculum and context (Abell, 2008; Henze, et al., 2008). However, in times of a curricular reform, teachers need to align their PCK with the reform demands. It 
is supposed that teachers develop their PCK when they enact innovative learning material in class. Is class enactment of innovative materials sufficient to bring this change about?

The aim of this study was to assess the changes of teachers' PCK after class enactment of the module without their involvement in the design and development of the module. The research question was: what changes in teachers' PCK take place when they class enact innovative learning material developed by teachers in a network.

\subsection{MeTHOD}

\subsubsection{Participants}

Five teachers enacted the module and were willing to participate in this study. The following names will be used to identify them: Ann, Art, Iris, Hank, and Gene. Four of these five were experienced teachers with more than five years of chemistry teaching experience. One teacher, Art, only had two years experience. Four of the five teachers held a masters degree in chemistry plus a teaching qualification, the remaining teacher, Hank, had completed a four-year professional teacher-training program. Art and Hank were employed at the same school. They used the material in their own class. All others taught at different schools. One teacher, Ann, used the module without the role-plays; the other four used the module with the role-plays.

\subsubsection{Learning material}

The five teachers could select one of the following two modules. In 'Baking a cake' the concepts addressed were for example: what is a chemical reaction and how can one determine whether a (baking) process is a chemical reaction, the law of conservation of matter, and the use of process charts both on paper and by using a computer program. In the other module, "Paint", ions and the ionic bond was introduced. This last module also incorporated two role plays, one to visualize filtration and another to picture a chemical reaction. In both modules the following cooperative learning elements were advocated: (a) the use of a group logbook, to keep track of all learning outcomes plus specific information regarding the cooperation within the group; (b) the use of T-cards to discuss 
effective cooperative skills in class. One T-card addresses one specific cooperative skill on a practical level (Ebbens, et al., 1996); (c) the rotation of student roles within a group; and (d) possible ways to compose the cooperative groups.

\subsubsection{Procedure and instruments}

To prepare these five teachers for class enactment, the network teachers who had developed the modules, conducted a half-day workshop. First the rationale and goals of the modules were briefly introduced and specific features of each module discussed, and then the teachers' guide was explained. Class experiences the network teachers had with the modules, and practical aspects regarding class use, were also part of the workshop program. With respect to cooperative learning, experiences with different grouping strategies were discussed as well as why student roles within a group are important and why these should rotate. The need to discuss cooperative skills with the students, and the use of the resulting T-cards as resources to which a teacher can refer to when the group experiences problems cooperating, were also addressed. And finally different ways of logbook use were explained, both in relation to correcting mistakes on assignments and exercises, as well as regarding student learning processes and cooperation within the group.

To capture teachers' PCK, semi-structured interviews were held, one before and one after class use, both after the introductory workshop. Nine open questions were posed in the interviews before class use. The interview after class enactment consisted of fifteen questions including factual questions related to class use. The questions are shown in the appendix (6.5). One opposing viewpoints question was used in both interviews (questions 9 and 22) and was of the "forced choice" response type because we wanted teachers to weigh the two viewpoints and then select the one they considered most important. The results of this question were used to supplement and validate the interview findings. All interviews were conducted at the school of the interviewed, and lasted between 40 and 80 minutes.

\subsubsection{Design and analysis}

As the purpose of this study was to investigate the PCK changes of individual teachers within their real-life context, a descriptive multiple case study design (Yin, 2003) was used. First, we considered each teacher as an individual case, 
and portrayed for each one the changes in the different PCK components. From these individual reports, cross-case conclusions were drawn and these were used to develop policy and theoretical implications in relation to teacher learning for a curriculum renewal (Yin, 2003).

All recorded interviews were transcribed verbatim. Open coding (Gibbs, 2007, p. 50) using a computer program to analyze qualitative data, atlas.ti (www.atlasti.com), resulted in passages that exemplified thematic ideas related to the five PCK components. After all transcripts had been coded, the data showed that redefining the domains would make it easier to understand changes in teacher PCK. This process of axial coding resulted in three domains used to report the results: (a) knowledge and beliefs on context-based education, (b) knowledge and beliefs on cooperative learning, and (c) knowledge and beliefs on assessment of science learning. The coded passages were transferred to word tables. In order to answer our research question it was important to know what adaptations, if any, each teacher had made in the module before class enactment and this was added as an additional category. To report on the 'forced choice' type of questions, the idea of a conceptually ordered matrix was used (Miles \& Huberman, 1994, p. 183). The results of this matrix (Table 6.6) were used to validate the findings reported in the word tables.

After capturing the elements described above, the main results from the individual teachers were summarized in order to facilitate comparison and to find cross-case patterns.

To determine the reliability, a research assistant previously not involved in this study checked for each of the coded passages whether it could be located in the interview transcripts. This resulted in $99 \%$ agreement. The validity of the classification of the coded passages in the different domains was verified by the same research assistant. Disagreements were discussed and finally agreed upon.

\subsection{Results}

The results will be reported for each teacher separately in Tables 6.1 through 6.5 . Adaptations and additions each teacher made to the module before class enactment are firstly indicated. Next, the presence or absence of changes in the PCK is described. The 'forced choice' questions are combined in one matrix for all teachers in Table 6.6. In the separate reports we will refer to Table 6.6 for validating or supplementing purposes. Finally, findings of all teachers are summarized. 


\subsubsection{Ann}

Ann did make adaptations to the learning material before class enactment. She inserted two demonstration experiments, converted one open research experiment into a recipe type of experiment, and developed questions students could use at the end to reflect on the module. She made the module less open as she anticipated that her students would not be able to cope with the open assignments, especially because there was some time pressure.

Ann's PCK before and after class enactment is shown in Table 6.1.

Before class use, Ann was not convinced that the context-based approach would work out well, as she said: "the intention is that students start off with a context. Once students become interested in the topic, the relevant concepts will be introduced gradually. I am very curious how this will work out." With respect to evaluation she said to have mixed feelings. On the one hand she wanted evaluation instruments that could be used more or less objectively, like a paper and pencil test. On the other hand she also liked the idea of using presentations, course work and posters, but was unsettled that grading these products in a fair and consistent manner would be difficult.

\section{Table 6.1 Ann's PCK}

\begin{tabular}{|c|c|c|}
\hline $\begin{array}{l}\text { Knowledge } \\
\text { and beliefs on }\end{array}$ & Before class enactment & After class enactment \\
\hline $\begin{array}{l}\text { Context-based } \\
\text { chemistry }\end{array}$ & $\begin{array}{l}\text { - Attention for relation of chemistry } \\
\text { with students' life. } \\
\text { - Different contexts can be used to } \\
\text { address certain concepts. }\end{array}$ & $\begin{array}{l}\text { - Students do not consider "baking } \\
\text { a cake" as chemistry. } \\
\text { - My views on context-based } \\
\text { chemistry have not changed. }\end{array}$ \\
\hline $\begin{array}{l}\text { Co } \\
\text { lea }\end{array}$ & $\begin{array}{l}\text { I have no experience with } \\
\text { cooperative learning. } \\
\text { - Used groups of two students, } \\
\text { never larger groups. } \\
\text { - My role is supervisor and coach } \\
\text { and less content expert. } \\
\text { - I have to explain things now and } \\
\text { then but let students work } \\
\text { themselves as much as possible. }\end{array}$ & $\begin{array}{l}\text { - } \text { Cooperative learning worked well. } \\
\text { students. } \\
\text { - I did not use T-cards to teach } \\
\text { cooperative skills. } \\
\text { - Students having different roles } \\
\text { and changing these roles each } \\
\text { period worked out well. } \\
\text { - Students loved to cooperate but } \\
\text { hated completing the logbook. }\end{array}$ \\
\hline $\begin{array}{l}\text { Assessment of } \\
\text { science } \\
\text { learning }\end{array}$ & $\begin{array}{l}\text { I like presentation, course work } \\
\text { and poster. } \\
\text { - Students' learning results need to } \\
\text { be graded. }\end{array}$ & $\begin{array}{l}\text { I had never used a poster session } \\
\text { in class. } \\
\text { - I graded the answers in the } \\
\text { logbook. }\end{array}$ \\
\hline
\end{tabular}




\section{Changes in Ann's PCK}

Ann was surprised that her students did not consider "baking a cake" as chemistry. She finds linking daily life with chemistry important, and experienced that this does not happen in her traditional teaching approach. Ann noticed that her students had difficulties getting the concepts clear from the context and she thinks that students should acquire the necessary skills (see also Table 6.6, viewpoint 3). Even though she had made the module less open before class use, this was apparently not enough as after class she is in favour of recipe type of experiments instead of open research type and she wants to attribute a larger role to the teacher with respect to knowledge presentation (see also Table 6.6, viewpoint 6).

With respect to cooperative learning Ann learned how to form larger groups, in which group members had roles that rotated, and used a logbook. She experienced that marking the logbook after each period positively contributed to the students' learning processes. But she also learned that the teacher still has a role in presenting the knowledge (see also Table 6.6, viewpoints 7,8 and 9).

Ann learned to use poster sessions for assessment (see also Table 6.6, viewpoint 10) and experienced the potential of grading the logbook.

\subsubsection{Art}

A colleague of Art, Hank, also participated in this research. They adapted the materials in consultation: they included homework, made a sourcebook, formulated questions, and selected some texts. They prepared T-cards to teach cooperative skills and modified the logbook to their needs.

Art's PCK before and after class enactment is shown in Table 6.2.

Before class enactment Art was, as he said “..... lightly sceptical. It would be nice if it worked out well, but I wonder. I am afraid that when one takes a context, this context will have its boundaries, and that a concept will encompass more than the context." 
Table 6.2 Art's PCK

\begin{tabular}{|c|c|c|}
\hline $\begin{array}{l}\text { Knowledge } \\
\text { and beliefs on }\end{array}$ & Before class enactment & After class enactment \\
\hline $\begin{array}{l}\text { Context- } \\
\text { based } \\
\text { chemistry }\end{array}$ & $\begin{array}{l}\text { I am sceptical about starting off } \\
\text { with a context. A context has its } \\
\text { limits and a concept might not fit. } \\
\text { - Acquiring knowledge of chemistry } \\
\text { at high school is important. }\end{array}$ & $\begin{array}{l}\text { I am still sceptical about context- } \\
\text { based: do students get to the } \\
\text { concepts? Going from a concept to } \\
\text { a context is easier. } \\
\text { - My views on context-based have } \\
\text { hardly changed. }\end{array}$ \\
\hline $\begin{array}{l}\text { Cooperative } \\
\text { learning }\end{array}$ & $\begin{array}{l}\text { - Put students to work, and let them } \\
\text { answer questions. } \\
\text { - I see my role as coach, not as } \\
\text { instructor. }\end{array}$ & $\begin{array}{l}\text { - Cooperative learning was new to } \\
\text { me and the experience was } \\
\text { positive. } \\
\text { - Students used existing groups. } \\
\text { - Teachers prepared T-cards but we } \\
\text { did not discuss these with } \\
\text { students. } \\
\text { - Students used a logbook including } \\
\text { changing roles. } \\
\text { - I read the logbooks after each } \\
\text { period but did not mark nor grade } \\
\text { them. } \\
\text { - I did not use the role-play; I } \\
\text { considered one a bit childish. }\end{array}$ \\
\hline $\begin{array}{l}\text { Assessment of } \\
\text { science } \\
\text { learning }\end{array}$ & $\begin{array}{l}\text { Evaluation will not differ from } \\
\text { what we do now: written tests and } \\
\text { reports of experiments. }\end{array}$ & $\begin{array}{l}\text { I did not evaluate learning result } \\
\text { because of time constraints. } \\
\text { - Do students get the concepts clear? }\end{array}$ \\
\hline
\end{tabular}

\section{Changes in Art's PCK}

Little changes in PCK occurred during enactment (see also Table 6.6, viewpoints 2,3, and 6): he acknowledges the need to teach the role of chemistry and not just chemistry content, moves towards skills acquisition and not just knowledge, and wants practical work less open.

With respect to cooperative learning Art did not learn much as he hardly used elements unfamiliar to him. He sees a larger role for himself as presenter of knowledge (see also Table 6.6, viewpoint 7).

No learning on assessment occurred as Art did not evaluate any learning results.

\subsubsection{Iris}

Iris did not make adaptations in advance; she adopted the module as such. But she realized that taking the module to class would not be easy as she said: "you need to get it in your fingers". 
Initially Iris said to be "suspicious towards this chemistry education renewal" and said: "so I thought, let me join the tryout of the learning material and see how I will look at it afterwards".

Iris's PCK before and after class enactment is shown in Table 6.3.

Before class enactment Iris expressed her goals for chemistry education being: "I would say geared towards further education. This can be divers and I think it should be broad, for example prepare students well for studies like physiotherapy and medicine". She had not used cooperative learning before, but working in smaller groups was common. She said: "I love group work as such but I also love to explain things when the groups cannot resolve something". A bit further she said: "I would love to emphasise group work, but sometimes things do not become sufficiently clear for students and I have to explain in plenary class".

Table 6.3 Iris's PCK

\begin{tabular}{|c|c|c|}
\hline $\begin{array}{l}\text { Knowledge } \\
\text { and beliefs on }\end{array}$ & Before class enactment & After class enactment \\
\hline $\begin{array}{l}\text { Context-based } \\
\text { chemistry }\end{array}$ & $\begin{array}{l}\text { - Chemistry teaching needs to } \\
\text { prepare for further education. } \\
\text { - Also on scientific literacy, but that } \\
\text { is for me in second place. }\end{array}$ & $\begin{array}{l}\text { I am still not convinced about } \\
\text { context-based approach. }\end{array}$ \\
\hline $\begin{array}{l}\text { Cooperative } \\
\text { learning }\end{array}$ & $\begin{array}{l}\text { I love students cooperating, but I } \\
\text { often have to explain things in } \\
\text { plenary class. } \\
\text { - My role is more coaching, assist } \\
\text { students to get to an answer. Also } \\
\text { coaching to acquire study skills. } \\
\text { - There is a shift from a content } \\
\text { expert role towards coaching. } \\
\text { - Students need to be active } \\
\text { learners. }\end{array}$ & $\begin{array}{l}\text { Cooperative learning in } \\
\text { combination with open questions } \\
\text { was new to me. } \\
\text { - I used cooperative learning. } \\
\text { Wanted balanced and equally } \\
\text { strong groups, so I personally } \\
\text { formed groups of } 5 \text {. } \\
\text { - Did not use T-cards, did use } \\
\text { student roles and the logbook. } \\
\text { - I browsed regularly through the } \\
\text { logbooks but not systematically. } \\
\text { - Students did the first role-play, } \\
\text { found it a bit childish. Skipped the } \\
\text { second. }\end{array}$ \\
\hline $\begin{array}{l}\text { Assessment of } \\
\text { science } \\
\text { learning }\end{array}$ & . & $\begin{array}{l}\text { I used a "normal" written test for } \\
\text { evaluation. Results were as } \\
\text { expected and in line with previous } \\
\text { results. }\end{array}$ \\
\hline
\end{tabular}




\section{Changes in Iris's PCK}

Class enactment slightly changed her PCK in the area of cooperative learning, and also towards concept learning and experiments (see also Table 6.6, viewpoints 4,5 and 8 ).

\subsubsection{Hank}

Hank adapted the materials in consultation with Art: they included homework, made a sourcebook, formulated questions and selected some texts. They prepared T-cards to teach cooperative skills and modified the logbook to their needs.

Hank's doubts about the context-based renewal are clearly demonstrated by his reason to participate, as he said: "Chemistry is going to change and we wanted to look as a school what this change is, so we can better join in and be in the frontline than to say afterwards.....".

Hank's PCK before and after class enactment is shown in Table 6.4.

\section{Table 6.4 Hank's PCK}

\begin{tabular}{|c|c|c|}
\hline $\begin{array}{l}\text { Knowledge } \\
\text { and beliefs on }\end{array}$ & Before class enactment & After class enactment \\
\hline $\begin{array}{l}\text { Context-based } \\
\text { chemistry }\end{array}$ & $\begin{array}{l}\text { - Goal is to determine whether or } \\
\text { not students have the ability to } \\
\text { pursue a chemistry related study. } \\
\text { - Let students become enthusiastic } \\
\text { for chemistry. } \\
\text { - Students should learn some basic } \\
\text { concepts, and get some historic } \\
\text { notion about the development of } \\
\text { chemistry }\end{array}$ & $\begin{array}{l}\text { I had the impression that in this } \\
\text { module the designers had started } \\
\text { from the concept and worked } \\
\text { towards a context. }\end{array}$ \\
\hline $\begin{array}{l}\text { Cooperative } \\
\text { learning }\end{array}$ & $\begin{array}{l}\text { - Students have worked in } \\
\text { cooperative groups before, } \\
\text { including logbook and group } \\
\text { roles. } \\
\text { - I want to use group work, groups } \\
\text { of } 3-4 \text { students. } \\
\text { - Students need to be active, plan } \\
\text { activities, do assignments. }\end{array}$ & $\begin{array}{l}\text { - Cooperative learning was new to } \\
\text { me, was positive. } \\
\text { - Students formed groups of five, but } \\
\text { my preference is smaller groups. } \\
\text { - We prepared T-cards but did not } \\
\text { discuss these with students. } \\
\text { - I commented in the logbooks after } \\
\text { each period, and indicated how to } \\
\text { proceed next period. } \\
\text { - I did not grade the logbooks. } \\
\text { - One group did the role play, were } \\
\text { very playful! }\end{array}$ \\
\hline $\begin{array}{l}\text { Assessment of } \\
\text { science } \\
\text { learning }\end{array}$ & $\begin{array}{l}\text { A variety of evaluation } \\
\text { instruments can be used. }\end{array}$ & $\begin{array}{l}\text { We did not evaluate learning } \\
\text { results of this module. }\end{array}$ \\
\hline
\end{tabular}




\section{Changes in Hanks' PCK}

Related to context-based chemistry Hank did not learn much, just that it is also important to teach skills and not just knowledge (see also Table 6.6, viewpoint 3). Cooperative learning was new to him, and he learned how to let students use group roles and experienced the use of a group logbook as he went over these after each period.

He did not evaluate the learning results and did not gain new knowledge and beliefs with respect to assessment.

Art and Hank were teaching at the same school and made the adaptations to the material in cooperation. There was no consultation during teaching and therefore each enacted the module in a personal manner.

\subsubsection{Gene}

Before class use a number of adaptations were made in the material, and texts and questions were added.

The main reason for Gene to participate was that "Society and students change, and I find it important to continuously develop myself". Gene also had his doubt with the context-based approach as he said: "How much overlap is going to occur? Can we still cover the same number of concepts in the same time?"

Gene's PCK before and after class enactment is shown in Table 6.5. 


\begin{tabular}{|c|c|c|}
\hline $\begin{array}{l}\text { Knowledge } \\
\text { and beliefs on }\end{array}$ & Before class enactment & After class enactment \\
\hline $\begin{array}{l}\text { Context-based } \\
\text { chemistry }\end{array}$ & $\begin{array}{l}\text { Learning from a context is more } \\
\text { motivating but I am afraid that it } \\
\text { takes extra time. } \\
\text { - I used to teach concepts and then } \\
\text { mention a context demonstrating } \\
\text { the concept. } \\
\text { Most important goal in education } \\
\text { is to learn to be critical. It includes } \\
\text { chemical processes around us. }\end{array}$ & $\begin{array}{l}\text { We did less chemistry concepts } \\
\text { but I can live with it as I wonder } \\
\text { on what arguments chemical high } \\
\text { school content is based? } \\
\text { - Students have less knowledge but } \\
\text { are able to apply better what they } \\
\text { have learned. } \\
\text { - How do the students get the } \\
\text { concepts clear? Can they do this or } \\
\text { is this a teacher task? }\end{array}$ \\
\hline & $\begin{array}{l}\text { - Students in my classes are not } \\
\text { used to working in groups. } \\
\text { - My experiences with group work } \\
\text { are negative; there are always } \\
\text { students who hardly participate. } \\
\text { - In chemistry self-directed learning } \\
\text { might be a bit complicated } \\
\text { because of the practical work. } \\
\text { - I am more a content expert, an } \\
\text { instructor, not so much of a coach. } \\
\text { - Practical activities have to be } \\
\text { included, but should be } \\
\text { manageable. Learning by doing. }\end{array}$ & $\begin{array}{l}\text { - Cooperative learning was new to } \\
\text { me. It required a new role from } \\
\text { me, and this was difficult. } \\
\text { - I formed the mixed gender groups } \\
\text { myself. } \\
\text { - Students used the roles, but did } \\
\text { not understand what for. } \\
\text { - Used the T-cards, they were put } \\
\text { up on the wall. } \\
\text { - Used the logbook but I did not } \\
\text { comment in them. Next time I will } \\
\text { certainly do this, it is a } \\
\text { requirement for success. } \\
\text { - Students did the second role-play } \\
\text { and it put students on the right } \\
\text { track. }\end{array}$ \\
\hline $\begin{array}{l}\text { Assessment of } \\
\text { science } \\
\text { learning }\end{array}$ & $\begin{array}{l}\text { A kind of a practical test to assess } \\
\text { students' skills. This is difficult to } \\
\text { realize because of the number of } \\
\text { students. }\end{array}$ & $\begin{array}{l}\text { We did not evaluate the learning } \\
\text { results because of time constraints. }\end{array}$ \\
\hline
\end{tabular}

\section{Changes in Gene's PCK}

Gene learned that skills and concept learning are important (see also Table 6.6, viewpoint 3 and 4), and that context-based chemistry leads to different learning as students covered fewer concepts but understood these concepts better than in the traditional classes.

He also learned how to form mixed cooperative learning groups, and introduced the logbook. He does however not understand why different roles were assigned to group members and was not able to explain this to his students. 
No evaluation took place and therefore no new knowledge regarding assessment was gained.

Opposing viewpoints questions. In Table 6.6 all five teachers' responses on the viewpoints questions before and after class enactment are shown. A number 1 or 2 in the table means that a teacher both before as well as after class use had a preference for the first (1) or the second (2) viewpoint. The notation "Yes plus arrow" signifies a shift in viewpoint; the arrow indicates the direction of the change.

Table 6.6 Teachers' responses to the opposing viewpoints questions

\begin{tabular}{|c|c|c|c|c|c|c|}
\hline \multirow[b]{2}{*}{ Domains } & \multirow[b]{2}{*}{ Opposing viewpoints } & \multicolumn{5}{|c|}{ Changed after class enactment? } \\
\hline & & Ann & Art & Iris & Hank & Gene \\
\hline \multirow{6}{*}{$\begin{array}{l}\text { Context- } \\
\text { based } \\
\text { chemistry }\end{array}$} & 1. Context or concept. & 1 & 2 & 2 & 1 & 2 \\
\hline & $\begin{array}{l}\text { 2. Knowledge of the role of } \\
\text { chemistry or subject } \\
\text { (chemistry) knowledge. }\end{array}$ & 1 & Yes $\leftarrow$ & 2 & 1 & 1 \\
\hline & 3. Knowledge or skills. & Yes $\rightarrow$ & Yes $\rightarrow$ & 1 & Yes $\rightarrow$ & Yes $\rightarrow$ \\
\hline & $\begin{array}{l}\text { 4. Concept learning or } \\
\text { students enjoy learning. }\end{array}$ & 2 & 2 & Yes $\leftarrow$ & 2 & Yes $\leftarrow$ \\
\hline & $\begin{array}{l}\text { 5. Experiments/ practical } \\
\text { work or paper assignments. }\end{array}$ & 1 & 1 & Yes $\leftarrow$ & 1 & 1 \\
\hline & $\begin{array}{l}\text { 6. Practical from a recipe or } \\
\text { open research experiments. }\end{array}$ & Yes $\leftarrow$ & Yes $\leftarrow$ & 2 & 2 & 2 \\
\hline \multirow[t]{3}{*}{$\begin{array}{l}\text { Cooperative } \\
\text { learning }\end{array}$} & $\begin{array}{l}\text { 7. Teacher presents } \\
\text { knowledge or students } \\
\text { acquire knowledge. }\end{array}$ & Yes $\leftarrow$ & Yes $\leftarrow$ & 2 & 2 & 2 \\
\hline & $\begin{array}{l}\text { 8. (Learn to) cooperate or } \\
\text { independent work. }\end{array}$ & Yes $\leftarrow$ & 2 & Yes $\leftarrow$ & 1 & 1 \\
\hline & $\begin{array}{l}\text { 9. Offer identical content to } \\
\text { all students or students } \\
\text { partly choose their own } \\
\text { subject matter. }\end{array}$ & Yes $\leftarrow$ & 1 & 2 & 1 & Yes $\leftarrow$ \\
\hline \multirow[t]{2}{*}{ Assessment } & $\begin{array}{l}\text { 10. Paper and pencil test or } \\
\text { poster presentation. }\end{array}$ & Yes $\rightarrow$ & 1 & 1 & 1 & 1 \\
\hline & $\begin{array}{l}\text { 11. Written report for own } \\
\text { research project or oral } \\
\text { presentation. }\end{array}$ & Yes $\leftarrow$ & 1 & 1 & 1 & 1 \\
\hline
\end{tabular}

Note: $\rightarrow$ : Represents a shift from the first to the second viewpoint; $\leftarrow:$ Represents a shift from the second to the first viewpoint; 1 or 2: the first (1) or the second (2) viewpoint was mentioned both before as well as after class enactment. 
The results from this Table 6.6 will be used in the summary of the results below.

\subsubsection{Summary of the results}

Except for Iris, all teachers make adaptations or additions to the material before class enactment. These teachers did not implement the material the way it was envisaged by the developers.

In the following section teachers' PCK development for the three areas explored in this study are summarized.

Context-based approach. Of these five teachers, two did not learn anything related to context-based chemistry. Three teachers experienced their students having difficulties getting the concepts clear and assess skills development therefore important. Gene noticed that the context-based approach leads to fewer concepts though resulting in better understanding. This picture of minor changes in teacher PCK is confirmed by the opposing viewpoints questions: 10 out of 30 show a shift (Table 6.6, viewpoints 1 to 6). After enactment a vast majority of these teachers has the opinion that knowledge of the role of chemistry, skills acquisition, and experiments are most important.

Cooperative learning. Each of these five teachers used cooperative learning to some extent, and this evidently leads to different learning experiences for them. The main findings have been summarised in Table 6.7. In this table, "teacher formed" means that the teacher was in control of grouping students. Ann did this randomly, Iris combined students with different abilities into balanced groups, and Gene formed mixed groups based on gender.

As can be seen in Table 6.7, each of these teachers used a personal mix of these five components, and therefore each of them learned different aspects, a finding confirmed by the results in Table 6.6. This table also shows that after enactment four of these five teachers have a preference for cooperating students and for offering identical content to all students. 
Table 6.7 Overview of cooperative learning strategies used by each teacher

\begin{tabular}{|c|c|c|c|c|c|}
\hline & Ann & Art & Iris & Hank & Gene \\
\hline Grouping & $\begin{array}{l}\text { Teacher } \\
\text { formed } \\
\text { Random }\end{array}$ & $\begin{array}{l}\text { Students } \\
\text { formed } \\
\text { (existing } \\
\text { groups) }\end{array}$ & $\begin{array}{l}\text { Teacher } \\
\text { formed } \\
\text { Balanced }\end{array}$ & $\begin{array}{l}\text { Student } \\
\text { formed }\end{array}$ & $\begin{array}{l}\text { Teacher } \\
\text { formed } \\
\text { Mixed } \\
\text { groups }\end{array}$ \\
\hline Roles & $\begin{array}{l}\text { Were used } \\
\text { Positive } \\
\text { result }\end{array}$ & Were used & Were used & Were used & $\begin{array}{l}\text { Were used } \\
\text { Negative } \\
\text { result }\end{array}$ \\
\hline T-cards & Not used & $\begin{array}{l}\text { Prepared, } \\
\text { not discus- } \\
\text { sed }\end{array}$ & Not used & $\begin{array}{l}\text { Prepared, } \\
\text { not discus- } \\
\text { sed }\end{array}$ & $\begin{array}{l}\text { Prepared, } \\
\text { put up on } \\
\text { the wall }\end{array}$ \\
\hline Logbook & $\begin{array}{l}\text { Used, mar- } \\
\text { ked and } \\
\text { graded }\end{array}$ & $\begin{array}{l}\text { Used, read } \\
\text { through but } \\
\text { not marked }\end{array}$ & $\begin{array}{l}\text { Used, brow- } \\
\text { sed through } \\
\text { but not syste- } \\
\text { matically }\end{array}$ & $\begin{array}{l}\text { Used, } \\
\text { commented } \\
\text { all }\end{array}$ & $\begin{array}{l}\text { Used, but } \\
\text { not commen- } \\
\text { ted }\end{array}$ \\
\hline
\end{tabular}

Assessment. With respect to assessment little teacher learning occurred. Three of these teachers did not assess learning results of their students after this module because of time constraints, and therefore did not acquire new knowledge. A fourth teacher, Iris, used a traditional written test to evaluate her students' learning results. As this was her normal assessment method, she also did not come to new insights. Finally, Ann had her students present posters and graded these, and she was quite happy with this (see also Table 6.6, viewpoint 10). She was the only teacher who learned a new way of assessment.

This lack of learning is also clearly visible in Table 6.6, viewpoints 10 and 11 where only 2 out of 10 viewpoints changed.

\subsection{CONCLUSION AND DISCUSSION}

\subsubsection{Changes in teacher PCK}

Firstly, the data cause a change in the description of the teacher's Pedagogical Content Knowledge: three instead of five domains are used for it. The three domains related to the context-based approach in which teacher learning can take place are identified as: knowledge and beliefs on (a) context-based 
chemistry, (b) cooperative learning, and (c) assessment of science learning. As the first two domains do not coincide with the five PCK components from our theoretical framework, we will first describe the relation between these two. Knowledge and beliefs about context-based chemistry can be situated in two PCK components: knowledge and beliefs about orientations toward science teaching, for example regarding the purpose of context-based chemistry, and in the knowledge and beliefs about the science curriculum when it comes to understanding the use of the materials to meet the goals and objectives. Knowledge and beliefs about cooperative learning is within the PCK component on instructional strategies, and for one teacher also in assessment in science as she marked and graded the group logbook.

Secondly, the data show that after class enactment none of the five teachers has a different view on context-based chemistry. Initial hesitations and doubts each teacher had with respect to the feasibility of a context-based approach remain. Only Gene and Ann come to some new notions regarding context-based education during the enactment process. Gene observes that this approach leads to different learning results: fewer concepts but he has the impression that students understand these concepts better. Ann notices that although in class she always emphasizes the role of chemistry in daily life, students were surprised about the relation between baking and chemistry. An inventory about the students' ideas about chemistry in advance of the regular curriculum may be helpful for the teachers.

Cooperative learning is new for all teachers, but all implemented it in a personal manner as can be seen in Table 6.7. This results in learning outcomes for each of these teachers, but in different domains and to different degrees.

With respect to assessment very little learning occurs. Three teachers do not evaluate their students' learning results because of time constraints. One uses a to her familiar assessment method. One uses a poster session, new to her, for the summative evaluation and combined this with grades for the logbooks into final notes. This last teacher familiarizes herself with two new assessment methods.

In answer to our research question, the data show that these teachers change little with respect to their PCK, and those changes that do take place occur at diverse domains and to different degrees. Three conclusions materialize. Firstly, teachers make adaptations and additions to the materials, and consequently do not experience how students would react to the original material. Secondly, towards class enactment an idiosyncratic attitude exists as some teachers do not use 
activities they personally consider insignificant, even though the activities are explicitly incorporated in the material, a finding in line with previous research (Schneider, Krajcik, \& Blumenfeld, 2005). Thirdly, how students perceive certain learning activities, exemplified in this study by students' reaction to the role-play and to cooperative learning, can have an impact on a teachers' belief system: a held belief may be strengthened or in need of revision. In this sense students do influence curriculum implementation (Blake, 2002). These three conclusions demonstrate the idiosyncratic nature of teacher learning.

The five teachers of this study show little changes in teachers' PCK. The implications are discussed underneath.

\subsubsection{Theoretical and policy implications}

The underlying principle of this study is that teachers' PCK changes when they enact innovative learning material in their classes (Guskey, 2000). This presupposes three conditions. Firstly, that the teachers understand what the innovation is about, its goals and objectives, and adopt these. Secondly, that the teachers know how the new materials can be enacted in class: they need to familiarize themselves with the new materials and teaching approaches. Thirdly, because the teachers understand the goals of the renewal and know how to enact the innovative material in class, they will enact the material as it is. This enactment results in the teachers acquiring PCK.

All five teachers initially have doubts about the context-based approach. Their reasons to volunteer in the class enactment of the module are to experience the learning processes to take place in class, not because they applaud the contextbased idea. This means that the first condition is not met.

Four teachers make adaptations or additions to the material before class enactment, additionally all five teachers omitted elements of the materials during class enactment. This phenomenon has been reported in literature (Fullan, 1998), and is also seen in this study even though the module was developed, class enacted, redeveloped, and introduced by colleague teachers. Moreover, two different modules were available from which each teacher could select one. However, all teachers say that the interventions in the material had to be made in order to accommodate their students. Apparently teacher beliefs play a significant role in their decision not to adopt the material as it is. Teacher beliefs act like a filter through which new knowledge and practices are screened for meaning and if not consistent with innovation demands, these latter might 
be changed through adaptations in the learning material. The result is that teachers' PCK is not brought in line with the reform demands but the innovation is modeled to accommodate the existing PCK.

Another explanation for the little changes in teachers' PCK transpiring in this study is that, although PCK is developed and shaped in school practices, these teachers being experienced teachers, have to unlearn certain routines and practices, and then replace these by new ones, a complicated process requiring time.

In two previous studies (Author, 2009a; 2009b) we report on changes in teachers' PCK when teachers first develop student learning material for a context-based chemistry curriculum and subsequently enact this material in their classes. These studies show that during the development phase of the material, teachers' knowledge and beliefs in all five PCK components changes. For these teachers the goals and purposes of the renewal become clear. The development of new material also prepares the teachers in an excellent way for class enactment, both to cope with emotional aspects pertaining to this renewal as regarding how-to-do advice for innovative elements. However, after material development teachers still have a feeling of uncertainty and anxiety, as they wonder how their students are going to react, a feeling that disappears during class enactment. Class enactment moreover reinforces teacher learning taking place during the development process.

The teachers of this study and the teacher-developers of the previous studies engage in different kind of activities before class enactment. In their meetings the teacher-developers have ample opportunity to reflect on their practices (Park \& Oliver, 2008) and to discuss the purposes and goals and underlying principles of specific elements of the material (Penuel, et al., 2007). This process consisting of multiple cycles of discussion and material development seems essential for teacher learning. A reason for his might be that teachers first need to make their PCK explicit through discussion and reflection about their practices (Bindernagel \& Eilks, 2009) before it can be expanded.

This has implications for a professional development program to prepare teachers for a curriculum change. An introduction through a workshop in which procedural issues are discussed, and subsequent class enactment of innovative learning material are not sufficient to get to understand and appreciate the heart of an innovation. The rationale and goals of the innovation itself need specific attention. In addition to this, teachers need opportunities to make their PCK explicit and to share teaching and learning experiences with 
colleagues. Only procedural information will not lead to a firm PCK basis on which a teacher can rely when having to enact. Involving teachers in the development of the innovative material, even though this is a time consuming endeavor, provides many more opportunities for acquiring this understanding. Class enactment of this developed material reinforces this understanding. During such a process of development of learning material and enactment, teachers can bring their PCK in line with the new curriculum requirements.

\subsection{APPENDIX}

Semi-structured interview guide before class enactment of the module.

1. What are for you the goals for chemistry education (at this level)

2. How do you view your (teacher) role in this? What are your tasks?

3. How do you view the role of the students?

4. What is the relation between context and content?

5. What kinds of instruction are suitable for context-based education? What do the students do?

6. What ways of assessment do you consider appropriate for student learning in context-based education?

7. Do you use any specific literature to keep up to date?

8. Did you yourself:

a. Develop a teachers' guide?

b. Use innovative context-based learning material?

9. What do you consider most important with respect to the following opposing viewpoints:

a. Context or concept

b. Knowledge or skills

c. Concept learning or students enjoy learning

d. Knowledge of the role of chemistry or subject chemistry knowledge

e. Practical from a recipe or open research experiments

f. (learn to) cooperate or independent work

g. Teacher or material present knowledge or students acquire knowledge

h. Offer identical content to all students or students choose their own subject matter

i. Traditional paper and pencil test or poster presentation

j. Written report for own research project or oral presentation

k. Experiments or practical work or paper assignments

Semi-structured interview guide after class enactment of the module.

1. What was your reason to participate in the material implementation?

2. In what classes did you use the module?

3. How many periods did you have for the module?

4. Did you make changes before taking the module to class? If so what changes and why?

5. What was the reaction of the students on the module? 
6. What is your reaction on the module?

a. Would you use the module again next year?

b. What is your opinion on the context used in the module?

7. What do you consider innovative in the material (module)?

8. Did you have the students do the role-play? If not why not?

9. Cooperative learning.

c. How were the groups formed?

d. Did you use the T-cards? Experiences?

e. Did you let students use the different roles?

f. Did the groups use a logbook?

10. How did you assess students' learning results?

11. Did you have enough support (initially, during teaching, from school administration)?

12. Did you learn anything yourself, with respect to chemistry, to pedagogy, other things?

13. What do you consider most important with respect to the following opposing viewpoints:
g. Context or concept
h. Knowledge or skills
i. Concept learning or students enjoy learning
j. Knowledge of the role of chemistry or subject chemistry knowledge
k. Practical from a recipe or open research experiments
1. (learn to) cooperate or independent work
$\mathrm{m}$. Teacher or material present knowledge or students acquire knowledge
n. Offer identical content to all students or students choose their own subject matter
o. Traditional paper and pencil test or poster presentation
p. Written report for own research project or oral presentation
q. Experiments or practical work or paper assignments

14. How do you now, after have used this module, perceive context-based education?

15. Anything you would like to add? 


\title{
CHAPTER 7 \\ Teacher change in terms of a model of teacher learning and policy implications
}

\begin{abstract}
In Chapter 2.2 three models useful to describe in-service teacher learning have been presented. In 7.2 and 7.3 these models will be elaborated and used to interpret and understand the findings presented in the chapters 4, 5 and 6. In 7.4 the use of the extended IMTPG model as a hypothesised predictive tool is described. In 7.5, practical and policy implications for the design of teacher professional development programs for a new curriculum will be discussed. Finally, in 7.6 we will critically discuss this study. First we will summarize the main findings reported in the chapters 3, 4, 5 and 6.
\end{abstract}

\subsection{SUMMARY OF THE MAIN FINDINGS OF THE PREVIOUS CHAPTERS}

We conceptualise teacher change as growth or learning, as a natural and expected result of professional activities of teachers. This implies that teachers' prior knowledge and beliefs have to be taken as the starting point.

Therefore the first phase of this study, reported in chapter 3, consisted of an assessment of eight teachers' beliefs about the proposed context-based chemistry innovation. It turned out that the context-based approach can count on cautious approval although teachers do not have a clear picture about the implications of the innovation for student learning. Teachers hold firm beliefs about the content of a chemistry curriculum. They suppose that their academic and pedagogical content knowledge (PCK) domains need to be updated, and are explicit about strategies to prepare them for a context-based curriculum. Characteristics for a possible learning process are outlined: let teachers themselves develop innovative curriculum materials. This requires teachers to reflect on own practice, and it is supposed to create ownership, boosts teacher self-efficacy, and facilitates the development of teacher PCK. 
Although the 'teacher as developer' looks promising there is one major weakness: teachers need to have substantial time and need support during the development, and this signifies that the process will be costly. The question that arises is whether teachers will go through a similar learning process when they just enact curriculum material developed by colleague teachers, a process requiring fewer resources. In order to answer this question, this study reports the changes in knowledge and beliefs from (A) three teacher-developers who designed, developed and subsequently enacted learning material in class, and (B) five teachers who merely enacted this developed learning material in their classes.

A. Teacher-developers. The group of three teacher-developers, under the guidance of a coach in a network, first developed innovative learning material in the form of a module for a context-based chemistry curriculum. Subsequently each of these teachers enacted the module in their classes. In Figure 7.1 an outline of the development process is shown. The National Steering Committee can be considered as the external change agency, though it only provided rather open guidelines. The network could work out their own specifications: the network members themselves decided on the kind of activities they wanted to get engaged in, the manner in which this would take place, and the planning of their activities.

\begin{tabular}{|c|c|c|c|c|c|c|}
\hline $\begin{array}{l}\text { National level: } \\
\text { - curriculum } \\
\text { change } \\
\text { - development } \\
\text { guidelines }\end{array}$ & $\rightarrow$ & $\begin{array}{l}\text { Self regulatory } \\
\text { network developing } \\
\text { student learning } \\
\text { materials (a module): } \\
\text { writing phase }\end{array}$ & $\rightarrow$ & $\begin{array}{l}\text { Enactment in } \\
\text { class of the } \\
\text { module by the } \\
\text { developers: } \\
\text { enactment phase }\end{array}$ & $\longrightarrow$ & $\begin{array}{l}\text { Revision: } \\
\text { tested module } \\
\text { ready for } \\
\text { other schools }\end{array}$ \\
\hline
\end{tabular}

Figure 7.1 Framework of the development process of a module

In chapter 4 the focus is on (a) teacher-developers' perceived goals of contextbased chemistry and how this perception changes during the development and enactment process, and (b) on what the teacher developers themselves said to have learned during the writing and the class enactment phases. The results show that these three teacher-developers' goals of chemistry education mature from initially rather vague and general to concrete and at a conceptual level. During the writing phase teachers especially professionalise with respect to teaching methodology, and regarding learning material and chemistry content. The writing phase also prepares the teacher-developers well for class use as sufficient 'how-to-do' advice is generated and discussed. The class enactment 
phase strengthens the learning from the writing phase. Teacher learning appeared to be an idiosyncratic process.

In chapter 5 the focus is on changes in teacher PCK. Data show that changes on teacher knowledge and beliefs occur with respect to context-based chemistry, on cooperative learning, and on requirements for context-based learning. All three teacher-developers learn how to develop learning material starting from a context. In class they all experience the potential of the context-based material especially in terms of student motivation, but also experience that students had difficulties getting the concepts clear. Cooperative learning was the teaching methodology incorporated in the material and specific aspects, like group roles, the use of T-cards and of a logbook, were discussed and tailored to the module during the writing phase. Class enactment illustrates that introducing a new teaching methodology is not easy, as both the teacher as the students have to get used to it. Class enactment also shows the impact of specific cooperative learning elements. During the writing phase these teacher-developers, with respect to requirements for context-based chemistry, get to understand that the learning material requires different kinds of activities for students to explore the context and that assignments have to be challenging but feasible. Class enactment reveals that concept learning and especially connecting concepts, needs scaffolding activities.

B. Teacher enactors. The five teachers who merely enacted this module in their classes went through a process portrayed in Figure 7.2. After having received an introduction to the module they enacted it in their classes.

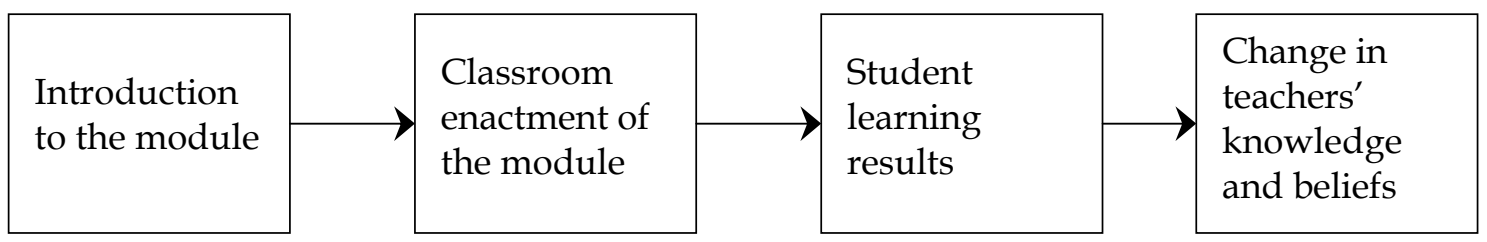

Figure 7.2 Change model for teachers enacting innovative material

It is supposed that this leads to specific student learning which in turn will be instrumental to changes in teacher knowledge and beliefs. This model is similar to Guskey's model (Chapter 2, Figure 2.2). Changes in teacher PCK after class enactment of context-based chemistry material is reported in chapter 6 . The data show that after class enactment none of these five teachers has a different view on context-based chemistry. Cooperative learning is implemented in an 
idiosyncratic way, resulting for the teachers in learning outcomes in different domains and to different degrees. With respect to assessment little learning occurs. The overall conclusion is that these teachers hardly changed with respect to their PCK.

The research question guiding this chapter is how these observed changes in teacher knowledge and beliefs can be interpreted and understood in terms of models of teacher learning. Our findings will be related to the three models introduced in chapter 2.2, that is: (a) the Concerns Based Adoption Model, (b) the effective training components from Joyce and Showers (2002), and (c) the Interconnected Model of Teacher Professional Growth (IMTPG) introduced by Clarke \& Hollingsworth (2002). Because this latter model allows distinguishing between the writing phase and the class enactment phase, an important difference between the teacher-developers and the teacher enactors, we will use this model to interpret our findings.

As the process for the two groups of teachers that participated in our study are so different, we will use the models to describe and interpret these for both groups separately.

\subsection{MODELLING TEACHER-DEVELOPERS' GROWTH}

In the IMTPG model, see chapter 2 section 2.2, four domains are distinguished. Three within the teachers' professional world: the Personal Domain, the Domain of Practice and the Domain of Consequence, and one domain outside this professional world, the External Domain. In the chapters 4 and 5, teacherdevelopers' professional growth in terms of changes in teachers' PCK during development and class enactment of context-based chemistry materials, are reported. PCK, in our conceptualisation consisting of five knowledge and beliefs components (see chapter 2.1.2) teachers use in their work in class, is situated in the Personal Domain of the IMTPG model. The teacher-developers acquired new PCK both during the writing phase and during the class enactment phase, therefore both phases can be considered instrumental in teacher learning. In this study, the External Domain (ED) comprises five distinct sources: (a) the written documents from the National Steering Committee outlining the contextbased approach and the construction guidelines; (b) specific literature, e.g. on cooperative learning and on the use of contexts for teaching; (c) the coach and 
in particular his expertise as a textbook author; (d) experiences from one teacher serve as reflective sources for the others (Parke \& Charles, 1997). The teachersdevelopers initiate an attitude of inquiry into one's own practice, and engage in deliberate reflection about a number of aspects of teaching and learning; and (e) discourse during network meetings about the draft learning materials and how these would contribute to student learning. In (d) and (e) reflection-on-action proves to be a strong learning tool (Park \& Oliver, 2008). An iterative and cyclic process takes place: one of the teacher-developers produces draft learning material. This is distributed and discussed at the next network meeting. Discourse results in suggestions and ideas to be incorporated in an improved draft which is developed, distributed and discussed in the following meeting. Previous experiences from the participating teacher-developers with activities and materials, located in the Personal Domain (PD), and specific literature, serve as reference tools in deciding what to do regarding the texts, activities and assignments. This process of writing, discourse, rewriting etc. continues until consensus is reached about a specific part of the learning material, and finally about the complete module. The Domain of Practice (DP) consists of class experiences with the developed materials, and the Domain of Consequence (DC) encompasses salient student learning results.

\subsubsection{Extension of the Interconnected Model of Teacher Professional Growth (IMTPG)}

Teachers in this study, in the aforementioned iterative and cyclic process first develop student learning material during a period of several months, and only thereafter enact this in class. The External Domain (ED) provides input for the learning material, which in turn fosters the discourse using input from the Personal Domain (PD). During the development process it turns out that the enactment and the reflection between the External Domain (ED) and the learning material 'under construction' substantially contributes to teacher learning (see sections 4.3 and 5.3). To accommodate this, the IMTPG model is extended with one new domain between the External Domain (ED) and the class room (DP). We label this the Developed Material Domain (DMD). The resulting extended model is shown in Figure 7.3.

The numbers 1 to 12 are included to facilitate the interpretation of our research findings. 
To illustrate the use of the model of Figure 7.3 we will for each of the teacherdevelopers discuss two selected areas of PCK development: the context-based approach, which was the main innovation incorporated in the material, and cooperative learning as the instructional strategy new to all teacher-developers. For the specific data we refer to the results section of chapter 5 .

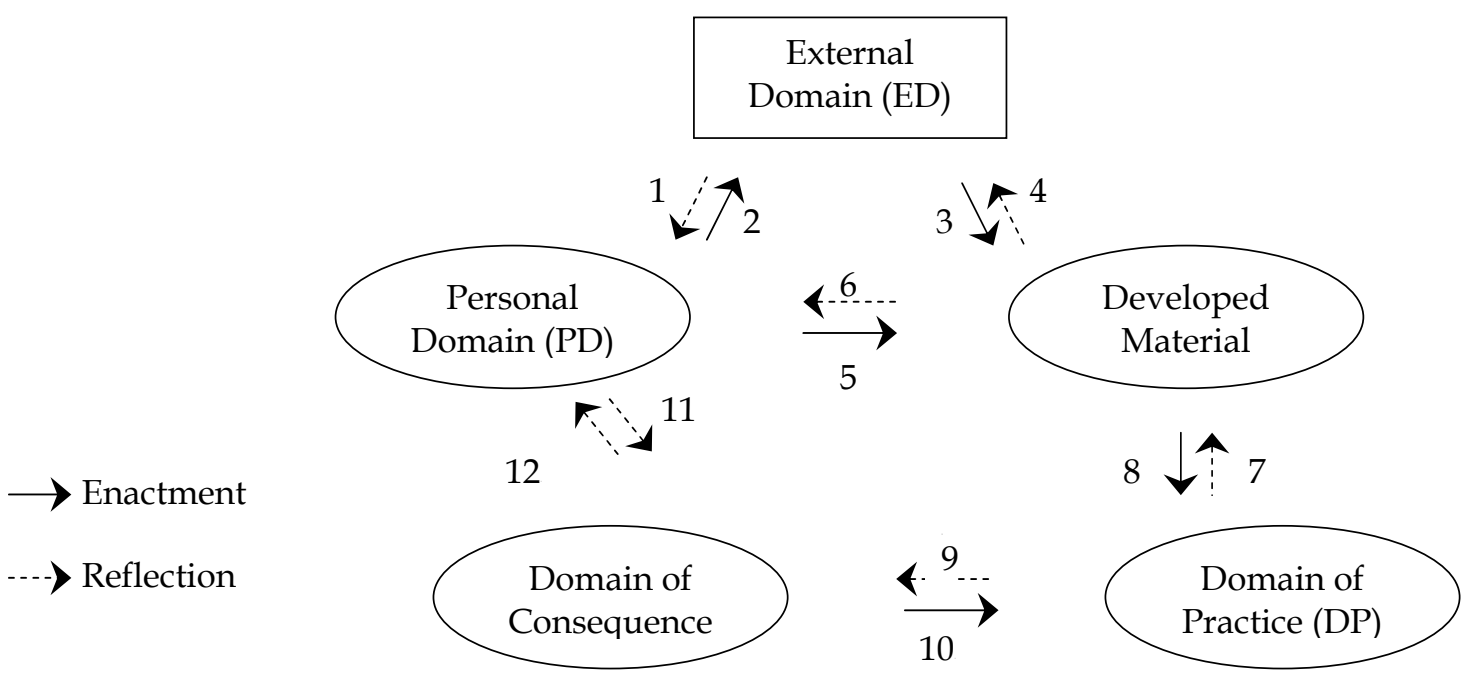

Figure 7.3 Extended Interconnected Model of Teacher Professional Growth (based on the IMTPG model from Clarke and Hollingsworth, 2002). See the text for an explanation of the numbers at the arrows.

Pete. In the extended model of Figure 7.3, the change in beliefs with respect to context-based chemistry is visualized by the following sequence. Pete's personal domain (PD) in addition to the context-based approach from the National Steering Committee (ED) is in a discourse process at network meetings translated into learning material (DMD) (arrows 1, 2, 3, 4), resulting in a module based on an appealing context for students. Pete however still has doubts about what students are to learn and about his own role in it (arrows 5, 6). Class experiences (DP) are positive in motivational terms (arrows 7, 8) but student concept learning is insufficient (DC) (arrows 9, 10), and this influences Pete's beliefs (PD) as he expresses that concepts are more important than context (arrows 11, 12). Experiences in class in fact determine how Pete finally perceives context-based issues.

The change in belief regarding instructional strategies can be described with the following sequence. Pete (PD) has not used cooperative learning earlier, but wants to try this and he has a preference for the recipe type of practical activities (arrows 1,2). Through the external domain (ED) more student control 
(cooperative learning and open research experiments) is included in the learning material (DMD) (arrows 3,4). This does not conflict with his beliefs (arrows 5, 6), he learns the why and how of cooperative learning, and he therefore decides to enact it in his classes. The subsequent class enactment (DP) (arrows, 7, 8) and the learning results (DC) (arrows 9, 10) prove that it worked well. This influences his personal domain (PD) in the sense that his knowledge and belief of cooperative learning is confirmed and the strength of open research experiments demonstrated (arrows 11, 12).

Lisa. Lisa's learning concerning context-based chemistry starts at the network meetings (ED), where the materials and also the 'how-to-do' aspects for class enactment is discussed (arrows 1, 2, 3, 4). The developed module (DMD) is for her instrumental for reflection (arrows 5, 6) as she wonders how students are going to react to it. Class enactment (DP) (arrows 7, 8) and the resulting learning outcome (DC) (arrows 9, 10) confirms the value of the context-based approach, though Lisa is not happy about the concept learning that occurred. She could however indicate how to improve this aspect in future (arrows 11, 12).

The discussions during the network meetings (ED) on what instructional strategies to include in the learning material provides ideas for cooperative learning and groups own research experiments and these are incorporated in the material (DMD) (arrows 1, 2, 3, 4). Class enactment (DP) (arrows 7, 8) is positive, and the students' learning results (DC) are good (arrows 9, 10), and Lisa's beliefs changes (PD) (arrows 11, 12).

Ed. Ed's growth with respect to context-based education can be described through the following sequence in the model. He has outspoken beliefs (PD) about what students have to learn and how this can be achieved. Network discourse (ED) hardly influences these beliefs (arrows 1, 2). He advocates the use of a context in the material (DMD) (arrows 3,4) as he wants students to start from the concrete. Ed and his students perceive class enactment (DP) positively (arrows 7,8 ) and the student learning results (DC) are as expected (arrows 9, 10) which strengthens his initial beliefs (arrows 11, 12).

Regarding instructional strategies a similar sequence unfolds, but with an unexpected turn. Ed (PD) wants students to be active learners and sees his role in class as coach and facilitator of Socratic conversations. He wants students to work on their own, not in cooperative groups. Network discourse and specific literature (ED) (arrows 1,2) results in incorporation of cooperative learning, 
including the use of a group logbook and student group roles, in the material (DMD) (arrows 3, 4). Before class enactment Ed however decides not to use cooperative learning, his personal belief (PD) results in changes in the instructional strategies advocated in the material (DMD) (arrows 5, 6). Class enactment (DC), of the adapted material, and learning results (DC) are positive, confirming Ed's initial beliefs (arrows 7, 8, 9, 10, 11, 12).

\subsection{2 "Change sequence" or "growth network"}

In chapter 2 section 2.2 two perspectives on "change sequence" and "growth network" are described, the original one from Clarke and Hollingsworth (2002, p 958) and the interpretation used by Justi and van Driel (2006, pp. 443, 444). The main difference between these two is in the definition of what constitutes a "growth network". We adopt the description from the first authors who used "growth network" for a more lasting change signifying professional growth. "Change sequence" in their view consists of change that "may be fleeting, a single instance of experimentation, quickly relinquished" (p 958).

Our data in relation to the two phases in the development process, the writing phase and the class enactment phase, support the argument that the changes that occur during the writing phase can be considered "change sequences". The following two descriptions illustrate this. Immediately after the writing phase, Pete and Lisa are anxious about how their students are going to react to the module, meaning that they are not yet fully convinced that what they have developed will actually work out in class. They have learned what context-based education is and how it can be introduced in class and are willing to experiment with it signifying that there is a beginning belief that it will work. However, lasting changes in knowledge and beliefs for these teachers only will occur after class experience. During the writing phase Ed also learned how context-based chemistry material can look like and how cooperative learning can be used as the instructional strategy. Ed however, has such strong beliefs about the Socratic conversations that he after completion of the module adapts particularly the instructional strategy advocated in the material to his personal preferences.

The enactment phase leads to "growth networks" for a given aspect of teacher knowledge and beliefs. Pete and Lisa are in general positive about the material and the buds of modifications in their knowledge and beliefs formed during the writing phase come to full growth during class enactment. They experience the potential of context-based chemistry and of cooperative learning for their 
students and for themselves, and this learning is not just theoretical but grounded in practice in class and therefore lasting. The same can be said about Ed, as he is satisfied about the Socratic conversations he will not easily adopt the cooperative learning strategy although he contributed to the development of the material that advocates cooperative learning. His knowledge and beliefs on context-based chemistry also becomes lasting.

\subsubsection{Extended IMTPG in relation to CBAM and effective training components}

According to the Concerns Based Adoption Model (CBAM) (Hall \& Loucks, 1978), all teachers go through several stages of concern when reconstructing their teaching (see also chapter 2, section 2.2). Implementation of a context-based chemistry curriculum requires teachers to reconsider and reconstruct their teaching. The teacher-developers of this study voluntarily participate in the development process and they are from the onset aware that the context-based approach requires a change. They realize that this will affect their teaching. All the other stages of concern will be addressed during the development and subsequent class enactment of the learning material. During the first cycle of the extended IMTPG model (PD-ED-DMD), the informational, personal and management concerns are discussed and attended to by the network. Teachers are actively engaged in this process in which their knowledge and beliefs at the start of the curriculum change act as the starting points. They have ample opportunities to express own concerns. In this process of writing and discourse, also the position to others is addressed, the collaboration concerns.

During the second cycle of the IMTPG model the consequence concerns are met during class enactment, and reorientation takes place after class enactment when the teacher-developers revise the learning material based on own class experiences.

The extended IMTPG model also encompasses the Joyce and Showers (2002) effective training components: theory, demonstration, practice and professional training (see also chapter 2, section 2.2). Our results clearly show that teacherdevelopers do get a better understanding of the rationale behind the contextbased approach. The discussions about and demonstrations of unfamiliar learning tasks during network meetings illustrate how these can be used. Network discourse and the resulting materials prepare the teacher-developers well for class enactment. Class enactment itself leads to durable changes. 


\subsection{MODELLING TEACHER ENACTORS' GROWTH}

The changes in knowledge and beliefs of the five teachers who only enacted the developed material are reported in chapter 6 . Their knowledge and beliefs change minimally and the changes that do occur are idiosyncratic.

These teachers receive an introduction to the two modules from the teacherdevelopers, and, as limited time is available the focus is on practical aspects, hardly on the rationale behind the modules. They therefore miss out on opportunities to make their own knowledge explicit, to present and reflect on own teaching and learning experiences, and to discuss in multiple cycles innovative learning activities and its meaning in students' learning processes. In terms of the IMTPG model this means that the External Domain (ED) for these teachers was very limited. This results in teachers making changes in the material (DMD) before taking it to class, and, because they did not understand the ideas and the rationale behind the context-based module, their class enactment (DP) was not in line with the developers' ideas and consequently the student learning results (DC) were disappointing.

In the CBAM and the Joyce and Showers models, these teachers miss out on opportunities to get to understand the rationale and theory behind the contextbased approach.

\subsection{The EXTENDED INTERCONNECTED MOdEl OF TEACHER Professional GROWTH (EIMTPG) AS A PREDICTIVE TOOL}

Based on the empirical data of this study, we hypothesise that the Extended Interconnected Model of Teacher Professional Growth can be used as a predictive tool suggesting mechanisms for teacher professional development. The aforementioned three cases illustrate that teachers' growth occurs in two distinctive cycles. In the first cycle the development of the student learning material is the central activity and in the second cycle it is class enactment and the resulting student learning.

The first cycle comprises the Personal Domain, the External Domain and the Developed Material Domain. The second cycle provides the feedback on the activity in the first cycle. The numbers below refer to the arrows in Figure 7.3.

1. Reflection on the External Domain influences the PCK in the Personal Domain. Other teacher-developers' experiences with activities, instructional 
methods and the resulting learning outcome constitute a window through which a specific teacher can reflect on his own practice. Discourse during the network meetings has a similar impact. This kind of refection is powerful as it bears on class room practices.

2. The teacher knowledge and beliefs (PCK), located in the Personal Domain, is direct input in the External Domain, and also acts as discourse attention points at network meetings. Personal Domain elements (knowledge, beliefs, and experiences) can also be conveyed to the External Domain through for example e-mail contact. Enactment entails two stages: (a) teachers have to select the knowledge and beliefs aspect they consider important enough for discussion, and (b) they need to translate these into a form comprehensible to the other network members before and during discourse.

3. In the External Domain the interplay between the different sources (in this study five sources were distinguished) results in learning material in the Developed Material Domain. The kind of activities, texts, and assignments to be incorporated in this learning material is first discussed at network meetings, then written down by one of the members and distributed to all network members.

4. Reflection on the (draft) learning material leads to (new) discourse at the next network meeting. This iterative and cyclic process results in a number of repeatedly improved versions of the learning material. And ultimately to an agreed final version.

5. The knowledge and beliefs in the Personal Domain can directly influence the content of the module. Especially the teacher-developer responsible for the actual writing of the module can include own ideas. Salient positive experiences with activities and strategies can find its way to the learning material. Strong experiences can also lead to ultimate changes in the material (or the enactment of this material in class).

6. Reflection on the content of the learning material and on the proposed instructional strategies influences the knowledge and beliefs in the Personal Domain.

The first cycle in this extended model shows that the development of learning material allows for multiple cycles of presentation and reflection on knowledge (Penuel, et al., 2007), in which teachers get to understand the goals of the renewal (Pintó, 2005) and in which their knowledge and beliefs are taken as starting points (Coenders, et al., 2008). The teacher-developers make their PCK explicit through reflection about their practices (Bindernagel \& Eilks, 2009). The 
iterative and cyclic process of developing material and discourse about this material leads to new knowledge and beliefs. Several "change sequences" are established in this process.

Two other advantages of this first cycle can be distinguished. Firstly, discourse at network meetings facilitates implementation by seeking 'how-to-do' advice, also with respect to new teaching approaches. Secondly, the 'teacher as developer' process narrows the gap between the ideal and the operational curriculum (Van den Akker, 1998).

After development, the material is enacted in class (Domain of Practice), and specific learning results (Domain of Consequence), both positive and negative, emerge. These in turn influence teachers' knowledge and beliefs (Personal Domain). This second cycle is described below.

7. Reflection on what a teacher experiences in class can lead to changes in material or in class enactment. When students react negatively to a certain activity, the teacher might skip a similar activity or adapt it the next time it is presented in the material.

8. The module is enacted in class. The development process, in which 'how-todo' issues were discussed and advice generated, acts as preparation for class enactment.

9. Reflection on class enactment shows salient results, and the teacher becomes aware of these.

10. Salient results reinforce class enactment. For example a teacher who started giving grades for the group logbook, noticed how positive the students responded to this, and then decided not just to continue this but to even give the students the opportunity to correct mistakes through which they could improve their grade.

11. Reflection starting from own knowledge and beliefs reinforces the salient class results. For example a teacher, who beliefs that something will work, and experiences this in class, will become strengthened in this belief.

12. Reflection on salient results is instrumental in changes in knowledge and beliefs. When teachers experience that something they are initially hesitant about in practice does work, they will have to bring their knowledge and beliefs in line with these results.

The second cycle in this extended model shows the consequences of enacting the material in class. Three different kinds of results may surface: (a) a student learning result hoped for by the teacher-developers does occur; (b) a learning 
result hoped for does not materialize; and (c) a not anticipated learning result does take place. If a student learning result was anticipated and indeed does take place, teachers' knowledge and beliefs will be reinforced, and this will lead to a "growth network" for given aspects of teacher knowledge. If a student learning result was anticipated but does not materialize a cognitive conflict arises. Teachers may revert to their previous' knowledge and beliefs, but it is also possible that the teachers can explain why the anticipated learning does not take place and can indicate how the materials can be adapted to repair this. This will also lead to lasting new knowledge and beliefs, in other words to "growth networks". If a not anticipated learning result does take place, teachers will try to attribute this to specific elements in the material or to the learning process, which may lead to "change sequences" or to "growth networks".

Both cycles are important when changes in teachers' knowledge and beliefs need to be lasting. In the first cycle the External Domain serves two important purposes: it facilitates the inclusion of renewal elements of a new curriculum, and it forms the starting point of teacher learning in terms of "change sequences". Elements of a new curriculum can only be included in the learning material when sufficient resources are available. For teacher learning it is important that teachers can make their own knowledge and beliefs explicit and that sufficient time is available. The second cycle, focusing on student learning (Fishman, Marx, Best, \& Tal, 2003), can subsequently lead to "growth networks".

\subsection{PRACTICAL AND POLICY IMPLICATIONS FOR PROFESSIONAL DEVELOPMENT PROGRAMS}

Preparing teachers for a curriculum renewal requires a program in which teachers can be actively engaged. The EIMTPG model is a useful tool to design such a preparation program.

Two cycles are distinguished. The first cycle provides opportunities for teachers to familiarize themselves with the goals and objectives of the renewal, to acquire knowledge and beliefs, and to prepare well for class enactment. During this cycle, the first four CBAM concerns, awareness, information, personal and management, are addressed. In the second cycle teachers enact the material in class and experience how their students react. The last three CBAM concerns are addressed in this cycle. 
In the first cycle particularly the design of the External Domain, and the interplay between this domain and the Personal Domain and the Developed Material Domain, is crucial. Teachers need appropriate sources to learn from and sufficient opportunities to make their own knowledge and beliefs explicit and to discuss personal experiences with peers. One way of doing this is by letting teachers develop specific student learning material for the new curriculum in a small network under the guidance of a coach. An example of this approach, and the resulting teacher learning, is described in the chapters 4 and 5. In chapter 6 it was clearly demonstrated that without a powerful External Domain little teacher learning will take place.

A similar kind of External Domain as the one above is the strategy by Stolk et al. (Stolk, Bulte, de Jong, \& Pilot, 2009). They propose to let teachers together with a supervisor (a) create a platform about the aims by exchanging personal beliefs about the nature of the new curriculum, and (b) design and discuss innovative units.

The activities in the first cycle will lead to teacher learning of the "change sequences" type, which is knowledge not yet put to the test and therefore not lasting.

In the second cycle, class enactment and salient outcomes are the central elements. The changes in knowledge and beliefs from the first cycle now become lasting, "growth networks" are formed or in other words professional growth occurs. Our results from chapter 6 show that teachers who have not been involved in the development of learning material and only enact this in their classes, hardly grow professionally, demonstrating that the combination of the two cycles is instrumental for professional growth.

Crucial for teacher professional growth is the design of the External Domain as this determines to a great extent what "change sequences" will be addressed by the participating teachers. Important elements to include in the External Domain are:

1. Opportunities to exchange practices and ideas of all participants, to catalyse reflection-on-action. Exchanging this kind of knowledge initiates an attitude of inquiry into one's own practice, and engages the participants in deliberate reflection about learning, teaching, students, and subject matter. This element should always be part of the External Domain as it facilitates that teachers' knowledge and beliefs are taken as a starting point of professional growth. 
2. Material outlining the renewal to be implemented. This can be in the form of written documents or articles about the innovation, by providing examples of innovative materials, or by attending conferences where an innovation is discussed, and preferable combinations of these.

3. Opportunities for the participants to familiarize with new content and with new pedagogies. Depending on the depth and breath of the new content and pedagogy teachers have a preference for different kinds of interventions (see Tables 3.6 and 3.7 in chapter 3), from a course at a university to learn new content to a course at school to get acquainted with a specific ICT application.

4. Specific expertise in the field of design and development of student learning material, for example through the involvement of an experienced author. Teachers find it motivating to combine teaching and developing learning material, but most lack the expertise, especially when it comes to developing complete chapters (see Table 3.5 in chapter 3).

5. Opportunities for discourse on draft material, and how this material affects student learning. Discourse can partly take place though e-mail, but face-toface meetings are necessary.

6. Opportunities to gain experiences with selected experiments, learning activities and other new elements through class enactment, without having to use a complete new chapter or module reduces anxiety and fosters ownership.

7. A critical condition for success is sufficient time to carry out the activities described above. Support from the school administration is crucial.

Follow up research could look into specifications for these elements in order to optimise teacher-developer learning. A second area that needs clarification is the development process. What is in terms of teacher growth the most effective way to organise the design and development process, for example with what roles of the participants during the development phase will the professional growth be optimal.

\subsection{Discussion}

The four research sub questions from chapter 1.4 will be answered in the next section.

Looking back at this study it is clear that teachers hold strong beliefs on a number of issues relevant to a new curriculum and with respect to ways to 
prepare for a new curriculum, and that it is possible to develop a new chemistry curriculum taking teachers' knowledge and beliefs as starting points.

This study also reveals that chemistry teachers, involved in the development and subsequent class use of innovative student learning material, do change with respect to the five PCK components: their beliefs about the context-based approach changed, their knowledge and beliefs about context-based education changed, they learned what cooperative learning is and how this effectively can be used in class, they learned about learning material , about chemistry content, and about new ways of assessment. It became clear that the combination of the writing phase followed by the class enactment phase is instrumental for teacher leaning.

However, teachers not involved in the development process, who merely enact the student learning material in class, hardly changed with respect to their PCK. This influences the way teacher learning can be modeled. When comparing the models described in Figure 2.2 and in Figure 7.2 it can be concluded that introducing the module to the teachers by means of a workshop is not sufficient to let them class enact the module as intended by the developers. This means that the design and execution of the professional development program, the first step in Guskey's model, is crucial. The other three steps of Guskey's model are similar to the second cycle of the EIMTPG model: Change in classroom practice equals the Domain of Practice; Change in student learning is similar to Domain of Consequence; and Change in teachers' attitudes and beliefs resembles the Personal Domain.

The observed changes in teacher PCK can be interpreted with The Extended Interconnected Model of Teacher Professional Growth. Crucial in this model is the design of the External Domain (see 7.5), as this will determine to a large extend how innovative the student learning material will be, and therefore what changes in teacher PCK can be expected.

Two aspects need to be discussed in relation to the findings of this study. First of all the number of respondents was limited. In the first study eight teachers were interviewed. In the second study three teachers participated, though these teachers were monitored intensively. In the final study five teachers who class enacted the material participated. The data gathering process, letting teachers as much as possible express own ideas and thoughts, required an interpretative step of the researchers as the data had to be linked to changes in teachers' PCK. The limited number of participants and the used methodology requires a careful use of the generalizations made. 
However, within these limitations, the differences in changes in teachers' PCK between teacher-developers and teachers who merely enacted the material clearly surfaces, and the EIMTPG looks promising to predict teacher professional growth.

Further studies can substantiate the results with respect to changes in teacher PCK as well as validate the EIMTPG model, with special attention to the content and processes in the External Domain. 


\section{References}

Abell, S. K. (2008). Twenty years later: Does pedagogical content knowledge remain a useful idea? International Journal of Science Education, 30(10), 1405 - 1416.

Ball, D. L., \& Cohen, D. K. (1996). Reform by the book: What is - or might be - the role of curriculum materials in teacher learning and instructional reform? Educational Researcher, 25, 6-14.

Ball, D. L., \& Cohen, D. K. (1999). Developing practice, developing practitioners. In L. Darling-Hammond, \& G. Sykes (Eds.), Teaching as the learning profession. Handbook of policy ans practice (pp. 3-32). San Francisco: Jossey-Bass.

Bandura, A. (1997). Self-efficacy: The exercise of control. New York: W. H. Freeman.

Barnett, J., \& Hodson, D. (2001). Pedagogical context knowledge: Toward a fuller understanding of what good science teachers know. Science Education, 85(4), 426-453.

Baxter, J. A., \& Lederman, N. G. (1999). Assessment and measurement of Pedagogical Content Knowledge. In J. Gess-Newsome, \& N. G. Nederman (Eds.), Examining Pedagogical Content Knowledge (pp. 147-161). Dordrecht: Kluwer Academic Publishers.

Berry, A., Loughran, J., \& van Driel, J. H. (2008). Revisiting the roots of Pedagogical Content Knowledge. International Journal of Science Education, 30(10), 1271 - 1279.

Bindernagel, J. A., \& Eilks, I. (2009). Evaluating roadmaps to portray and develop chemistry teachers' PCK about curricular structures concerning sub-microscopic models. Chemistry Education Research and Practice, 10(2), 77-85.

Blake, R. W. (2002). A dynamic balance among curriculum, context, and teacher beliefs. New York: Peter Lang.

Borko, H. (2004). Professional development and teacher learning: Mapping the terrain. Educational Researcher, 33(8), 3-15.

Bulte, A. M. W., Carelsen, F. J., Davids, W., Morelis, J., Jansen-Ligthelm, C. D., Pilot, A., et al. (2000). Nieuwe scheikunde. Hoofdlijnennotitie over een voorstel tot fundamentele herziening wan het scheikundeprogramma voor de bovenbouw van havo en vwo [New chemistry. A proposal for fundamental review of the chemistry high school curriculum]. . Enschede: SLO.

Burton, W., Holman, J., Lazonby, J., Pilling, G., \& Waddington, D. (2000). Salters Advanced Chemistry (2nd ed. ). Oxford, UK: Heineman.

Calderhead, J., \& Robson, M. (1991). Images of teaching: Student teachers' early conceptions of classroom practice. Teaching and Teacher Education, 7(1), 1-8.

Campbell, B., Lazonby, J., Millar, R., Nicolson, P., Ramsden, J., \& Waddington, D. (1994). Science: The Salters approach-a case study of the process of large scale curriculum development. Science Education, 78(5), 415-447.

Clarke, D., \& Hollingsworth, H. (2002). Elaborating a model of teacher professional growth. Teaching and Teacher Education, 18(8), 947-967. 
Clermont, C. P., Borko, H., \& Krajcik, J. S. (1994). Comparative-study of the pedagogical content knowledge of experienced and novice chemical demonstrators. Journal of Research in Science Teaching, 31(4), 419-441.

Cochran, K. F., DeRuiter, J. A., \& King, R. A. (1993). Pedagogical content knowing: An integrative model for teacher preparation. Journal of Teacher Education, 44, 263- 272.

Coenders, F., Terlouw, C., \& Dijkstra, S. (2008). Assessing teachers' beliefs to facilitate the transition to a new chemistry curriculum: What do the teachers want? Journal of Science Teacher Education, 19(4), 317-335.

Cotton, D. R. E. (2006). Implementing curriculum guidance on environmental education: The importance of teachers' beliefs. Journal of Curriculum Studies, 38, 67-83.

Cronin-Jones, L. L. (1991). Science teacher beliefs and their influence on curriculum implementation: Two case studies. Journal of Research in Science Teaching, 28, 235-250.

Davis, E. A., \& Krajcik, J. S. (2005). Designing educative curriculum materials to promote teacher learning. Educational Researcher, 34(3), 3-14.

Davis, K. S. (2003). "Change is hard": What science teachers are telling us about reform and teacher learning of innovative practices. Science Education, 87, 3-20.

De Jong, O., Van Driel, J. H., \& Verloop, N. (2005). Preservice teachers' pedagogical content knowledge of using particle models in teaching chemistry. Journal of Research in Science Teaching, 42(8), 947-964.

De Vos, W., \& Verdonk, A. H. (1990). Een vakstructuur van het schoolvak scheikunde [A subject structure for high school chemistry]. TD beta 8(1), 19-35.

Denzin, N. K., \& Lincoln, Y. S. (Eds.). (2000). Handbook of qualitative research (2nd ed.). Thousand Oaks: Sage Publications.

Driessen, H. P. W., \& Meinema, H. A. (2003). Chemie tussen context en concept. Ontwerpen voor vernieuwing [Chemistry between context and concept. Design for renewal.]. Enschede: SLO.

Duffee, L., \& Aikenhead, G. (1992). Curriculum change, student evaluation, and teacher practical knowledge. Science Education, 76, 493-506.

Duschl, R. A., \& Wright, E. (1989). A case study of high school teachers' decision making models for planning and teaching science. Journal of Research in Science Teaching, 26, 467-501.

Ebbens, S., Ettekoven, S., \& Rooijen, J. v. (1996). Samenwerkend leren, praktijkboek [Cooperative learning, practical book]. Groningen: Wolters Noordhoff.

Evers, W. J. G., Brouwers, A., \& Tomic, E. (2002). Burnout and self-efficacy: A study on teachers' beliefs when implementing an innovative educational system in the Netherlands. British Journal of Educational Psychology, 72, 227-243.

Fishman, B. J., Marx, R. W., Best, S., \& Tal, R. T. (2003). Linking teacher and student learning to improve professional development in systemic reform. [doi: DOI: 10.1016/S0742-051X(03)00059-3]. Teaching and Teacher Education, 19(6), 643-658. 
Ford, M. E. (1992). Motivating humans: Goals, emotions, and personal agency beliefs. California: Sage.

Friedman, I. A., \& Kass, E. (2002). Teacher self-efficacy: A classroom-organization conceptualization. Teaching and Teacher Education, 18(6), 675-686.

Friedrichsen, P. J., Abell, S. K., Pareja, E. M., Brown, P. L., Lankford, D. M., \& Volkmann, M. J. (2009). Does teaching experience matter? Examining biology teachers' prior knowledge for teaching in an alternative certification program. Journal of Research in Science Teaching, 46(4), 357-383.

Fullan, M. G. (1998). The new meaning of educational change. London: Cassell.

Gal'perin, P. I. (1992). The problem of activity in Soviet psychology. Journal of Russian and East European Psychology, 30, 37-59.

Garet, M. S., Porter, A. C., Desimone, L., Birman, B. F., \& Yoon, K. S. (2001). What makes professional development effective? Results from a national sample of teachers. American Educational Research Journal, 38(4), 915-945.

Geddis, A. N., Onslow, B., Beynon, C., \& Oesch, J. (1993). Transforming content knowledge: Learning to teach about isotopes. Science Education, 77(6), 575-591.

George, J. M., \& Lubben, F. (2002). Facilitating teachers' professional growth through their involvement in creating context-based materials in science. International Journal of Educational Development, 22(6), 659-672.

Gess-Newsome, J. (1999). Pedagogical content knowledge: An introduction and orientation. In J. Gess-Newsome, \& N. G. Lederman (Eds.), Examining pedagogical content knowledge (pp. 3-17). Dordrecht: Kluwer Academic Publishers.

Gess-Newsome, J. (1999 b). Secondary teachers' knowledge and beliefs about subject matter and their impact on instruction. In J. Gess-Newsome, \& N. G. Lederman (Ed.), Examining pedagogical content knowledge (pp. 51-94). Dordrecht:: Kluwer Academic Publishers.

Gibbs, J. R. (2007). Analyzing qualitative data. London: SAGE.

Gilbert, J. K. (2006). On the nature of "context" in chemical education. International Journal of Science Education, 28(9), 957 - 976.

Goodlad, J. (1979). Curriculum enquiry: The study of curriculum practice. New York: McGrawHill.

Grossman, P. (1990). The making of a teacher: Teacher knowledge and teacher education. New York: Teachers Collage Press.

Guskey, T. R. (1986). Staff development and the process of teacher change. Educational Researcher, 15(5), 5-12.

Guskey, T. R. (2000). Evaluating professional development. California: Corwin Press.

Hall, G. E., \& Loucks, S. (1978). Teacher concerns as a basis for facilitating and personalizing staff-development. Teachers College Record, 80, 36-53. 
Henze, I., van Driel, J. H., \& Verloop, N. (2008). Development of experienced science teachers' pedagogical content knowledge of models of the solar system and the universe. International Journal of Science Education, 30(10), 1321 - 1342.

Hollon, R. E., Roth, K. J., \& Anderson, C. W. (1991). Science teachers' conceptions of teaching and learning. In J. Brophy (Ed.), Advances in research on teaching (Vol. 2, pp. 145-186). Greenwich: CTA: JAI.

Jeanpierre, B., Oberhauser, K., \& Freeman, C. (2005). Characteristics of professional development that effect change in secondary science teachers' classroom practices. Journal of Research in Science Teaching, 42(6), 668-690.

Joyce, B. R., \& Showers, B. (1988). Student achievement through staff development. New York: Longman.

Joyce, B. R., \& Showers, B. (1995). Student achievement through staff development: Fundamentals of school renewal. White Plains, NY Longman.

Joyce, B. R., \& Showers, B. (2002). Student achievement through staff development (3rd ed.). Alexandria: ASCD.

Justi, R., \& van Driel, J. (2006). The use of the interconnected model of teacher professional growth for understanding the development of science teachers' knowledge on models and modelling. Teaching and Teacher Education, 22(4), 437-450.

Kansanen, P. (2009). Subject-matter didactics as a central knowledge base for teachers, or should it be called pedagogical content knowledge? Pedagogy, Culture and Society, 17(1), 29-39.

Kelchtermans, G. (2005). Teachers' emotions in educational reforms: Self-understanding, vulnerable commitment and micropolitical literacy. Teaching and Teacher Education, 21(8), 995-1006.

Keys, C. W., \& Bryan, L. A. (2001). Co-constructing inquiry-based science with teachers: Essential research for lasting reform. Journal of Research in Science Teaching, 38(6), 631-645.

Kupari, P. (2003). Instructional practices and teachers' beliefs in Finnish mathematics education. Studies in Educational Evaluation, 29, 243-257.

Lantz, O., \& Kass, H. (1987). Chemistry teachers' functional paradigms Science education, 71, 117-134.

Laplante, B. (1997). Teachers' beliefs and instructional strategies in science: Pushing analysis further. Science Education, 81(3), 277-294.

Lewin, K. (1935). A dynamic theory of personality. New York: McGraw-Hill.

Lieberman, A. (1995). Practices that support teacher development. Phi Delta Kappan, 76, 591 596.

Loucks-Horsley, S., Hewson, P. W., Love, N., \& Stiles, K. E. (1998). Designing professional development for teachers of science and mathematics. California: Corwin Press.

Loughran, J., Mulhall, P., \& Berry, A. (2004). In search of pedagogical content knowledge in science: Developing ways of articulating and documenting professional practice. Journal of Research in Science Teaching, 41(4), 370-391. 
Luft, J. A. (2001). Changing inquiry practices and beliefs: The impact of an inquiry-based professional development programme on beginning and experienced secondary science teachers. International Journal of Science Education, 23(5), 517 - 534.

Lumpe, A. T. (2007). Research-based professional development: Teachers engaged in professional learning communities. Journal of Science Teacher Education, 18(1), 125-128.

Lumpe, A. T., Haney, J. J., \& Czerniak, C. M. (2000). Assessing teachers' beliefs about their science teaching context. Journal of Research in Science Teaching, 37(3), 275-292.

Magnusson, S., Krajcik, J., \& Borko, H. (1999). Nature, sources, and development of pedagogical content knowledge for science teaching. In J. Gess-Newsome, \& N. G. Lederman (Eds.), Examining pedagogical content knowledge (pp. 95-132). Dordrecht: Kluwer Academic Publishers.

Meijer, P. C., Verloop, N., \& Beijaard, D. (2002). Multi-method triangulation in a qualitative study on teachers' practical knowledge: An attempt to increase internal validity. Quality \& Quantity, 36, 145-167.

Miles, M. B., \& Huberman, A. M. (1994). Qualitative data analysis (2nd ed.). London: Sage.

Olson, J. (2002). Systemic change/teacher tradition: Legends of reform continue. Journal of Curriculum Studies, 34(2), 129 - 137.

Pajares, M. F. (1992). Teachers beliefs and educational-research - cleaning up a messy construct. Review of Educational Research, 62(3), 307-332.

Parchmann, I., Gräsel, C., Baer, A., Nentwig, P., Demuth, R., \& Ralle, B. (2006). “Chemie im Kontext": A symbiotic implementation of a context-based teaching and learning approach. International Journal of Science Education, 28(9), 1041 - 1062.

Park, S., \& Oliver, J. (2008). Revisiting the conceptualisation of Pedagogical Content Knowledge (PCK): PCK as a conceptual tool to understand teachers as professionals. Research in Science Education, 38(3), 261-284.

Parke, H. M., \& Charles, R. C. (1997). Teachers designing curriculum as professional development: A model for transformational science teaching. Journal of Research in Science Teaching, 34(8), 773-789.

Penuel, W., Fishman, B. J., Yamaguchi, R., \& Gallagher, L. P. (2007). What makes professional development effective? Strategies that foster curriculum implementation. American Educational Research Journal, 44(4), 921-958.

Penuel, W., McWilliams, H., McAuliffe, C., Benbow, A., Mably, C., \& Hayden, M. (2008). Teaching for understanding in earth science: Comparing impacts on planning and instruction in three professional development designs for middle school science teachers. Journal of Science Teacher Education, Online first.

Pintó, R. (2005). Introducing curriculum innovations in science: Identifying teachers' transformations and the design of related teacher education. Science Education, 89(1), 1-12.

Resnick, L. B. (1987). Education and learning to think. Washington, DC: National Academic Press. 
Rollnick, M., Bennett, J., Rhemtula, M., Dharsey, N., \& Ndlovu, T. (2008). The place of subject matter knowledge in Pedagogical Content Knowledge: A case study of South African teachers teaching the amount of substance and chemical equilibrium. International Journal of Science Education, 30(10), 1365 - 1387.

Rousseau, C. K. (2004). Shared beliefs, conflict, and a retreat from reform: The story of a professional community of high school mathematics teachers. Teaching and Teacher Education, 20(8), 783-796.

Schmidt, M., \& Datnow, A. (2005). Teachers' sense-making about comprehensive school reform: The influence of emotions. Teaching and Teacher Education, 21(8), 949-965.

Schneider, R. M., Krajcik, J., \& Blumenfeld, P. (2005). Enacting reform-based science materials: The range of teacher enactments in reform classrooms. Journal of Research in Science Teaching, 42(3), 283-312.

Shulman, S. (1987). Knowledge and teaching: Foundations of the new reform. Harvard Educational Review, 57, 1-22.

Stolk, M. J., Bulte, A. M. W., de Jong, O., \& Pilot, A. (2009). Strategies for a professional development programme: Empowering teachers for context-based chemistry education. Chemistry Education Research and Practice, 10(2), 154-163.

Tal, R. T., Dori, Y. J., Keiny, S., \& Zoller, U. (2001). Assessing conceptual change of teachers involved in STES education and curriculum development - The STEMS project approach. International Journal of Science Education, 23(3), 247-262.

Tobin, K., \& McRobbie, C. J. (1996). Cultural myths as constraints to the enacted science curriculum. Science Education, 80(2), 223-241.

Valli, L. E. (1992). Reflective teacher education: Cases and critiques. Albany: State University of New York Press.

Van Berkel, B., De Vos, W., Verdonk, A. H., \& Pilot, A. (2000). Normal science education and its dangers: The case of school chemistry. [10.1023/A:1008765531336]. Science $\mathcal{E}$ Education, 9(1), 123-159.

Van den Akker, J. J. H. (1988). Ontwerp en implementatie van natuuronderwijs [Design and implementation of science education]. Lisse: Swets \& Zeitlinger.

Van den Akker, J. J. H. (1998). The science curriculum: Between ideals and outcomes. In B. Frazer, \& K. Tobin (Eds.), International handbook of science education. Dordrecht, The Netherlands: Kluwer.

Van Driel, J. H., Beijaard, D., \& Verloop, N. (2001). Professional development and reform in science education: The role of teachers' practical knowledge. Journal of Research in Science Teaching, 38(2), 137-158.

Van Driel, J. H., Verloop, N., \& De Vos, W. (1998). Developing science teachers' pedagogical content knowledge. Journal of Research in Science Teaching, 35(6), 673-695.

Van Koten, G., de Kruijff, B., Driessen, H. P. W., Kerkstra, A., \& Meinema, H. A. (2002). Bouwen aan scheikunde. Blauwdruk voor een aanzet tot vernieuwing van het vak scheikunde in de Tweede Fase van het HAVO en VWO. [Building on chemistry. A blueprint to come to a new chemistry high school curriculum.]. Enschede: SLO. 
Van Veen, K., \& Sleegers, P. (2006). How does it feel? Teachers' emotions in a context of change. Journal of Curriculum Studies, 38(1), 85 - 111.

Van Veen, K., Sleegers, P., \& van de Ven, P.-H. (2005). One teacher's identity, emotions, and commitment to change: A case study into the cognitive-affective processes of a secondary school teacher in the context of reforms. Teaching and Teacher Education, 21(8), 917-934.

Veal, W. R. (2004). Beliefs and knowledge in chemistry teacher development. International Journal of Science Education, 26(3), 329-351.

Voogt, J. M. (1993). Courseware for an inquiry-based science curriculum. An implementation perspective. University of Twente, Enschede.

Yin, R. K. (2003). Case study research, design and methods. (3 ${ }^{\text {rd }}$ ed.). London: Sage. 


\section{SUMMARY}

In 2002, a committee installed by the Ministry of Education concluded that four main problems regarding the high school chemistry curriculum necessitate a major curriculum renewal. A year later the following three recommendations for such a new curriculum were formulated: (a) the chemistry content should appeal to all students, not just to those who want to pursue a career in chemistry; (b) contemporary chemistry and societal challenges should be included in the curriculum; (c) a context-based approach, meaning that students acquire concepts starting from an appealing context, should form the basis of the curriculum.

Teachers are crucial when it comes to a curriculum renewal as they are the ones to implement a new curriculum through enactment in their classrooms. Teachers therefore need to understand the new curriculum, to be professionally prepared for an adequate use of new subject matter and embedded pedagogical knowledge, and have to be able to use the new curriculum materials in an adequate manner.

The National Steering Committee responsible for the development of the new curriculum recognizes this crucial role teachers have in the implementation process and proposes to involve teachers from the beginning in the renewal, both through participation in the development process as teacher-developers as well as through class enactment of materials developed by colleagues. It is supposed that participation will act as a learning process for the teachers involved, in which teachers are going to acquire knowledge, beliefs and skills, both in the field of the subject matter they are teaching as well as in the pedagogy.

The overall research question of this study is fourfold: (a) what are chemistry teachers' beliefs about the chemistry curriculum and about their roles, about the teacher as developer, and about professional development; (b) how do chemistry teachers professionally change, in other words what changes in knowledge and beliefs arise, when teachers are involved in the development and subsequent class enactment of innovative student learning material for the context-based approach; (c) how do teachers professionally change when they merely enact this material in their classes; and (d) what model is suitable to understand and interpret the observed changes in knowledge and beliefs. 
The first study, described in chapter 3, is designed to assess teachers' beliefs about the curriculum content, about their roles, about the teacher as developer of student learning material, and about professional development. Seven high school teachers are interviewed, using a semi structured interview guide to organize the interviews. The leading question for this study is: what do the chemistry teachers want? As teachers' beliefs influences the implementation of a curriculum, it is important to know whether or not they support a context-based chemistry curriculum, as proposed by the National Steering Committee, and if so how do they envisage teacher preparation programs for such a curriculum. How these teachers perceive the idea of the teacher as developer of student learning material is also assessed. The result of this study reveals that the proposed context-based approach can count on cautious approval, although teachers felt uneasy about the implications for their students' learning. Teachers recognize that the current curriculum is outdated and support an overhaul. They hold strong beliefs about the conditions a chemistry curriculum should meet. This study also shows that it is possible to develop a new curriculum in which teachers' knowledge and beliefs are taken as a starting point. Promising approaches to prepare teachers for such a new curriculum is to let them (co)develop and use curriculum materials: it creates ownership, and it is supposed that it strengthens and develops teachers' Pedagogical Content Knowledge (PCK).

A curriculum innovation requires new learning material for students and a preparation program for teachers, in which teacher learning is a key ingredient. Does teacher involvement in the design and development of student learning material lead to teacher learning, and if so what is it that the teacher-developers learn?

The teacher network of this study, consisting of three experienced chemistry teachers under the guidance of a coach, designed, developed and subsequently class enacted learning material consisting of a module for Form 3 students. The complete development process is shown in Figure 1.

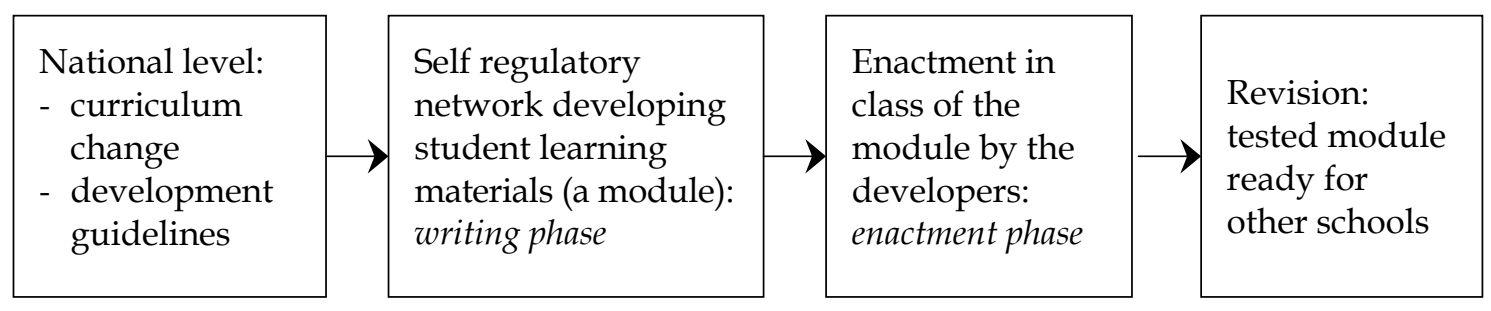

Figure 1 Framework of the development process of a module 
The network used the following instructions from the National Steering Committee: (1) the central element is the interaction between an interesting context for students and a number of chemistry concepts from this context (the context-based approach); (2) the network itself is responsible for the selection of the context and the concepts; (3) concepts should follow "naturally" from the context; (4) the four stages used by Chemistry in Context in Germany have to be used: (a) introduction stage, (b) curiosity and planning stage, (c) carry out stage, and $(\mathrm{d})$ finalization stage.

In chapter 4 we describe how the three experienced teachers from this network professionalize with respect to the perceived goals of chemistry education and what they report to have learned. For data collection a questionnaire, three interviews and discussion transcripts are used. Our results show that the three teacher-developers' goals of chemistry education change from initially rather vague and general to concrete and at a conceptual level. During the writing phase teachers especially professionalise with respect to teaching methodology, and regarding learning material and chemistry content. The writing phase also prepares the teacher-developers well for class use at a 'how-to-do' level. The class enactment phase strengthens the learning from the writing phase.

Chapter 5 details the changes in these teacher-developers' pedagogical content knowledge (PCK) during development and class enactment of student learning material for a context-based chemistry curriculum. Semi-structured interviews, a questionnaire and transcripts of the network meeting discussions during development served to solicit teachers' knowledge and beliefs. Our results show changes in teachers' knowledge and beliefs in three domains: (a) context-based chemistry, (b) cooperative learning, and (c) requirements for context-based chemistry. These changes can be attributed to the two phases in the development process. The writing phase, for the production of learning material and the concurrent preparation phase for class enactment, turned out to be powerful for learning. The subsequent class enactment phase reduced teachers' anxiety towards the feasibility of the material, and served to build new teaching routines.

Teacher-developers do professionalize, but it is a costly process requiring substantial resources. The question that arises is what changes in knowledge and beliefs occur when teachers only enact innovative material in their classes. Chapter 6 describes the pedagogical content knowledge (PCK) changes of five chemistry teachers when they class enact multi-faceted innovative learning 
material, developed by colleague teachers. These five teachers change little with respect to their PCK. Three conclusions demonstrating the idiosyncratic nature of teacher learning materialized: (a) Teachers adapt materials, and consequently do not experience how students would react to the original innovative material; (b) teachers skip activities they personally consider insignificant, even though explicitly incorporated in the material; (c) students' perception of learning activities impacts on a teacher' belief system.

The result of this study implies that in order to change teacher knowledge and beliefs it is not sufficient to let them class enact innovative materials, even when these materials are developed by their colleagues. Involvement in the development process of innovative material is crucial for teacher learning.

Finally in chapter 7 the focus is on how the observed changes in teacher knowledge and beliefs can be interpreted and understood in terms of a model of teacher learning. On the basis of our empirical evidence, the Interconnected Model of Teacher Professional Growth is extended with a new domain, the Developed Material Domain (see chapter 7, Figure 7.3).

The process by which changes occur can be described in terms of establishing relationships between different domains for a given aspect of teacher knowledge, so called "change sequences", non lasting changes. When the occurrence of change is more than momentary, the process is labeled "growth networks" and this is seen as professional growth. During the writing phase of the learning material, "change sequences" occur as a result of reflection and enactment between the Personal Domain, the External Domain and the Developed Material Domain. The class enactment phase results in "growth networks" through reflection and enactment between the Developed Material Domain, the Domain of Practice and the Personal Domain.

This research demonstrates that the combination of design and development of student learning material and subsequent class enactment is instrumental for teacher professional growth. 


\section{NEDERLANDSE SAMENVATTING}

Een door de Minster van Onderwijs ingestelde commissie kwam in 2002 tot de conclusie dat er vier hoofdproblemen zijn met het huidige havo en vwo scheikundecurriculum die een omvangrijke curriculumvernieuwing noodzakelijk maken. Een jaar later formuleerde de Nationale Stuurgroep drie belangrijke kenmerken voor een dergelijk nieuw curriculum: (a) de inhoud van het scheikundeprogramma moet aantrekkelijk zijn voor alle leerlingen, niet alleen voor diegenen die een scheikunde vervolgstudie ambiëren; (b) moderne ontwikkelingen en maatschappelijke vraagstukken moeten in het curriculum worden opgenomen; (c) een context-concept aanpak, wat betekent dat leerlingen concepten leren uitgaande van aansprekende contexten, moet de basis van het curriculum vormen.

Docenten zijn cruciaal bij curriculumveranderingen want zij moeten een nieuw programma implementeren door gebruik in de klas. Docenten moeten daarvoor het nieuwe curriculum begrijpen, voldoende professioneel zijn voorbereid om op gepaste wijze zowel de vakinhoud en de erbij horende didactiek te kunnen gebruiken, en ze moeten de nieuwe curriculum materialen op een adequate manier kunnen gebruiken.

De Nationale Stuurgroep onderkent deze cruciale rol van docenten tijdens de implementatie en stelt voor om docenten vanaf het begin bij de vernieuwing te betrekken, zowel door ze te laten deelnemen in het ontwikkelproces als docentontwikkelaar als door het in de klas laten gebruiken van door collega's ontwikkelde materialen. We veronderstellen dat deelname als een leerproces voor participerende docenten dienst doet, waarin docenten kennis, opvattingen en vaardigheden leren, zowel op vakinhoudelijk gebied als in de didactiek.

De onderzoeksvraag is vierledig: (a) welke opvattingen hebben docenten over het scheikundecurriculum en over hun rol, over de docent als ontwikkelaar van leermaterialen, en over nascholing; (b) hoe veranderen scheikundedocenten professioneel, in andere woorden welke veranderingen in kennis en opvattingen treden op wanneer docenten betrokken zijn bij de ontwikkeling en 
daarna het gebruik in de klas van innovatieve leermaterialen voor een contextconcept aanpak; (c) hoe veranderen scheikundedocenten professioneel wanneer ze alleen deze innovatieve leermaterialen in hun klas gebruiken, en (d) welk model is geschikt om de waargenomen veranderingen in kennis en opvattingen te begrijpen en te interpreteren.

Het eerste deelonderzoek, beschreven in hoofdstuk 3, is uitgevoerd om de opvattingen van scheikundedocenten in kaart te brengen over de inhoud van het scheikundecurriculum, over hun rol in de klas, over de docent als ontwikkelaar van leermaterialen en over nascholing. Zeven scheikundedocenten zijn geïnterviewd, gebruik makend van een semigestructureerde vragenlijst. De leidende vraag was: wat willen de scheikundedocenten? Omdat de opvattingen van docenten de implementatie van een curriculum beïnvloeden, is het belangrijk om te weten of docenten de door de Nationale Stuurgroep voorgestelde context-concept vernieuwing al dan niet steunen. Bovendien is het belangrijk te weten hoe docenten zich op een dergelijke vernieuwing willen voorbereiden, en hoe ze aankijken tegen het idee van de docent als ontwikkelaar van leermaterialen. De uitkomsten van dit deelonderzoek laten zien dat docenten de voorgestelde context-concept aanpak wel ondersteunen, maar ze plaatsen wel vraagtekens bij de implicaties die deze aanpak heeft voor het leren van hun leerlingen. De docenten zijn van mening dat het huidige curriculum gedateerd is en een flinke opknapbeurt nodig heeft. Ze hebben uitgesproken opvattingen over de condities waaraan een scheikundecurriculum moet voldoen. Dit onderzoek laat ook zien dat het mogelijk is een nieuw curriculum te ontwikkelen waarin de kennis en opvattingen van de docenten als startpunt dienen. Een veelbelovende aanpak om docenten op een dergelijk curriculum voor te bereiden is ze leermaterialen te laten (mee)ontwikkelen en in de klas gebruiken. Dit creëert eigenaarschap en we veronderstellen dat het zal leiden tot het ontwikkelen en versterken van de vakdidactische ${ }^{6}$ kennis (PCK) van de docenten.

Een curriculuminnovatie vereist nieuwe leermaterialen voor leerlingen en een voorbereidings- programma voor docenten, waarin het leren van docenten een hoofdbestanddeel is. Leidt het betrekken van docenten in het ontwerpen en

6 Eigenlijk is het woord vakdidactische kennis niet helmaal juist omdat het gaat om de Pedagogical Content Knowledge. Het verschil tussen vakdidactische kennis en PCK wordt beschreven in Kansanen (2009). 
ontwikkelen van leermaterialen voor leerlingen tot het leren van docenten, en zo ja, wat leren docenten daar dan van?

Het docentennetwerk uit dit onderzoek, wat bestond uit drie ervaren scheikundedocenten en een coach, ontwikkelde leermateriaal voor leerlingen uit de derde klas van het voortgezet onderwijs. Na ontwikkeling gebruikten de docenten het leermateriaal in hun klas. Het hele proces is weergegeven in Figuur 1.

\begin{tabular}{|c|c|c|c|}
\hline $\begin{array}{l}\text { Nationaal } \\
\text { niveau: } \\
\text { - } \text { curriculum } \\
\quad \text { verandering } \\
\text { - } \text { ontwikkel } \\
\quad \text { richtlijnen }\end{array}$ & $\begin{array}{l}\text { Zelf sturend netwerk } \\
\text { wat leermateriaal voor } \\
\text { leerlingen ontwikkeld } \\
\text { (een module): } \\
\text { Schrijf fase }\end{array}$ & $\begin{array}{l}\text { Gebruik van de } \\
\text { module in de } \\
\text { klas door de } \\
\text { ontwikkelaars: } \\
\text { Uitvoeringsfase }\end{array}$ & $\begin{array}{l}\text { Revisie: geteste } \\
\text { module, klaar } \\
\text { voor gebruik } \\
\text { door andere } \\
\text { scholen }\end{array}$ \\
\hline
\end{tabular}

Figuur 1 Raamwerk van het ontwikkelproces van een module

Het netwerk gebruikte de volgende instructies van de Nationale Stuurgroep: (1) centraal element is de interactie tussen een voor leerlingen interessante context en een aantal chemische concepten uit die context (de context-concept aanpak); (2) het netwerk zelf is verantwoordelijk voor de selectie van een context en de concepten; (3) de concepten moeten "natuurlijk" uit de contexten volgen; (4) de vier fasen uit het Duitse "Chemie im Kontext" moeten worden gebruikt, dat zijn: (a) de introductie fase, (b) de nieuwsgierigheid en planning fase; (c) de uitvoeringsfase en (d) de afrondingsfase.

In hoofdstuk 4 beschrijven we hoe drie ervaren docenten uit dit netwerk veranderen met betrekking tot de doelen van scheikundeonderwijs en wat ze zelf zeggen te hebben geleerd gedurende het hele ontwikkelproces. Data zijn verzameld met behulp van een vragenlijst, drie interviews en de transcripten van de netwerkbijeenkomsten. De resultaten laten zien dat de opvattingen van de docenten veranderen van aanvankelijk vaag en algemeen tot concreet en op conceptueel niveau. Tijdens de schrijf fase ontwikkelen de docenten zich vooral op het gebied van lesmethodologie, en op het gebied van leermaterialen en scheikundige vakkennis. De schijf fase dient tevens ter voorbereiding van de docenten op het gebruik in de klas. Het gebruik in de klas versterkt het geleerde uit de schrijf fase.

Hoofdstuk 5 gaat over veranderingen in de vakdidactische kennis (PCK) van deze docent-ontwikkelaars tijdens het ontwikkelen van de leermaterialen en 
vervolgens het gebruik in de klas. Semigestructureerde interviews, een vragenlijst en transcripten van de netwerkbijeenkomsten zijn gebruikt op de kennis en opvattingen van de docenten boven tafel te krijgen. De resultaten laten zien dat de kennis en opvattingen van docenten veranderen op drie terreinen: (a) context-concept chemie, (b) samenwerkend leren, en (c) voorwaarden voor context-concept chemie. Deze veranderingen kunnen worden toegeschreven aan de twee fasen uit het ontwikkelproces. De schrijf fase waarin de leermaterialen werden ontwikkeld en tegelijk de voorbereiding voor gebruik in de klas plaats vond, bleek een krachtige leeromgeving. Het erop volgende gebruik in de klas reduceerde de onzekerheid voor wat betreft de haalbaarheid van het materiaal. De eerste lesroutines werden tevens opgebouwd.

De docent-ontwikkelaars professionaliseren. Echter het ontwikkelen van leermaterialen in een netwerk is een langdurig proces, en als alle docenten aan dit type professionalisering gaan deelnemen zijn daarvoor substantiële middelen nodig. De vraag doet zich daarom voor hoe de kennis en opvattingen zich ontwikkelen van docenten die niet betrokken zijn bij het ontwikkelen van de materialen maar deze alleen in de klas gebruiken. Hoofdstuk 6 beschrijft de veranderingen in vakdidactische kennis en opvattingen (PCK) van vijf scheikundedocenten wanneer zij innovatieve leermaterialen gebruiken die door collega-docenten zijn ontwikkeld. Deze vijf docenten blijken erg weinig te veranderen in hun vakdidactische kennis en opvattingen. Het idiosyncratische karakter van het leren van docenten kan worden gedemonstreerd door de volgende resultaten uit het onderzoek: (a) docenten passen leermaterialen aan waardoor ze niet kunnen ervaren hoe leerlingen zouden reageren op de oorspronkelijke materialen; (b) docenten slaan activiteiten over die zij zelf niet van belang vinden, ondanks het feit dat die activiteiten expliciet in de materialen zijn opgenomen; (c) hoe leerlingen de leermaterialen ervaren heeft invloed op de opvattingen van docenten.

De resultaten van dit onderzoek betekenen dat om de kennis en opvattingen van docenten te veranderen, het niet genoeg is om docenten innovatieve materialen te laten gebruiken in de klas, zelfs als deze materialen door collega's ontwikkeld zijn. Deelname aan het ontwikkelproces zelf is cruciaal voor het leren van docenten.

In hoofdstuk 7 tenslotte wordt beschreven hoe de waargenomen veranderingen in de kennis en opvattingen van docenten kunnen worden geïnterpreteerd en begrepen in termen van een leermodel. Het Interconnected Model of Teacher 
Professional Growth is op basis van onze empirische gegevens uitgebreid met een extra domein: het Developed Material Domain (zie hoofdstuk 7, Figuur 7.3). Het veranderingsproces kan worden beschreven in termen van het ontstaan van relaties tussen verschillende domeinen, de zogenoemde "change sequences", niet blijvende veranderingen. Als de veranderingen een meer den momentaan karakter vertonen, worden ze "growth networks" genoemd, wat we beschouwen als professionele ontwikkeling. Tijdens de schrijf fase van het leermateriaal, zullen "change sequences" optreden als resultaat van de reflectie en het bewust gebruiken van elementen tussen het Personal Domain, het External Domain en het Developed Material Domain. Gebruik in de klas resulteert in "growth networks" door reflectie en bewust gebruik van elementen tussen het Developed Material Domain, het Domain of Practice en het Personal Domain.

Dit onderzoek laat zien dat de combinatie van ontwerpen en ontwikkelen van leermaterialen voor leerlingen en het vervolgens gebruiken in de klas instrumenteel is voor de professionele groei van docenten. 


\section{APPENDICES}

\section{COOPERATIVE LEARNING: T-CARD}

Examples of T-cards.

The first one is about 'cooperation', the second about 'discussion'.

The teacher discusses each T-card with his students and lets the students add aspects that can be heard and seen. The card is then put up on the wall in class.

\section{Group discussion}

\begin{tabular}{|c|c|}
\hline Sounds like? & Looks like? \\
\hline $\begin{array}{l}\text { - } \text { One students at the time } \\
\text { talking } \\
\text { - Conversation at a quit tone } \\
\text { - } \text { Conversation about the issue } \\
\text { - }\end{array}$ & $\begin{array}{ll}\text { - } & \text { One student talking } \\
\text { - } & \text { Students watching the one } \\
& \text { talking } \\
\text { - } & \text { Students are sitting actively } \\
& \text { (with material in front of them) }\end{array}$ \\
\hline
\end{tabular}

Encouraging

\begin{tabular}{|l|l|}
\hline Sounds like? & Looks like? \\
\hline - 'great' & - Thumps up \\
- 'good idea' & - Nodding \\
- 'Very well' & - - Facing each other \\
- & - Looking at each other \\
\hline
\end{tabular}




\section{COOPERATIVE LEARNING: GROUP ROLES}

\begin{tabular}{|c|c|}
\hline Role & Tasks \\
\hline Chief $(\mathrm{C})$ & $\begin{array}{l}\text { Is responsible for the course of the lesson. This means: } \\
\text { - Opens the lesson by checking members' roles. } \\
\text { - Is responsible for general group aspects. } \\
\text { - Monitors members fulfilling their roles. }\end{array}$ \\
\hline Writer $(W)$ & $\begin{array}{l}\text { - Picks up logbook at beginning of the lesson. } \\
\text { - Fills in the logbook. } \\
\text { - } \text { Returns the logbook after the lesson. }\end{array}$ \\
\hline Time keeper(T) & $\begin{array}{l}\text { - } \quad \text { Looks after the time investments. } \\
\text { - Ensures members stick to agreed time frames. } \\
\text { - Writes down how much time an activity took. } \\
\text { - Gives } 10 \text { minutes before the end of the lesson a signal to ensure } \\
\text { home work can be set and the logbook filled in. }\end{array}$ \\
\hline Material chief (M) & $\begin{array}{l}\text { - Is responsible for the material. } \\
\text { - } \quad \text { Contacts the technical assistant. }\end{array}$ \\
\hline Questioner (Q) & $\begin{array}{l}\text { - Is responsible for contact with the teacher (the teacher will } \\
\text { only answer questions from the questioner after these have } \\
\text { been discussed in the group). }\end{array}$ \\
\hline
\end{tabular}




\section{COOPERATIVE LEARNING: LOGBOOK FOR EFFECTIVE COOPERATION}

At least one page for each lesson.

\begin{tabular}{|l|l|l|l|l|}
\hline \multicolumn{2}{|l|}{ LESSON: DATE: } & time keeper (T) & $\begin{array}{l}\text { material chief } \\
(\mathrm{M})\end{array}$ & questioner $(\mathrm{Q})$ \\
\hline chief $(\mathrm{C})$ & writer $(\mathrm{W})$ & & & \\
\hline & & & \\
\hline
\end{tabular}

Did we do the agreed homework?

yes/no

If not, who did not, what was not done and why was it not done?

What are we going to do this lesson? Time estimate

\begin{tabular}{|l|l|}
\hline & \\
\hline & \\
\hline & \\
\hline
\end{tabular}

Answers to the questions: (if necessary add extra sheets to this logbook)

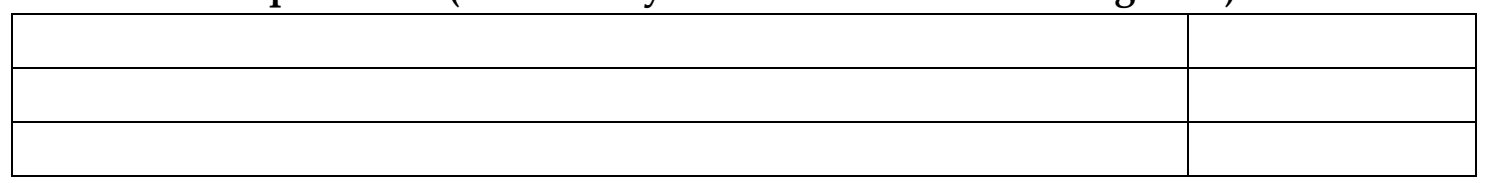

Homework: What has to be done for the next lesson? By whom?

\begin{tabular}{|l|l|}
\hline & \\
\hline & \\
\hline & \\
\hline
\end{tabular}

What are we going to do the next period?

How did the cooperation in the group go? (give the reason for your answer) 


\section{CONTENT OF THE MODULE DEVELOPED BY THE TEACHER-DEVELOPERS IN A TABLE}

\begin{tabular}{|c|c|}
\hline Title & That tastes nice \\
\hline $\begin{array}{l}\text { Description } \\
\text { of the } \\
\text { content }\end{array}$ & $\begin{array}{l}\text { Students first have to bake an apple pie (appelflap). Several chemical } \\
\text { concepts students have learned before return in this module. Students } \\
\text { have to make choices with respect to ingredients, the recipe and the } \\
\text { costs. During the preparations students learn the purpose of the } \\
\text { different ingredients. They then learn more about yeast and other } \\
\text { substances to make the dough rise. Students present their result in a } \\
\text { flow chart. } \\
\text { Module is suitable for the last period of year } 3 \text { havo or vwo. }\end{array}$ \\
\hline $\begin{array}{l}\text { Prerequisite } \\
\text { knowledge }\end{array}$ & $\begin{array}{l}\text { - Introduction to separation techniques } \\
\text { - Chemical reaction } \\
\text { - Mass proportion, law of } \\
\text { - Reagents }\end{array}$ \\
\hline $\begin{array}{l}\text { Concepts } \\
\text { and content }\end{array}$ & $\begin{array}{l}\text { - Separation techniques } \\
\text { - Mass proportion } \\
\text { - Flow chart } \\
\text { - Up scaling } \\
\text { - Yeast and other rising substances } \\
\text { - Reactions demonstrating the presence of specific substances }\end{array}$ \\
\hline Activities & $\begin{array}{l}\text { - Cooperative learning } \\
\text { - Research projects } \\
\text { - Making calculations } \\
\text { - Logbook use } \\
\text { - Different group tasks } \\
\text { - Specific attention for cooperative skills }\end{array}$ \\
\hline Material & $\begin{array}{l}\text { The module can be obtained for the website from the National Steering } \\
\text { Committee: http://nieuwescheikunde.nl/. }\end{array}$ \\
\hline
\end{tabular}




\section{CURRICUlum VITAE}

Fer Coenders was born on July 25 in 1952 in Lottum, a small settlement in the north of Limburg. After having gone through primary school in his birth town, he continued his education at the HBS, first at Blariacum in Blerick, and the last years at the Boschveldlyceum in Venray. In 1970, he enrolled in the chemistry program at Nijmegen University, where he graduated as a biochemist and received a teaching qualification, early in 1978.

He started teaching in Arnhem at the Rijks Pedagogische Academie where he taught chemistry and physics. After four years moved to Andreas Scholengemeenschap in Zevenaar to teach chemistry. In 1985 and 1986, during a leave period from the school in Zevenaar, he taught chemistry at the Escola Secundária Francisco Manyanga in Maputo in Mozambique. He was here also responsible for the construction of the National Chemistry exam.

From 1992 he joined the SMART (Science and Maths Advice and Regional Training) project at the University of Swaziland (UNISWA). The SMART project provided in-service for science teachers with the long-term goal of improving the quality of science and maths education in Swaziland High Schools. Fer was especially involved in the areas of strengthening the professional quality of the chemistry teachers through a more student-centered teaching approach, in the strengthening of local structures, and in improving the laboratory conditions in the schools. Teacher guidance and support was mainly provided through the design of student learning material accompanied by teacher support material, which was disseminated at National workshops and seminars. Follow-up activities at regional workshops, and during school visits, were held to reflect on the teaching and learning experiences. At the end of this project, the developed student learning material was converted into a chemistry book that was published and sold at Uniswa. 
After his return to the Netherlands in 1997, Fer first enjoyed a sabbatical period during which he was able to get to grips with the new developments in the Dutch educational system, especially with respect to chemistry education. He then taught some time as a substitute chemistry teacher, and developed material for a chemistry book and for Teleac school-TV. In September 1998 Fer joined the University of Twente. His main responsibilities are in the field of initial and in-service teacher training, in educational research and in areas in which high school and university chemistry meet.

Fer is married to Jeannette and they have three, grown up, children. 
